UNIVERSIDADE DE SÃO PAULO

Faculdade de Medicina de Ribeirão Preto

Departamento de Ciências da Saúde

Tamyris Padovani dos Santos

\begin{abstract}
ALTA FREQUÊNCIA, MÉDIA DURAÇÃO E LIVRE EXPLORAÇÃO DO MEMBRO SUPERIOR PARÉTICO TORNA EFICAZ A REABILITAÇÃO DE PACIENTES CRÔNICOS PÓS-ACIDENTE VASCULAR ENCEFÁLICO
\end{abstract}

Ribeirão Preto 


\title{
ALTA FREQUÊNCIA, MÉDIA DURAÇÃO E LIVRE EXPLORAÇÃO DO MEMBRO SUPERIOR PARÉTICO TORNA EFICAZ A REABILITAÇÃO DE PACIENTES CRÔNICOS PÓS-ACIDENTE VASCULAR ENCEFÁLICO
}

\author{
Tese apresentada à Faculdade de Medicina de \\ Ribeirão Preto da Universidade de São Paulo \\ junto ao Departamento Ciências da Saúde, para \\ obtenção do título de doutor em Reabilitação e \\ Desempenho Funcional.
}

Área de Concentração: Fisioterapia Orientador: João Eduardo de Araújo

VERSÃO CORRIGIDA 
AUTORIZO A REPRODUÇÃO E DIVULGAÇÃO TOTAL OU PARCIAL DESTE TRABALHO, POR QUALQUER MEIO CONVENCIONAL OU ELETRÔNICO, PARA FINS DE ESTUDO E PESQUISA, DESDE QUE CITADA A FONTE.

FICHA CATALOGRÁFICA

Alta frequência, média duração e livre exploração do membro superior parético torna eficaz a reabilitação de pacientes crônicos pós-Acidente Vascular Encefálico. Ribeirão Preto, 2019.

119 p.: II. $30 \mathrm{~cm}$

Tese de doutorado apresentada à Faculdade de Medicina de Ribeirão Preto da Universidade de São Paulo/USP - Programa de Pós-graduação em Reabilitação e Desempenho Funcional, Área de concentração: Motricidade, Plasticidade Neuromuscular e Neuronal.

Orientador: De Araujo, João Eduardo

1. Acidente Vascular Encefálico, 2. Hemiparesia, 3. Membro Superior, 4. Frequência, 5 Duração. 
Título do Trabalho: ALTA FREQUÊNCIA, MÉDIA DURAÇÃO E LIVRE EXPLORAÇÃO DO MEMBRO SUPERIOR PARÉTICO TORNA EFICAZ A REABILITAÇÃO DE PACIENTES CRÔNICOS PÓS-ACIDENTE VASCULAR ENCEFÁLICO

Tese apresentada à Faculdade de Medicina de Ribeirão Preto da Universidade de São Paulo junto ao Departamento de Ciências da Saúde, para obtenção do título de doutor em Reabilitação e Desempenho Funcional.

Área de Concentração: Fisioterapia

Orientador: João Eduardo de Araújo

Aprovado em: 1

\section{Banca Examinadora}

Prof.Dr. Instituição:

Julgamento: Assinatura:

Prof.Dr. Instituição:

Julgamento: Assinatura:

Prof.Dr. Instituição:

Julgamento: Assinatura:

Prof.Dr. Instituição:

Julgamento: Assinatura: 


\section{DEDICATÓRIA}


Dedico com todo amor e gratidão a minha família, que com muito amor e carinho, nunca mediram esforços para que eu conseguisse alcançar meus objetivos. 


\section{AGRADECIMENTOS}

Agradeço primeiramente à Deus, por me guiar durante a execução de todo esse trabalho com saúde e sabedoria para superar todos os obstáculos que apareceram, me acalmando nos momentos de aflições e desespero com tranquilidade, paciência e me fortalecendo para que minha trajetória continuasse.

Agradeço imensamente aos meus pais, Guilherme Divino dos Santos e Sonia Marcia Padovani dos Santos, por todo apoio e incentivo para que eu conseguisse alcançar meus objetivos. Sempre estiveram ao meu lado, acompanhando e participando de todas as etapas da minha vida. E a minha mãe, obrigada por todas as orações a mim dedicadas, permitindo que eu prosseguisse com calma e tranquilidade. Se tudo isso se tornou possível, foi devido ao apoio, amor, carinho e paciência que tiveram comigo. Obrigada por tudo e principalmente por terem acreditado que eu seria capaz de chegar até aqui. Amo vocês!

Aos meus queridos irmãos, Nathan Padovani dos Santos e Thainá Padovani dos Santos, por todo o apoio, amor, carinho, paciência comigo durante essa trajetória e por estarem comigo em todos os momentos. Ao meu irmão, pela ajuda nas formatações, sempre me socorrendo quando o desespero batia. E a minha irmã, pela preocupação a cada página que eu escrevia e pelas vibrações em cada fase que eu terminava. Mas sempre me apoiando e incentivando a seguir em frente. Amo vocês!

Ao meu namorado Fabio Florêncio de Lima, que sempre me apoiou a correr atrás dos meus sonhos e objetivos, me mostrando que tudo seria possível. Obrigada pela paciência, amor, carinho, compreensão e por ter aguentado meus nervosismos! Amo você!

Aos meus avós, Ercio Padovani e Izaura Baratto Padovani, também pelo incentivo, apoio e pelas orações para que eu seguisse em frente e alcançasse os meus objetivos. 
Aos meus tios, tias, primos e primas pelo apoio e incentivo durante toda essa caminhada.

À minha professora de graduação, Dra. Fernanda Lopes Buiatti de Araujo, que sempre acreditou no meu potencial, me orientou e me mostrou que seria possível. Muito obrigada!

Agradeço imensamente ao meu orientador Dr. João Eduardo de Araujo, por todos ensinamentos durante a pós-graduação (mestrado e doutorado), pelo incentivo, pela confiança e pelas oportunidades que me concedeu. Eu aprendi e amadureci muito, tanto pessoal quanto profissionalmente durante essa etapa. A você professor, o meu muito obrigada!

Agradeço a professora Dra. Ana Cláudia Mattiello-Sverzut, pela colaboração com o recrutamento dos pacientes deste trabalho. Sua colaboração foi de suma importância para conclusão do meu trabalho. Obrigada!

Aos alunos do Laboratório de Neuropsicobiologia e Comportamento Motor, em especial a Lígia Brancalion Catapani, pela dedicação, pela ajuda no recrutamento, contato com os pacientes e nas coletas, a Giovanna Toffano, por toda a dedicação aos nossos pacientes durante todos esses anos e a Ana Claudia Nunciato, que mesmo não estando muito presente no laboratório, estava sempre disposta a me ajudar no que fosse preciso, me ajudou e contribuiu muito com meu crescimento profissional. Muito obrigada por tudo!

Agradeço a todos os funcionários do Centro Integrado de Reabilitação, onde passei esses 4 anos coletando meus dados. Aos recepcionistas Donizete e Ana Beatriz, por todos os agendamentos realizados em cima da hora e pela prontidão sempre tentar me ajudar. Agradeço a todas as fisioterapeutas do serviço, em especial a Isabel Calsani, por todos os pacientes encaminhados ao meu protocolo, por todas as experiências trocadas e por todos os casos discutidos. A Priscila Botelho por todos os pacientes inseridos no CROSS e por lembrar de mim a cada guia inserida e encaminhar para o meu protocolo $100 \%$ dos pacientes que possivelmente se enquadrariam nos critérios de inclusão. A Patricia Silva, que me ajudou no 
recrutamento e nas triagens iniciais. Também agradeço muito a terapeuta ocupacional Amanda Polin por lembrar do meu protocolo a cada triagem que realizava e, sempre que possível me encaminhava os pacientes. Ainda, pela ajuda em relação as orientações e adaptações realizadas aos pacientes. Não poderia deixar de agradecer a Danila Petian pelo enorme incentivo, por fazer eu entender as minhas prioridades e seguir em frente. A vocês, o meu muito obrigada!

À fisioterapeuta do complexo regulador da Secretaria Municipal da Saúde de Ribeirão Preto, Roberta Zucoloto de Abreu, pela imensa colaboração no recrutamento dos pacientes para o protocolo, uma vez que separava todas as guias encaminhadas para fisioterapia neurológica e agendava comigo na secretaria para que eu pudesse olhar uma por uma e pegar o contato do paciente quando ele se enquadrava nos critérios de inclusão. Sempre prestativa e pronta a me ajudar a qualquer hora. Agradeço muito pela ajuda!

Aos funcionários do programa de pós-graduação em Reabilitação e Desempenho Funcional pela oportunidade de convivência e pelas informações e orientações fornecidas.

À todas as pessoas que direta ou indiretamente contribuíram para a execução e conclusão do meu trabalho de doutorado.

À contribuição da banca examinadora do exame de qualificação que contribuíram para conclusão deste trabalho e pela participação dos membros da banca examinadora da defesa. Muito obrigada!

Ao apoio da Coordenação de Aperfeiçoamento de Pessoal de Nível Superior Brasil (CAPES) - Programa de demanda social, pela bolsa de estudo que foi imprescindível para a realização e conclusão do doutorado. 
RESUMO 


\section{RESUMO}

SANTOS, T. P. Alta frequência, média duração e livre exploração do membro superior parético torna eficaz a reabilitação de pacientes crônicos pós-Acidente Vascular Encefálico. 2019. 119 f. Tese (Doutorado) - Faculdade de Medicina de Ribeirão Preto, Universidade de São Paulo, Ribeirão Preto, 2019.

Diferentes técnicas de reabilitação são utilizadas para recuperar a função do membro superior (MS) pós-Acidente Vascular Encefálico (AVE) sem considerar os parâmetros frequência e duração do protocolo de reabilitação. O presente estudo tem como objetivo analisar os resultados de um protocolo específico com baixa frequência e duração (BFCD) e outro protocolo BFCD com adição de alta frequência, média duração e livre exploração do MS parético (BFCD+AFMD) na qualidade de vida, motricidade e funcionalidade. Participaram deste estudo 45 sujeitos hemiparéticos crônicos pós-AVE, randomizados em dois grupos de tratamento por 4 semanas consecutivas: BFCD (protocolo específico para o MS, 2 vezes por semana e duração de 40 minutos, $n=22$ ) e BFCD+AFMD (livre exploração, 5 vezes na semana e 12 horas por dia, n=23). A adição de frequência e duração foi realizada pela contensão do MS não parético. Para análise, utilizamos a National Institute of Health Stroke Scale (NIHSS), a Stroke Specific Quality of Life (SS-QOL), Wolf Motor Function Test (WMFT), Fugl-Meyer Assessment (FMA), Motor Activity Log (MAL), Ashworth Scale (AS), dinamometria de preensão manual e eletromiografia de superfície (EMG). Com o teste em t de Student a homogeneidade da amostra foi analisada e uma ANOVA de duas vias comparou os grupos e as avaliações. Valores de $p$ significativos $<0,05$. $O$ WMFT quantitativo revelou a homogeneidade da amostra $(t=-0,41 ; p=0,68)$. $O$ BFCD+AFMD em relação ao BFCD apresentou redução a NIHSS $\left(F_{1,335: 23,33)}\right.$ e do WMFT quantitativo $\left(\mathrm{F}_{1,335}: 30,98\right)$, e aumento na SS-QOL $\left(\mathrm{F}_{1,335}: 22,79\right)$, no $\mathrm{MAL}$ quantitativo $\left(F_{1,335}: 17,81\right)$ e qualitativo $\left(F_{1,335}: 15,80\right)$. O BFCD aumentou a pontuação na $A S$ em relação ao BFCD+AFMD $\left(F_{1,335: 6,81}\right)$. A interação entre os grupos e as avaliações revelou uma diminuição no BFCD+AFMD para a NIHSS na avaliação 4 e final $\left(F_{7,335}: 0,21\right)$ e no WMFT quantitativo nas avaliações 2,3 , seguimento 1 e 3 $\left(F_{7,335}: 1,37\right)$, aumento na SS-QOL na avaliação 3,4 e seguimento $1\left(F_{7,335}: 0,25\right)$, aumento no MAL quantitativo nas avaliações 2 e $3\left(F_{7,335}: 3,46\right)$, e no MAL qualitativo na avaliação $3\left(F_{7,335}: 2,95\right)$ em relação ao BFCD. Comparações com a avaliação inicial no BFCD+AFMD revelaram diminuição no WMFT quantitativo nas avaliações 4 , final, seguimento 1,2 e 3, aumento no MAL quantitativo nas avaliações 3 , 4, final e seguimento 1 e no MAL qualitativo nas avaliações 4 e seguimento 1 . Sujeitos com lesão no hemisfério cerebral esquerdo (HCE) em relação aos sujeitos com lesão no hemisfério cerebral direito (HCD) no grupo BFCD mostraram aumento no MAL quantitativo nas avaliações $2,3,4$ e final $\left(F_{7,151}: 0,44\right)$ e no MAL qualitativo nas avaliações 2, 3 e $4\left(F_{7,151}: 0,41\right)$. Sujeitos com lesão no HCD em relação aos sujeitos com lesão no HCE no BFCD+AFMD mostraram aumento da força na dinamometria na avaliação de seguimento $3\left(F_{7,168}: 0,12\right)$. A adição AFMD com livre exploração do MS parético a um protocolo de BFCD com alta especificidade torna a reabilitação do MS parético eficaz.

Palavras-chave: Acidente Vascular Encefálico, Hemiparesia, Membro Superior, Frequência, Duração. 
ABSTRACT 


\begin{abstract}
SANTOS, T. P. Hight frequency, medium duration, and free paretic upper limb exploration become effective the rehabilitation in chronic patients post-stroke. 2019. 119 f. Tese (Doutorado) - Faculdade de Medicina de Ribeirão Preto, Universidade de São Paulo, Ribeirão Preto, 2019.
\end{abstract}

Post-stroke several rehabilitation techniques are used to upper limb (UL) function recovery, without considering in the rehabilitation protocol frequency, and duration parameters. The present study aims to analyze a specific protocol with low frequency and short duration (LFSD) and another protocol LFSD with the addition of high frequency, medium duration and free paretic UL exploration (LFSD+HFMD) in quality of life, motricity and functionality. Forty-five chronic post-stroke hemiparetic subjects were randomized into two treatment groups for 4 consecutive weeks: LFSD (2-weekspecific protocol, duration of 40 minutes, $n=22$ ), and LFSD+HFMD (5 times a week and duration of 12 hours, $n=23$ ). The constraint of non-paretic UL performed addition of frequency and duration. For analysis, we used the National Institute of Health Stroke Scale (NIHSS), Stroke Specific Quality of Life (SS-QOL), Wolf Motor Function Test (WMFT), Fugl-Meyer Assessment (FMA), Motor Activity Log (MAL) Ashworth Scale (AS), handgrip dynamometry and surface electromyography (EMG). With Student's ttest, the homogeneity of the sample was analyzed and a two-way ANOVA compared the groups and the evaluations. Significant $p$ values $<0.05$. The quantitative WMFT showed the homogeneity of the sample $(t=-0.41, p=0.68)$. The LFSD+HFMD compared to the LFSD showed a decrease to NIHSS $\left(F_{1,335}: 23.33\right)$ and quantitative WMFT $\left(F_{1,335}: 30.98\right)$, and increase in SS-QOL $\left(F_{1,335}: 22.79\right)$, in the quantitative MAL $\left(F_{1,335}: 17.81\right)$ and qualitative $\left(F_{1,335}: 15.80\right)$. LFSD increased scores on the $A S$ in relation to $L F S D+H F M D\left(F_{1,335}: 6.81\right)$. Interaction between groups and evaluations showed a decrease in LFSD+HFMD for NIHSS in the 4 and final evaluation $\left(F_{7,335}\right.$ : $0.21)$ and in the quantitative WMFT in the evaluations 2,3 , follow-up 1 and $3\left(F_{7,335}\right.$ : 1.37), SS-QOL increased in evaluation 3,4 and follow-up $1\left(F_{7,335}: 0.25\right)$, increased in quantitative $M A L$ in evaluations 2 and $3\left(F_{7,335}: 3.46\right)$, and in qualitative $M A L$ evaluation $3\left(F_{7,335}: 2.95\right)$ in relation to the LFSD. Comparisons with the initial evaluation in the LFSD+HFMD revealed a decrease in the quantitative WMFT in the 4, final, follow-up 1,2 and 3 evaluations, increase in the quantitative MAL in the evaluations 3,4 , final and follow-up 1 and in the qualitative MAL follow-up 1. Subjects with left brain lesion (LBL) comparing to subjects with right brain lesions (RBL) in the LFSD showed an increase in the quantitative MAL in the 2, 3, 4 and final evaluations $\left(F_{7,151}: 0.44\right)$ and the qualitative MAL in the 2, 3 and $4\left(F_{7,151}: 0.41\right)$. Subjects with $R B L$ compared to subjects with LBL in the LFSD+HFMD showed dynamometry strength increase in the follow-up evaluation $3\left(\mathrm{~F}_{7,168}: 0.12\right)$. The addition of HFMD with free paretic UL exploration to a LFSD protocol with high specificity gets the paretic UL rehabilitation effective.

Key words: Stroke, Hemiparesis, Upper Limb, Frequency, Duration. 


\section{LISTA DE FIGURAS}

Figura 1. Fluxograma de seleção dos sujeitos.

Figura 2. Sujeito com a contensão do MS não parético utilizada para aumentar a frequência e a duração.

Figura 3. Figura representativa do posicionamento do paciente durante a coleta de dados da dinamometria de preensão manual.

Figura 4. Figura representativa do posicionamento do paciente durante a coleta de dados dos músculos extensores do punho pela EMG

Figura 5. Gráfico representativo da pontuação da NIHSS

Figura 6. Gráfico representativo da pontuação da SS-QOL

Figura 7. Gráfico representativo da pontuação do WMFT quantitativo.

Figura 8. Gráfico representativo da pontuação do WMFT qualitativo.

Figura 9. Gráfico representativo da pontuação total da FMA

Figura 10. Gráfico representativo da pontuação do punho da FMA

Figura 11. Gráfico representativo da pontuação da mão da FMA

Figura 12. Gráfico representativo da pontuação do MAL quantitativo

Figura 13. Gráfico representativo da pontuação do MAL qualitativo

Figura 14. Gráfico representativo da pontuação da AS para $0 \quad 73$ cotovelo.

Figura 15. Gráfico representativo da pontuação da AS para o punho.

Figura 16. Gráfico representativo da dinamometria de preensão manual.....

Figura 17. Gráfico representativo da EMG dos músculos flexores do 76 punho. 
Figura 18. Gráfico representativo da EMG dos músculos extensores do punho... 


\section{LISTA DE TABELAS}

Tabela 1. Características clínicas e dados demográficos dos sujeitos da

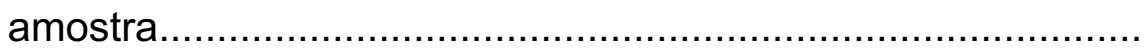




\section{LISTA DE SIGLAS}

AC - Artéria Carótida

ACA - Artéria Cerebral Anterior

ACM - Artéria Cerebral Média

ADM - Amplitude de movimento

AFMD - Alta frequência e média duração

AIT - Ataque Isquêmico Transitório

AS - Asworth Scale

AVDs - Atividades de vida diária

AVE - Acidente Vascular Encefálico

ASHT - American Society of Hand Therapists

BFCD - Baixa frequência e curta duração

BFCD+AFMD - Baixa frequência e curta duração com adição de alta frequência e média duração

CER - Cerebelar

CIR - Centro Integrado de Reabilitação

CONSORT - Consolidated Standards of Reporting Trials

D - Direito

E - Esquerdo

EMG - Eletromiografia de superfície

F - Feminino

FMA - Fugl-Meyer Assessment

FNP - Facilitação Neuromuscular Proprioceptiva

HCD - Hemisfério cerebral direito 
HCE - Hemisfério cerebral esquerdo

HERP - Hospital Estadual de Ribeirão Preto

LAC - Lacunar

M - Masculino

MAL - Motor Activity Log

MS - Membro superior

MSD - Membro superior direito

MSE - Membro superior esquerdo

MMSS - Membros superiores

NI - Não identificado

NIHSS - National Institute of Health Stroke Scale

OMS - Organização Mundial da Saúde

PROBE - Prospective Randomized Open, Blinded End-point

RMS - Root Mean Square

SMS-RP - Secretaria Municipal da Saúde de Ribeirão Preto

SNC - Sistema Nervoso Central

SS-QOL - Stroke Specific Quality of Life

TCLE - Termo de consentimento livre e esclarecido

WMFT - Wolf Motor Function Test 
SUMÁRIO 


\section{SUMÁRIO}

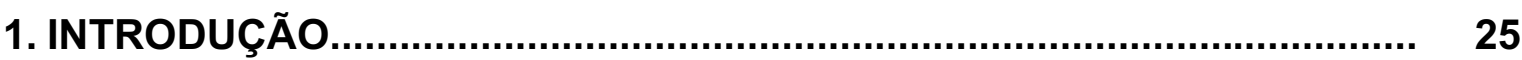

1.1 Acidente Vascular Encefálico......................................................... 26

1.2 Recuperação Funcional Pós-AVE................................................ 27

1.2.1 Plasticidade Uso-Dependente................................................ 28

1.2.2 Não Uso Aprendido............................................................ 29

1.3 Reabilitação Pós-AVE................................................................... 30

1.3.1 Técnicas Clássicas em Reabilitação........................................ $\quad 30$

1.3.2 Técnicas Contemporâneas Baseadas no Aprendizado Motor...... $\quad 31$

1.4 Dosagem do Tratamento Pós-AVE.................................................... 33

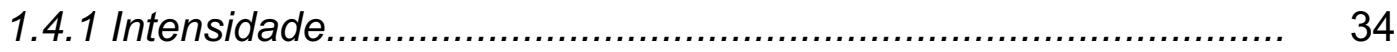

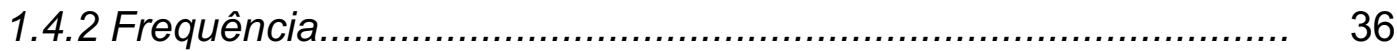

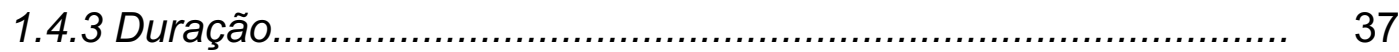

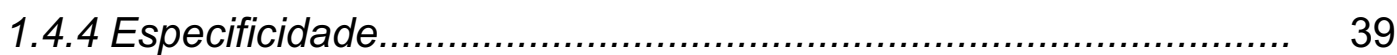

1.5 Diretrizes para Reabilitação Pós-AVE.............................................. 40

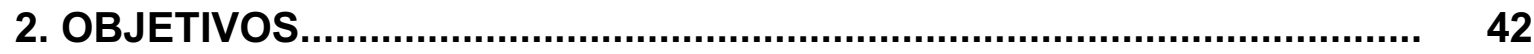

2.1 Objetivo Geral........................................................................ 43

2.2 Objetivos Especificos............................................................. 43

3. MATERIAL E MÉTODOS

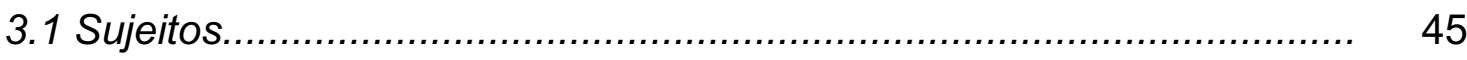

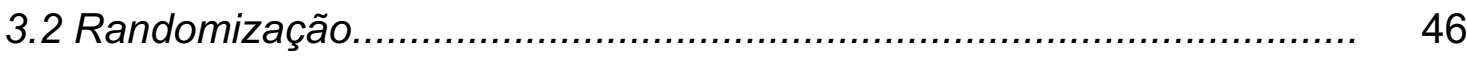

3.3 Protocolos de Intervenção........................................................ 47

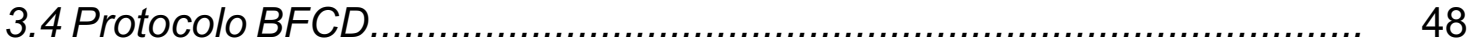

3.5 Procedimento para Adição de AFMD ................................................. 48

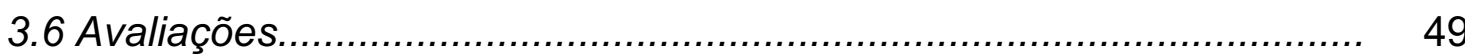

3.7 Escalas de Avaliação..................................................................... 50

3.7.1 National Institutes of Health Stroke Scale................................ $\quad 50$

3.7.2 Stroke Specific Quality of Life............................................ 50

3.7.3 Wolf Motor Function Test..................................................... 51 
3.7.4 Fugl-Meyer Assessment................................................. 51

3.7.5 Motor Activity Log........................................................ 52

3.7.6 Asworth Scale ................................................................. 52

3.7.7 Avaliação Instrumental......................................................... 53

3.7.7.1 Dinamometria de Preensão Manual................................ 53

3.7.7.2 Eletromiografia de Superfície....................................... 54

3.8 Análise Estatística................................................................ 56

4. RESULTADOS

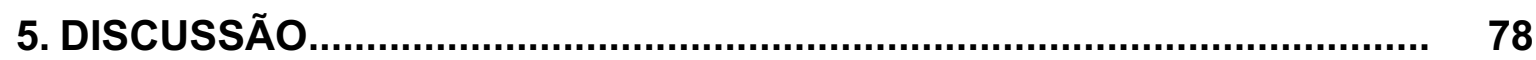

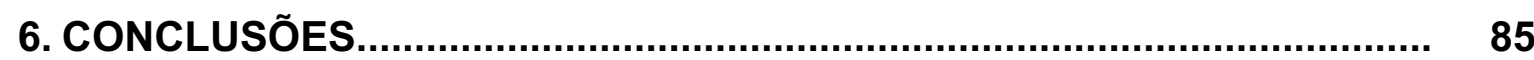

REFERÊNCIAS BIBLIOGRÁFICAS....................................................... 88

ANEXOS

Anexo A - Aprovação Comitê de Ética...................................................... 103

Anexo B - NIHSS - "National Institute of Health Stroke Scale"................... 104

Anexo C - AS - "Ashworth Scale"........................................ 105

Anexo D-SS-QOL - "Stroke Specific Quality of Life"....................... 106

Anexo E - WFMT - "Wolf Motor Function Test"........................................ 109

Anexo F - FMA "Fugl-Meyer Assessment"................................. 110

Anexo G - MAL "Motor Activity Log"....................................... 113

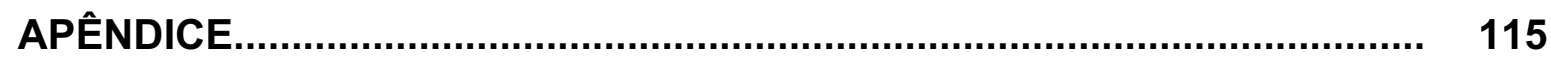

Apêndice - Termo de Consentimento Livre e Esclarecido........................... 116 
INTRODUÇÃO 


\section{INTRODUÇÃO}

\subsection{ACIDENTE VASCULAR ENCEFÁLICO}

O Acidente Vascular Encefálico (AVE) é definido pela presença de sinais clínicos focais de origem vascular pela obstrução da circulação sanguínea no encéfalo (COUPLAND et al., 2017; SACCO et al., 2013). No entanto, quando ocorre um curto episódio de disfunção neurológica, causada por isquemia focal ou retiniana sem evidências de infarto agudo, é definido como Ataque Isquêmico Transitório (AIT) (EASTON et al., 2009).

Em relação a fisiopatologia, o AVE pode ser classificado em isquêmico ou hemorrágico. No AVE hemorrágico, ocorre a ruptura espontânea de veias ou artérias acarretando um extravasamento de sangue (PONTES-NETO et al., 2009). De acordo com a sua etiologia, se o extravasamento de sangue for para o interior do cérebro é denominado hemorragia intraparenquimatosa, para sistema ventricular é chamado de hemorragia intraventricular e quando se instala no espaço subaracnóideo é classificada como hemorragia subaracnóidea (PONTES-NETO et al., 2009). Já no AVE isquêmico, ocorre o bloqueio ou a interrupção da circulação de sangue no encéfalo (CAPRIOTTI; MURPHY, 2016). Do ponto de vista etiológico, essa interrupção pode ocorrer pela formação de um coágulo em uma artéria cerebral, denominado trombose, pelo deslocamento de um coágulo de outra parte do corpo, denominado embolia ou pelo estreitamento de artérias cerebrais, chamado de estenose (CAPRIOTTI; MURPHY, 2016).

De acordo com dados epidemiológicos, o AVE é classificado pela Organização Mundial de Saúde (OMS) como a segunda maior causa de mortes e a principal causa de incapacidades em todo o mundo (BONITA et al., 2004). Ainda que, as taxas de mortalidade e incidência do AVE vem declinando nas últimas duas décadas, o número de sobreviventes com incapacidades adquiridas pós-AVE e o número de mortes pela doença ainda estão aumentando (HANKEY, 2017).

Os gastos médios anuais relacionados a reabilitação pós-AVE nos Estados Unidos ultrapassam 11 mil dólares, aproximadamente $16 \%$ do orçamento anual do 
país (MOZAFFARIAN et al., 2015). Mesmo assim, apenas dois terços dos sobreviventes são inseridos nos serviços de reabilitação após a hospitalização (MOZAFFARIAN et al., 2015).

Aproximadamente $20 \%$ dos sobreviventes são institucionalizados nos primeiros três meses e cerca de 30\% permanecem incapacitados (GOLDSTEIN et al., 2011). A inabilidade mais comum entre os sobreviventes está relacionada a paresia no membro superior (MS) (NAKAYAMA et al., 1994), acarretando limitações nas atividades funcionais (KWAKKEL et al., 2003) e dependência para execução das atividades de vida diária (AVDs) (WINSTEIN et al., 2016).

Em se tratando da capacidade funcional do MS, é preciso considerar como os hemisférios cerebrais direito (HCD) e esquerdo (HCE) controlam as atividades motoras nos diferentes lados do corpo, uma vez que existe um grau de lateralização funcional, e essa está diretamente relacionada a especialização hemisférica do controle motor em ambos os braços. Um exemplo disso, é que sujeitos com lesão no HCE apresentam comprometimentos na coordenação dos movimentos do cotovelo e ombro (BAGESTEIRO, 2002), enquanto que os sujeitos com lesão no HCD apresentam prejuízos na capacidade de atingir posições finais precisas (BAGESTEIRO, 2003).

Do ponto de vista social, a dificuldade ou incapacidade de retornar ao trabalho pós-AVE promove um ônus econômico na sociedade (PERSSON; FERRAZ-NUNES; KARLBERG, 2012). Cerca de $25 \%$ dos custos com a doença estão relacionados a redução da produção decorrente de licenças médicas e aposentadoria antecipada (AARNIO et al., 2018).

\subsection{RECUPERAÇÃO FUNCIONAL PÓS-AVE}

A recuperação funcional pós-AVE é de suma importância para a reintegração social e realização das atividades cotidianas (BORGES et al., 2018). No entanto, essa recuperação é um processo complexo, dinâmico e multifatorial, uma vez que, há uma interação entre fatores fisiopatológicos, sociodemográficos e terapêuticos que podem determinar a trajetória final da recuperação (ALAWIEH; ZHAO; FENG, 2018). 
Já está bem reportado na literatura que o cérebro é capaz de reorganizar suas conexões e se adaptar após uma lesão (GERROW; BROWN, 2017). Esse fenômeno é denominado neuroplasticidade, uma vez que o Sistema Nervoso Central (SNC) é capaz de alterar suas propriedades morfológicas e funcionais para reorganizar os circuitos neurais e recuperar funções pedidas (LÖVDÉN et al., 2010; MARK; TAUB; MORRIS, 2006). É o mecanismo pelo qual o cérebro lesado é capaz de reaprender o comportamento perdido pós-lesão em resposta a reabilitação (KLEIM; JONES, 2008). No entanto, essa capacidade de reorganização dos circuitos neurais é altamente dependente da experiência, uma vez que esse processo depende da capacidade dos circuitos motores que não foram lesados adquirir novas estratégias em resposta a modificações ambientais ou experiências para compensar os danos pós lesão (JOHNSTON, 2004; KRAKAUER, 2006).

Existem na literatura dois conceitos bem descritos e que parecem nos ajudar a entender como o SNC após uma lesão é capaz de se organizar. Esses conceitos são o da plasticidade uso-dependente (MAWASE et al., 2017; MONFILS; PLAUTZ; KLEIM, 2005; NUDO et al., 1996) e do não uso aprendido (JONES et al., 2013; KREISEL; HENNERICI; BÄZNER, 2007; TAUB et al., 2006).

\subsubsection{PLASTICIDADE USO-DEPENDENTE}

O córtex motor é organizado em mapas funcionais somatotópicos que apresentam grandes níveis de plasticidade uso-dependente, ou seja, os mapas podem ser modificados pela experiência (NUDO et al., 1996). Os mapas motores representam um conjunto de neurônios do córtex motor específicos dos músculos, que permitem a aprendizagem e a execução de movimentos formando um engrama motor. A repetição de tarefas também favorece o mecanismo da plasticidade usodependente e pode estar relacionada a melhora no desempenho motor (MAWASE et al., 2017). Na direção oposta, quando esses mapas motores são danificados por uma lesão, o engrama motor é perdido (MONFILS; PLAUTZ; KLEIM, 2005).

A plasticidade uso-dependente pode ser induzida pelo treinamento motor (BÜTEFISCH et al., 1998; CLASSEN et al., 1998; MONFILS; PLAUTZ; KLEIM, 2005). 
Já foi demonstrado em humanos que, um curto período de treinamento composto por movimentos simples, voluntários e repetidos em uma direção específica promovem alterações nas áreas de representação cortical do polegar (CLASSEN et al., 1998). Além disso, a repetição de movimentos no MS conduz a plasticidade uso-dependente modificando as áreas de representações motoras no córtex. A área cortical responsável pelo movimento que está sendo repetido expande suas ramificações dendríticas, promovendo um aumento da resposta sináptica. Por outro lado, as áreas que representam os movimentos que não estão sendo repetidos não se expandem podendo até reduzir o seu tamanho (COHEN et al., 1993; NUDO et al., 1996).

\subsubsection{NÃO USO APRENDIDO}

$\mathrm{Na}$ fase crônica da recuperação as modificações morfológicas decorrentes de uma lesão isquêmica, como a perda de inervação ou o desequilíbrio entre os hemisférios quase sempre levam a uma adaptação motora (KREISEL; HENNERICl; BÄZNER, 2007). Como resultado, podem ser observados padrões de movimentos ineficazes no membro parético. Além disso, como somente o membro não parético passa a ser utilizado, esse vai gradualmente apresentando um melhor desempenho motor (KREISEL; HENNERICI; BÄZNER, 2007; TAUB et al., 2006). Dessa maneira, sujeitos com inabilidades motoras pós-lesão, aprendem a não usar o membro parético para a realização das AVDs (JONES et al., 2013).

Outros dois mecanismos comportamentais podem ser adicionados ao panorama descrito acima. $\mathrm{O}$ reforçamento negativo pelas contínuas falhas motoras no uso do membro parético, somado ao reforçamento positivo pelo uso satisfatório do membro não parético. Esses aspectos constituem a base da teoria comportamental do não uso aprendido (TAUB et al., 2006) que é definida pela diminuição do uso de um segmento corporal pós-lesão em comparação ao seu real potencial de utilização. 


\subsection{REABILITAÇÃO PÓS-AVE}

Uma vez que o AVE é uma doença altamente incapacitante, é prioritário entender os diferentes mecanismos que podem contribuir para a retomada de função motora e assim potencializar os recursos utilizados para a reabilitação pós-AVE. Com esse fim, vários estudos vêm sendo realizados com o objetivo de analisar as diferentes ferramentas de reabilitação e reverter os déficits funcionais pós-AVE (DICKSTEIN et al., 1986; KOLLEN et al., 2009; LANGHORNE; BERNHARDT; KWAKKEL, 2011; POLLOCK et al., 2007).

De uma maneira geral, a reabilitação é fundamentada no treinamento das capacidades motoras perdidas (DICKSTEIN et al., 1986) e também no treinamento para o uso dos membros não paréticos (ALLRED; JONES, 2008; DOBKIN, 2005; KERR et al., 2013). Seguindo os dois conceitos correntes de abordagem restaurativa ou compensatória (LANG et al., 2013).

\subsubsection{TÉCNICAS CLÁSSICAS EM REABILITAÇÃO}

No início da década de 70, surgiram as técnicas de neurofacilitação, que consistem em ferramentas que visam a reorganização do controle motor por meio de movimentos normais, inibidores ou facilitadores (SCHAECHTER, 2004). Entre elas, pode-se destacar a Facilitação Neuromuscular Proprioceptiva (FNP) (KABAT, 1952; POLLOCK et al., 2007) e o Conceito Bobath (KOLLEN et al., 2009).

A FNP é uma abordagem clássica amplamente utilizada na reabilitação neurofuncional (KABAT, 1952; POLLOCK et al., 2007). Esse método desenvolvido pelo Dr. Herman Kabat é executado por meio de padrões de movimento em diagonal e espiral, somado a técnicas de facilitação neuromuscular, buscando respostas motoras para melhorar a função muscular. Está relacionada a ativação do sistema de proprioceptores com o objetivo de facilitar ou inibir a ação de grupos musculares (KABAT, 1952). Nesse sentido, já foi evidenciado na literatura os benefícios da FNP 
no desempenho da marcha (AKOSILE et al., 2011; KAWAHIRA et al., 2004) e na melhora do desempenho motor e funcional (RIBEIRO et al., 2014).

O conceito Bobath, desenvolvido por Berta e Karel Bobath, é uma abordagem focada na solução de problemas, tratamento dos déficits funcionais e controle postural após lesões no SNC (KOLLEN et al., 2009). O conceito integra o controle postural no desempenho de tarefas e controla movimentos seletivos, com o objetivo de produzir sequências coordenadas de movimentos, ou seja, facilita o lado afetado e incentiva os padrões normais de movimentos. Esses aspectos são considerados cruciais para promover a recuperação motora (GRAHAM et al., 2009; KOLLEN et al., 2009). Um estudo piloto demonstrou benefícios no desempenho da marcha pós-AVE utilizando intervenções baseadas no conceito Bobath (BROCK et al., 2011).

Os dois conceitos descritos acima são considerados tradicionais na reabilitação pós-AVE, produzem resultados positivos na função motora e não possuem evidências de superioridade de resultados entre si (DICKSTEIN et al., 1986; KOLLEN et al., 2009; LANGHAMMER; STANGHELLE, 2011).

\subsubsection{TÉCNICAS CONTEMPORÂNEAS BASEADAS NO APRENDIZADO MOTOR}

Com o passar dos anos, o entendimento dos conceitos de aprendizado motor foram sendo modificados e na década de 80 , estudos demonstraram o importante papel da neuropsicologia e do aprendizado motor na reabilitação pós-AVE (ANDERSON; LOUGH, 1986; POLLOCK et al., 2007; TAUB; CRAGO; USWATTE, 1998).

O treinamento de tarefas específicas (FRENCH et al., 2007; HUBBARD et al., 2009; WINSTEIN; STEWART, 2005) surgiu dos estudos com prática de habilidades motoras e pode ser definido como um treinamento onde o sujeito realiza tarefas motoras específicas e recebe um feedback do seu desempenho (WINSTEIN; STEWART, 2005). O treinamento não é focado nos músculos, e sim no aprimoramento das tarefas funcionais executadas por meio da prática repetida (HUBBARD et al., 2009). Já está demonstrado que o treino de tarefas específicas 
pode ser justificado pelas modificações da plasticidade uso-dependente (PLAUTZ; MILLIKEN; NUDO, 2000).

As Terapias Restritivas foram desenvolvidas pelo neurocientista comportamental Edward Taub (MORRIS et al., 1997; TAUB E, USWATTE G, 1999; TAUB; CRAGO; USWATTE, 1998) e utilizam a contensão do MS não parético (MORRIS et al., 1997; TAUB et al., 2013; TAUB; USWATTE, 2003; WOLF et al., 2006). Adicionalmente, utiliza ainda um protocolo de treinamento intenso de tarefas específicas e a transferência dos ganhos obtidos da prática clínica para o ambiente real do paciente (TAUB et al., 2013). Diferentes estudos atestaram a eficácia dessa ferramenta terapêutica na reabilitação do MS parético (KWAKKEL et al., 2015; MARK; TAUB; MORRIS, 2006; MORRIS et al., 1997; TAUB et al., 2013; WOLF et al., 2002) e na reorganização cortical pós-AVE (LIEPERT et al., 1998, 2000; SCHAECHTER et al., 2002).

Outra intervenção comportamental é o treinamento de movimentos bilaterais. O treinamento bilateral simultâneo está relacionado a execução de tarefas idênticas, realizadas simultaneamente em ambos os membros superiores (MMSS) (MUDIE; MATYAS, 2000). Acredita-se que os benefícios do treinamento bilateral estão relacionados aos movimentos do MS não parético, uma vez que, esses movimentos facilitam os movimentos do MS parético. Ainda, alguns autores sugerem que a prática sincrônica de movimentos bilaterais ativam o hemisfério cerebral não acometido, facilitando assim a ativação do hemisfério cerebral contralateral acometido, por meio da inibição inter-hemisférica (CAURAUGH; KIM; SUMMERS, 2008; STINEAR et al., 2008).

Diferente do treinamento bilateral, a educação cruzada busca o aumento de força muscular no membro em repouso, após um programa de treinamento unilateral (FARTHING, 2009). Entretanto, o ganho de força parece ser específico para músculos homólogos e a magnitude no ganho de força no membro em repouso é proporcional ao membro treinado (CARROLL et al., 2006; HORTOBÁGYI et al., 1999). Acredita-se que esse fenômeno é resultante de adaptações neurais (HENDY; SPITTLE; KIDGELL, 2012) e alterações bilaterais no córtex motor (CARROLL et al., 2006; HORTOBÁGYI et al., 1999). No entanto, é preciso considerar o tipo de contração, a intensidade e se o treinamento é aplicado no membro de preferência motora, uma vez que esses fatores são de suma importância para a transferência de força (CARROLL et al., 
2006). A relevância da educação cruzada, para a reabilitação pós-AVE, está relacionada a presença de um hemicorpo preservado, uma vez que, geralmente o comprometimento no hemicorpo afetado é grande, o que dificulta o desenvolvimento dos treinamentos de força (LAGERQUIST, 2006). Recentemente uma revisão sistemática da Cochrane demonstrou um impacto positivo da utilização dessa ferramenta na reabilitação pós-AVE (EHRENSBERGER et al., 2016).

Utilizando tecnologia, a realidade virtual é uma abordagem recente que pode possibilitar a prática simulada de tarefas aumentando a dosagem da reabilitação (KWAKKEL et al., 2004). Baseada na utilização de computadores e softwares, cria um ambiente de simulações interativas que permitem aos sujeitos a execução de tarefas semelhantes ao mundo real, em um ambiente virtual. Em função de sua popularização, pesquisadores estão adaptando jogos recreativos de baixo custo e adaptando esse jogos com objetivos terapêuticos (WEISS; KIZONY, 2006; WINSTEIN et al., 2016). Os dispositivos presentes nos consoles comercias como câmeras ou sensores de movimento, permitem aos sujeitos interagir com o ambiente e com os objetos virtuais por meio de feedback visual, auditivo e tátil (WEISS; KIZONY, 2006). Recentemente, foi demonstrado que a realidade virtual promove benefícios na velocidade da marcha e equilíbrio pós-AVE (CORBETTA; IMERI; GATTI, 2015).

Apesar de atualmente encontrarmos propostas de reabilitação com as técnicas clássicas ou baseadas no aprendizado motor, é importante considerar outros aspectos envolvidos no processo de reabilitação.

\subsection{DOSAGEM DO TRATAMENTO PÓS-AVE}

Existem indícios na literatura que a reabilitação pós-AVE deve ser pautada em parâmetros relacionados a intensidade do tratamento, a frequência semanal dos atendimentos e também na repetição dos exercícios, na duração diária e total do tratamento e na especificidade das tarefas propostas independentemente de conceitos ou métodos de reabilitação (WINSTEIN; STEWART, 2005). Nesse sentido, adequar esses parâmetros pode ser extremamente importante para promover os resultados esperados na reabilitação funcional desses pacientes (TOOLE et al., 2005). 
De certa maneira, esses parâmetros caracterizam a dosagem da terapia. Assim como na farmacologia, a dosagem está relacionada com a concentração do princípio ativo, bem como a frequência de ingestão de um medicamento e a duração de sua utilização (BOSCH et al., 2014). Apesar que, existem indicações para a adoção desses parâmetros na reabilitação há mais de 15 anos, ainda não existe um consenso na literatura em relação a sua implementação nos protocolos de reabilitação (KWAKKEL et al., 1997).

\subsubsection{INTENSIDADE}

De acordo com a literatura, a intensidade na reabilitação pode ser interpretada por vários aspectos. Em relação aos conceitos biomecânicos, é definida pela quantidade de energia utilizada para execução de um conjunto de tarefas (KWAKKEL, 2006), ou seja, a quantidade de trabalho que está sendo realizado ou a magnitude do esforço para realizar determinada atividade (AMMANN et al., 2014). Ainda, pode ser relacionada com a frequência das repetições realizadas (KAWAHIRA et al., 2004).

Toda habilidade motora adquirida somente será mantida durante sua utilização, por exemplo, a prática de uma modalidade esportiva ou a habilidade para tocar um instrumento musical. Essas habilidades estão diretamente relacionadas com uma dose de treinamento para aprendizagem e para a manutenção das habilidades, ou seja, quanto maior o tempo e repetição dedicado a prática, melhor o desempenho de determinada habilidade (AMMANN et al., 2014).

Considerando que, durante o processo de reabilitação funcional pós-AVE, os pacientes reaprendem a realizar atividades básicas da vida diária, como vestir-se e alimentar-se, pode-se dizer que a reabilitação pós-AVE deve ser guiada pelos mesmos aspectos descrito anteriormente (KWAKKEL, 2006b). Nesse sentido, evidências científicas vêm demonstrando que os sujeitos submetidos a protocolos de reabilitação intensiva podem apresentar um melhor desempenho motor comparado com uma reabilitação menos intensa (CHAN, 2015; KWAKKEL et al., 1999; KWAKKEL; KOLLEN; WAGENAAR, 2002). 
O aumento da intensidade, do ponto de vista econômico, nos protocolos de reabilitação resulta em menores custos e produzem melhor desempenho motor associado a um menor tempo de internação (CHAN, 2015). Em um artigo de revisão, envolvendo 1051 pacientes pós-AVE, foi encontrada uma relação entre intensidade e efeito, ou seja, quanto maior a intensidade maior o tamanho do efeito entre os grupos controle e experimental (KWAKKEL et al., 1997). Outros trabalhos também apontam na mesma direção, quanto maior a intensidade da prática, melhor a recuperação funcional (LANGHORNE; BERNHARDT; KWAKKEL, 2011), nos membros inferiores e na marcha (OUTERMANS et al., 2010), bem como no desempenho dos MMSS (HAN et al., 2013).

No entanto, a intensidade é um parâmetro pouco controlado, uma vez que nem sempre é possível medir com precisão a intensidade de um exercício. Isso pode ocorrer devido a falta de equipamentos capazes de monitorar o trabalho e a energia gasta (AMMANN et al., 2014).

Outro fator importante pode ser a falta de conhecimento da quantidade exata de esforço, que sujeitos saudáveis ou doentes utilizam para realizar determinadas tarefas, dificultando ainda mais a aplicação da dosagem correta do tratamento (KWAKKEL, 2006a). Alguns equipamentos como, por exemplo, o ciclo ergômetro e a esteira, podem fornecer o esforço exato utilizado para realizar um exercício. Por outro lado, em muitos protocolos de reabilitação, esses equipamentos não são utilizados. Mas sempre que possível, deve ser relatado o número de repetições dedicadas a prática de uma tarefa e o tempo consecutivo dedicado ao treinamento (AMMANN et al., 2014).

De acordo com o panorama descrito acima, adequar a intensidade dos programas de reabilitação é importante para otimizar a recuperação. Segundo Taub (1999), não são as ferramentas utilizadas no processo de reabilitação que devem ser revisadas, e sim a intensidade com que elas são aplicadas (TAUB, 1999). Apesar das evidências, no entanto, não existe um consenso na literatura que quantifica a intensidade ideal no tratamento fisioterapêutico pós-AVE. 


\subsubsection{FREQUÊNCIA}

A frequência é definida pelo número de vezes que uma atividade é realizada e também está relacionada ao número de sessões durante um dia ou semana (AMMANN et al., 2014; LANG; LOHSE; BIRKENMEIER, 2015; PAGE; SCHMID; HARRIS, 2012; SONODA et al., 2004).

A frequência da execução de exercícios aeróbicos seguem alguns parâmetros bem descritos (BILLINGER, 2016). Os exercícios aeróbicos devem ser realizados de 20-60 minutos por dia, na frequência de 2 a 5 vezes por semana (BOYNE et al., 2017), sendo que, 3 vezes por semana é a frequência mais utilizada, com duração total de aproximadamente 6 meses. No entanto, para a reabilitação neurofuncional, a frequência do tratamento não está bem descrita na literatura. Já, nos Estados Unidos, os serviços de reabilitação são regulamentados e determinam que a reabilitação deve ser realizada por no mínimo 3 horas diárias nos 5 dias da semana (MILLER et al., 2010).

Estudos com modelos animais vêm demonstrando a importância de controlar a frequência do exercício pós isquemia encefálica, uma vez que, o treino de marcha em esteira com alta frequência preserva o desempenho motor (DE ARAUJO et al., 2008) e treinamento de baixa frequência não produz os mesmos resultados em gerbilos isquêmicos (KITABATAKE et al., 2015).

Em humanos, o aumento da frequência diária na reabilitação, promove resultados mais eficazes, uma vez que, oferecer sessões de fisioterapia todos os dias da semana pode reduzir em média 7 dias o período de internação de pacientes pósAVE (RAPOPORT; JUDD-VAN EERD, 1989). Acredita-se que a recuperação da mobilidade nas duas primeiras semanas pós-AVE poderia ser realizada em sessões de fisioterapia mais curtas, entretanto com maior frequência. Já o treino de atividades funcionais, poderia ser realizado de maneira progressiva com alta frequência (todos os dias da semana) ao invés de longas sessões separadas por vários dias de inatividade (BERNHARDT et al., 2016). Ainda nessa fase da doença, um tratamento multidisciplinar de alta frequência (mais de uma vez por dia, todos os dias da semana) promoveu um impacto positivo na independência funcional pós-lesão (KARGES; SMALLFIED, 2009). 
No primeiro ano pós-AVE, a maior frequência de reabilitação, está diretamente relacionada com a menor incidência, mortalidade (CHENG et al., 2017) e pode reduzir o índice de recorrência da doença (LO; TSENG, 2017). Na fase crônica, a adição de frequência semanal e intensidade diária melhora o desempenho funcional e pode ser favorável ao processo de reabilitação (SONODA et al., 2004) uma vez que, pode promover uma redução do tempo de utilização dos serviços de reabilitação (DISOTTO-MONASTERO et al., 2012) e ainda, ser preditor de um melhor prognóstico funcional (KINOSHITA et al., 2017).

Da mesma maneira que a intensidade, a frequência é um parâmetro que precisa ser controlado e ajustado para melhorar a eficácia da reabilitação neurológica. No entanto, ainda não há um consenso na literatura relacionado a frequência de tratamento ideal para promover esses benefícios.

\subsubsection{DURAÇÃO}

A duração da reabilitação pode ser definida pelo tempo gasto, por dia ou por semana, dedicados a aprendizagem de uma determinada habilidade ou o tempo total da reabilitação (KWAKKEL, 2006b; PAGE; SCHMID; HARRIS, 2012), relacionada assim ao tempo em minutos, duração da sessão (AMMANN et al., 2014), ou ao período total do processo de reabilitação (KWAKKEL, 2006a).

Estudos clínicos, sugerem que uma maior duração do processo de reabilitação pode promover melhores resultados relacionados a recuperação funcional (DIMYAN; COHEN, 2011; HAN et al., 2013; KWAKKEL; WAGENAAR, 2002; LOHSE; LANG; BOYD, 2014; MURPHY; CORBETT, 2009; ROSE et al., 2017; VEERBEEK et al., 2014).

Nos Estados Unidos, em 1982, foi desenvolvida uma diretriz relacionada a duração das intervenções nos serviços de reabilitação americanos. Os pacientes em ambiente médico hospitalar devem receber no mínimo 3 horas diárias de terapias relacionadas a reabilitação durante os 7 dias na semana (JOHNSTON; MILLER, 1986). 
O aumento da duração diária de um protocolo de reabilitação, pode melhorar os ganhos funcionais (WANG et al., 2013), assim como aumentar a duração total da reabilitação, uma vez que, adicionar 40 horas a mais de treinamento, também promove maior recuperação funcional (HAN et al., 2013). Na mesma direção, uma meta-análise relatou que nos primeiros 6 meses pós-AVE deve-se acrescentar 16 horas de tratamento ao protocolo de reabilitação (KWAKKEL et al., 2004).

Uma revisão da Cochrane investigou os efeitos da duração da reabilitação em diferentes treinamentos de marcha em esteira. Foi evidenciado que os tratamentos de 4 semanas ou mais foram eficazes para melhorar a velocidade e a resistência da marcha (MEHRHOLZ; POHL; ELSNER, 2014). Ainda, em relação ao treino de marcha em esteira, foi demonstrado que o treinamento locomotor com duração de 12 semanas (36 sessões) melhorou a velocidade da marcha (PLUMMER et al., 2007). Em relação ao desempenho das AVDs, o aumento da duração da intervenção também tem um efeito positivo, mantendo os ganhos funcionais em um período de 6 meses de seguimento (GALVIN et al., 2008).

Recentemente, uma revisão sistemática demonstrou que é preciso aumentar a duração da intervenção, por meio de terapias extras, em 240\% para promover ganhos na execução das atividades funcionais (SCHNEIDER et al., 2016). Por outro lado, aumentar a duração da terapia em aproximadamente 22 horas, com frequência de 2 dias na semana, por meio de intervenções realizadas em grupo, apresentou resultados semelhantes ao protocolo convencional (ENGLISH et al., 2015).

Nesse sentido, em relação ao panorama descrito, não há um consenso na literatura relacionado ao período ideal de reabilitação (WANG et al., 2013). Dessa maneira, o ajuste desses parâmetros na reabilitação é de suma importância para otimizar os resultados da reabilitação pós-AVE, uma vez que compreender a quantidade de tempo e de sessões de determinado tipo de intervenção é crucial para aplicar uma conduta fisioterapêutica baseada em evidências (ROSE et al., 2017). 


\subsubsection{ESPECIFICIDADE}

O treino de tarefas específicas tem como objetivo melhorar a habilidade para execução de atividades funcionais ou de movimentos selecionados (SCHAECHTER, 2004). Dessa maneira, a especificidade é um parâmetro relacionado a realização de tarefas específicas de uma determinada habilidade motora, uma vez que, o treino de determinado exercício ou habilidade é de suma importância para melhorar o desempenho (AMMANN et al., 2014).

Nesse sentido, já foi evidenciado na literatura que a especificidade do treinamento ativo é um parâmetro importante no processo de recuperação motora pós-lesão (PLATZ et al., 2009). Diferentes estudos vêm demonstrando os efeitos do treinamento específico na melhora do desempenho motor e nas alterações da função cerebral pós-AVE (BAYONA et al., 2005; CAREY et al., 2002; HUBBARD et al., 2009; PLATZ et al., 2009; RICHARDS et al., 2008; WOLDAG; STUPKA; HUMMELSHEIM, 2010).

Modelos experimentais revelaram que a especificidade do treinamento de uma tarefa é capaz de restaurar a função cerebral por meio da ativação de áreas adjacentes (NUDO et al., 1996) ou suplementares (NUDO; FRIEL; DELIA, 2000) a lesão. Sendo assim, a recuperação funcional após uma lesão no SNC é dependente da estimulação externa e induzida pela especificidade da intervenção (ROSSI; GIANOLA; CORVETTI, 2007).

Essas alterações da plasticidade neural também foram demonstradas em estudos com seres humanos. O treinamento de tarefas específicas foi capaz de promover a melhora do controle motor dos dedos associado a alterações nos mapas corticais em exames de ressonância magnética funcional. Antes do início do protocolo, somente o córtex motor ipsilateral foi ativado, entretanto, após a realização do treinamento específico, foi observada a ativação do córtex motor contralateral (CAREY et al., 2002). Acredita-se então que, a especificidade do treinamento, pode estar associada com o equilíbrio da ativação cortical (SCHAECHTER, 2004).

Uma meta-análise realizada em 2008 demonstrou que a reabilitação baseada em intervenções direcionadas, ou seja, específicas, promovem a recuperação motora do MS pós-AVE acompanhada por alterações nos mapas neurais do hemisfério 
cerebral acometido (RICHARDS et al., 2008). No mesmo ano, uma revisão sistemática verificou que o treinamento de tarefas específicas melhorou a função motora global (FRENCH et al., 2008). Na mesma direção, o treinamento doméstico de tarefas funcionais específicas para o membro superior (MS) foi mais eficaz em relação ao tratamento doméstico inespecífico (WOLDAG; STUPKA; HUMMELSHEIM, 2010).

Dessa maneira, já está bem estabelecido na literatura que a prática de tarefas específicas é necessária para que a aprendizagem motora aconteça (PAGE, 2003). Por outro lado, a reabilitação pós-AVE nem sempre está pautada nesse conceito. Na maioria das vezes, os pacientes são submetidos a programas de intervenção inespecíficos durante o processo de reabilitação (MACKEY et al., 1996; PAGE, 2003). Assim, é possível entender o motivo pelo qual as abordagens fisioterapêuticas clássicas têm sido menos eficazes (BÜTEFISCH et al., 1995; CLASSEN et al., 1998).

Nesse sentido, o treinamento de tarefas específicas também é considerado um elemento chave para várias ferramentas de reabilitação (HUBBARD et al., 2009). Pode ser ajustada focando em estratégias que melhoram a aprendizagem e a reaprendizagem motora ou até mesmo para otimizar a utilização do MS parético na execução das AVDs (WINSTEIN; STEWART, 2005).

\subsection{DIRETRIZES PARA REABILITAÇÃO PÓS-AVE}

Nos Estados Unidos, as diretrizes para a reabilitação e recuperação em adultos pós-AVE, recomendam que os sujeitos recebam protocolos de intervenção relacionados ao objetivo a ser alcançado, de maneira que os pacientes possam tolerar a intensidade adotada, considerando que a intensidade será proporcional ao benefício esperado com a reabilitação (WINSTEIN et al., 2016). Ou seja, que o sujeito receba a intervenção necessária para recuperar ou reestabelecer a independência funcional (DUNCAN et al., 2005).

No Reino Unido e na Holanda, de acordo com as recomendações das diretrizes clínicas para a reabilitação pós-AVE, os sujeitos devem receber a terapia de reabilitação com duração mínima de 45 minutos (VEERBEEK et al., 2014), em uma 
frequência suficiente para o alcance das metas estabelecidas (INTERCOLLEGIATE STROKE WORKING PARTY, 2016).

Em relação a duração, apesar da regulamentação nesses países, algumas evidências mostram que elas não são seguidas (OTTERMAN et al., 2012; VEERBEEK et al., 2014).

No Brasil, as diretrizes de atenção a pessoa com AVE preconizam que a reabilitação seja iniciada precocemente e em toda a sua integralidade, para o reestabelecimento das funções e independência funcional (Diretrizes de atenção à reabilitação da pessoa com Acidente Vascular Cerebral, 2013).

A principal limitação das diretrizes apresentadas, é a falta de referência na literatura em relação aos parâmetros de reabilitação (DEJONG et al., 2005). Assim, das evidências que apresentamos acima, as diretrizes de reabilitação pós-AVE de diferentes países parecem não considerar esses aspectos.

Um trabalho recente do nosso laboratório, investigou os benefícios do controle dos parâmetros frequência, duração e especificidade. Nesse trabalho, mostramos que um protocolo inespecífico de alta frequência e duração foi mais eficaz comparado a um protocolo específico de baixa frequência e duração na reabilitação do MS afetado pós-AVE (SANTOS; FUZARO; DE ARAUJO, 2019).

Sendo assim, no presente estudo novamente queremos investigar os parâmetros de alta frequência, media duração e baixa especificidade, aliados a um protocolo padrão de fisioterapia. A nossa hipótese é que, um protocolo com alta frequência e média duração com livre exploração do MS parético, adicionado a um protocolo com especificidade, baixa frequência e duração melhore o desempenho motor e funcional de pacientes crônicos pós-AVE. 
OBJETIVOS 


\section{OBJETIVOS}

\subsection{OBJETIVO GERAL}

Verificar as repercussões funcionais e motoras de um protocolo especifico com baixa frequência e curta duração com adição de alta frequência, média duração e livre exploração na reabilitação motora do MS parético de pacientes crônicos pós-AVE.

\subsection{OBJETIVOS ESPECÍFICOS}

A. Avaliar o desempenho funcional dos sujeitos usando as escalas Wolf Motor Function Test, Fugl-Meyer Assessment e Motor Activity Log.

B. Avaliar ativação elétrica e a força de preensão manual usando eletromiografia de superfície dos músculos flexores e extensores do punho e dinamometria.

C. Avaliar a qualidade de vida e o impacto do AVE usando a Stroke Specific Qualit of Life e a National Institutes of Health Stroke Scale.

D. Avaliar as repercussões da lateralidade nos protocolos BFCD e BFCD+AFMD. 


\section{MATERIAL E MÉTODOS}




\section{MATERIAL E MÉTODOS}

\subsection{SUJEITOS}

Trata-se de um estudo PROBE (do inglês, Prospective Randomized Open, Blinded End-point) prospectivo, randomizado, aberto, com avaliação cega de desfechos e exploratório. Participaram deste estudo 45 sujeitos, com lesões encefálicas à direita (D) e à esquerda $(E)$ pós-AVE isquêmico, de ambos os sexos, na faixa etária entre 33 e 74 anos, com média de idade entre 58,50 \pm 9,41 e tempo médio de lesão entre $32,47 \pm 24,60$.

O cálculo amostral foi realizado por meio do software G-Power ${ }^{\circledR}$ (versão 3.1), baseado no desfecho do domínio relacionado ao MS da Fugl-Meyer Assessment do trabalho de Page e Sisto (2001). Foi estimada uma amostra composta por 52 pacientes, com um poder de $95 \%, 5 \%$ de significância e tamanho do efeito estimado de 0,94 (PAGE; SISTO, 2001).

Os sujeitos foram recrutados no Centro Integrado de Reabilitação (CIR) anexo ao Hospital Estadual de Ribeirão Preto (HERP) e na Secretaria Municipal de Saúde de Ribeirão Preto (SMS-RP).

Os critérios de inclusão para participação no estudo foram: ter sofrido AVE isquêmico há no mínimo 6 meses, apresentar hemiparesia como sequela motora, ter boa cognição, ausência de bloqueios articulares, boa amplitude de movimento (ADM) no MS (mínimo $20^{\circ}$ de extensão ativa de punho e $10^{\circ}$ na articulação metacarpo falangeana), não participar de nenhum outro serviço de reabilitação, capacidade de deambular sem auxílio e preferência motora para o membro superior direito (MSD). Uma vez que, sujeitos com preferência motora para o membro superior esquerdo (MSE) não apresentam homogeneidade comportamental (PRZYBYLA; GOOD; SAINBURG, 2012).

Os critérios de exclusão incluíram, além dos critérios de admissão: hipertensão arterial descontrolada (a critério do examinador), insuficiência cardíaca descompensada (classe funcional 2, 3 ou 4), distúrbios respiratórios graves (doença pulmonar obstrutiva crônica, pneumonia, entre outras), impossibilidade de 
comparecer aos atendimentos e não assinatura do termo de consentimento livre e esclarecido (TCLE). Pacientes utilizando medicamentos próprios ao tratamento do AVE e anti-hipertensivos foram aceitos no estudo. Os sujeitos incluídos no estudo assinaram o TCLE para a participação no estudo.

Este estudo foi aprovado pelo Comitê de Ética e Pesquisa do Hospital das Clínicas da Faculdade de Medicina de Ribeirão Preto da Universidade de São Paulo, sob protocolo número 6663/2015. Também foi registrado no Sistema Nacional de Informações em Ética e Pesquisa com Seres Humanos (CAAE34021614.0.0000.5440) e no site ClinicalTrials.gov (NTC02441374).

\subsection{RANDOMIZAÇÃO}

A randomização foi realizada em blocos por meio do site www.random.org. Os sujeitos foram alocados aleatoriamente em dois grupos (Figura 1) conforme os protocolos:

- Baixa frequência e curta duração (BFCD): recebeu como forma de tratamento um protocolo específico para o MS parético, em sessões com duração de 40 minutos, frequência de 2 vezes por semana e duração total de 4 semanas $(n=22)$;

- Baixa frequência e curta duração com adição de alta frequência e média duração (BFCD+AFMD): recebeu como forma de tratamento um protocolo específico para o MS parético, em sessões com duração de 40 minutos, frequência de 2 vezes por semana e duração total de 4 semanas. Foi adicionado ao protocolo a contensão do MS ipsilateral a lesão encefálica (não parético) e a livre exploração do MS parético, com duração de 12 horas diárias, frequência de 5 dias por semana e duração total de 4 semanas $(n=$ 23). 


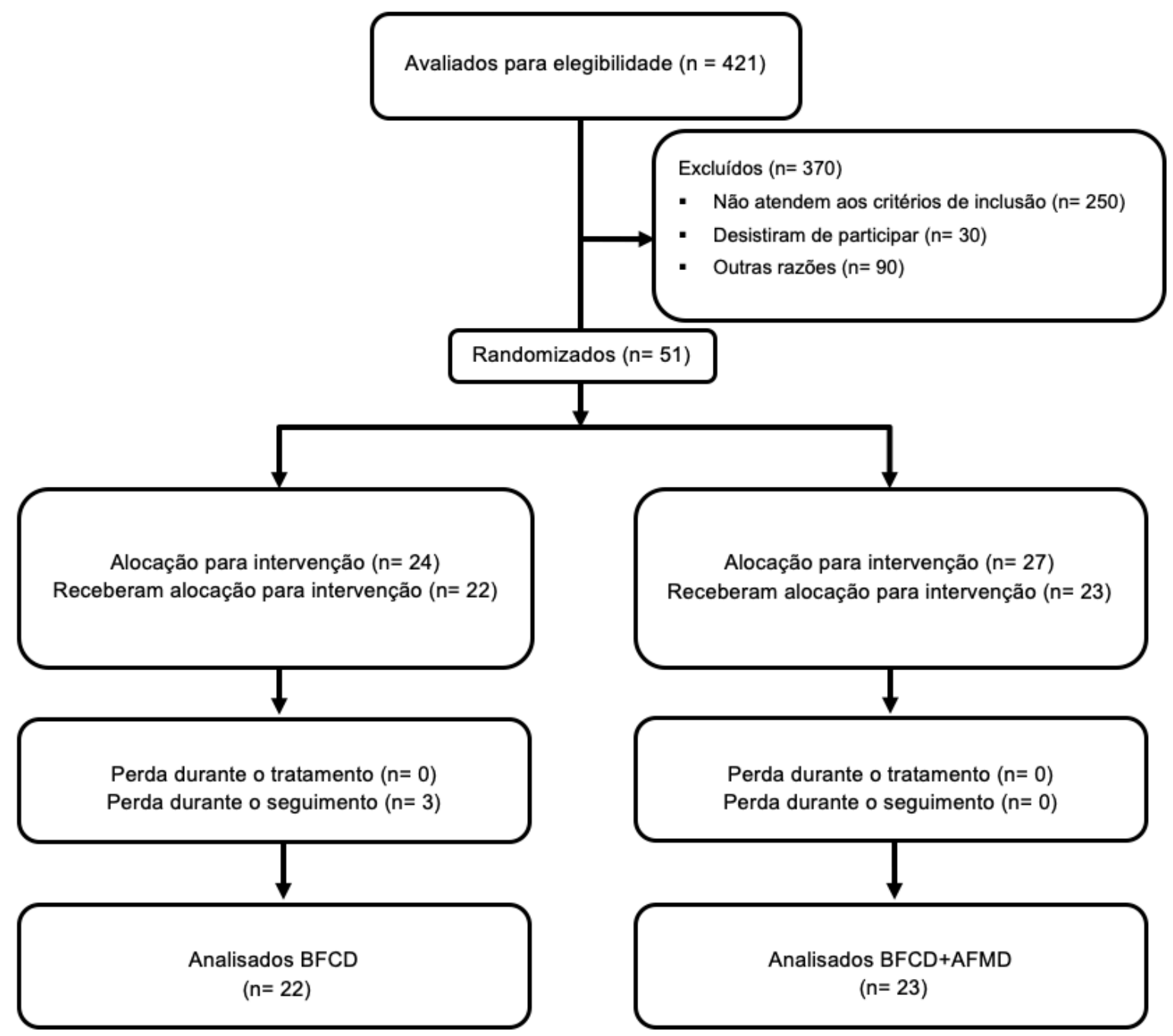

Figura 1 - Fluxograma de seleção dos sujeitos conforme a declaração de normas consolidadas sobre a notificação de ensaios - CONSORT (Consolidated Standards of Reporting Trials). BFCD: Baixa frequência e curta duração e BFCD+AFMD: Baixa frequência e curta duração com adição de alta frequência e média duração.

\subsection{PROTOCOLOS DE INTERVENÇÃO}

Os dois protocolos de intervenção foram realizados no CIR, anexo do HERP. 


\subsection{PROTOCOLO BFCD}

O protocolo de reabilitação para o MS foi realizado utilizando a técnica clássica de FNP. O tratamento foi realizado pela resistência manual de um fisioterapeuta presente no CIR, com experiência prévia no método. Durante os 40 minutos de atendimento, foram executadas 4 diagonais de movimento direcionadas ao MS não parético: flexão-abdução-rotação externa, extensão-adução-rotação interna, flexãoadução-rotação externa e extensão-abdução-rotação interna. O movimento do MS não parético, em cada diagonal foi interrompido quando a maior intensidade de irradiação contralateral de força muscular foi observada, para tanto, foi utilizada a resistência máxima necessária para interrupção do movimento. Cada diagonal foi executada por um período de 10 minutos. $O$ tratamento foi realizado com a frequência de 2 vezes por semana e duração de 4 semanas.

\subsection{PROCEDIMENTO PARA ADIÇÃO DE AFMD}

Os sujeitos do grupo BFCD+AFMD, no primeiro dia do início do protocolo, tiveram seu MS ipsilateral a lesão encefálica contido por meio de uma malha tubular. O MS foi posicionado em adução, rotação interna de ombro, flexão de cotovelo maior que $90^{\circ}$ e flexão de dedos (Figura 2). Os sujeitos foram instruídos a retirar a malha tubular 12 horas após o horário inicial de contensão. No dia seguinte os sujeitos foram instruídos a colocar uma nova malha tubular no MS parético no mesmo horário do dia anterior. Todas as quartas e sextas-feiras, os sujeitos eram tratados com o protocolo BFCD e nesse caso, o fisioterapeuta responsável pelo atendimento fazia a colocação da malha tubular. Todas as segundas-feiras, após as avaliações, os sujeitos recebiam as 2 malhas tubulares necessárias para a auto colocação que acontecia as terças e quintas-feiras. Em todos os casos, as malhas foram usadas uma única vez e descartadas. Os sujeitos foram ensinados a colocar e retirar a malha tubular nos horários pré-estabelecidos. Além disso, com o objetivo de controlar a utilização do MS parético, os sujeitos receberam um diário e foram orientados a descrever todas as 
atividades diárias realizadas com o MS parético. O protocolo AFMD foi mantido com duração de 12 horas diárias, frequência de 5 dias por semana e duração total de 4 semanas. O mesmo protocolo de contensão foi utilizado em um trabalho anterior do nosso laboratório, com redução da duração diária no tempo de contensão (SANTOS; FUZARO; DE ARAUJO, 2019).

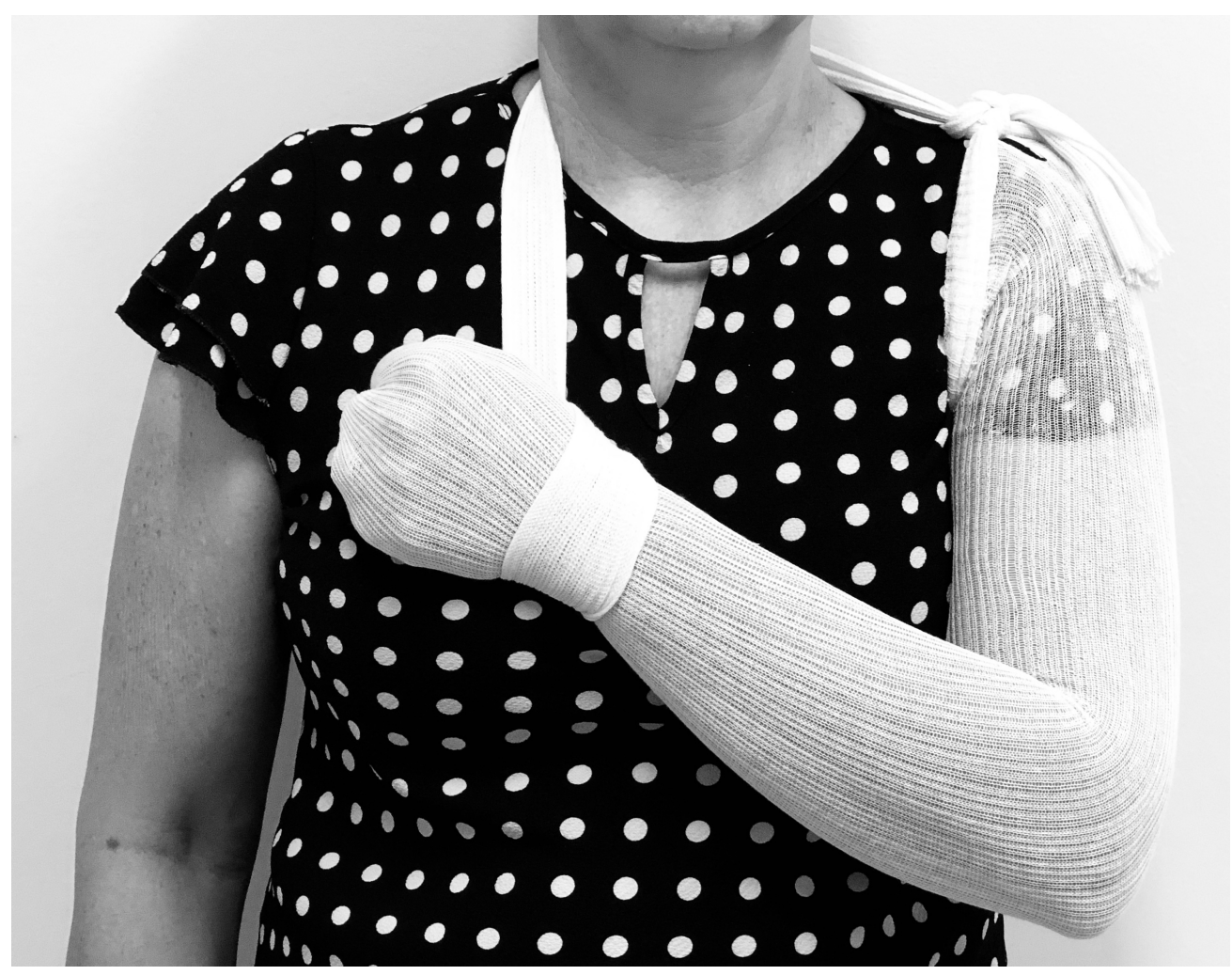

Figura 2 - Sujeito com a contensão do MS não parético utilizada para aumentar a frequência e a duração.

\subsection{AVALIAÇÕES}

As avaliações aconteceram todas as segundas-feiras, durante as 4 semanas de intervenção e mensalmente nas avaliações de seguimento. A avaliação inicial foi realizada antes do início dos protocolos. As avaliações 2, 3 e 4, foram realizadas semanalmente durante a execução dos protocolos. A avaliação 5 , aconteceu após o término dos protocolos e as avaliações de seguimento 1,2 , e 3 , foram realizadas mensalmente após o término dos protocolos. 


\subsection{ESCALAS DE AVALIAÇÃO}

Para as avaliações, foram utilizadas escalas que permitem analisar o impacto do $A V E$, a qualidade de vida, a função motora e sua evolução.

\subsubsection{NATIONAL INSTITUTES HEALTH STROKE SCALE}

A National Institute of Health Stroke Scale (NIHSS) foi utilizada com o objetivo de quantificar a gravidade do AVE (BROTT et al., 1989). Essa escala fornece uma visão geral dos déficits pós-AVE, tanto na prática clínica quanto em pesquisas. É composta por 11 itens do exame neurológico que permite atribuir um valor numérico a esse déficit. Incluí os domínios referentes ao nível de consciência, movimentos oculares, integridade dos campos visuais, movimentos faciais, força muscular nos braços e nas pernas, sensibilidade, coordenação, linguagem, fala e negligência. De acordo com cada comprometimento, a pontuação é realizada em uma escala ordinal variando de 0 a 4 . A soma da pontuação total pode variar de 0 a 42 pontos, sendo que, quanto maior a pontuação, maior a gravidade do AVE (KWAH; DIONG, 2014). Foi utilizada a versão traduzida e validada para o nosso idioma e cultura (CINCURA et al., 2009).

\subsubsection{STROKE SPECIFIC QUALITY OF LIFE}

Foi utilizada a Stroke Specific Quality of Life (SS-QOL), um instrumento específico para avaliar a qualidade de vida dos sujeitos pós-AVE. Essa escala possui 49 itens em 12 domínios (energia, papel familiar, linguagem, mobilidade, humor, personalidade, autocuidado, papel social, raciocínio, função de MS, visão e trabalho/produtividade). Existem 3 possibilidades de resposta, onde cada item possui escores de 1 a 5 e a referência para as respostas é a semana anterior. O escore pode 
variar entre 0 e 245 pontos, uma vez que quanto maior a pontuação melhor a qualidade de vida pós-AVE (WILLIAMS et al., 1999). Foi utilizada a versão traduzida e validada para nosso idioma e cultura (LIMA et al., 2008).

\subsubsection{WOLF MOTOR FUNCTION TEST}

Foi utilizado o Wolf Motor Function Test (WMFT) para avaliar a execução das AVDs. Este teste avalia o tempo gasto para desempenhar a tarefa e também a qualidade do movimento, por meio de tarefas simples e sequenciais relacionadas as articulações envolvidas (de ombro a dedos) e aumentando o nível de dificuldade (habilidade motora grossa para habilidade motora fina) (WOLF et al., 1989). É composto por 17 itens que podem ser testados na clínica, com pontuação que varia de 0 a 5 para cada item. Em relação a dimensão qualitativa, a pontuação total pode variar entre 0 a 75 pontos. Em relação a dimensão quantitativa, ou seja, a velocidade durante a execução das tarefas, o tempo gasto para realizar cada tarefa não pode ultrapassar 120 segundos (MORRIS et al., 2001; WOLF et al., 2001).

Para a análise da dimensão quantitativa, utilizamos uma normalização em porcentagem, onde a primeira avaliação correspondeu a $100 \%$ do tempo total gasto. Foi utilizada a versão traduzida e validada para o nosso idioma e cultura (PEREIRA et al., 2011).

\subsubsection{FUGL-MEYER ASSESSMENT}

A Fugl-Meyer Assessment (FMA) foi utilizada para avaliar a recuperação da paresia pós-AVE. Esta escala é composta por 5 domínios: função motora, sensorial, equilíbrio, ADM articular e dor articular. Cada domínio possui itens com escores que variam de 0 a 2 pontos ( 0 = não é possível executar, 1 = executa parcialmente, 2 = executa na íntegra). O domínio motor contém itens de ADM, coordenação e ação reflexa sobre o ombro, cotovelo, antebraço, punho, mão, quadril, joelho e tornozelo. 
Nesse domínio, a pontuação varia de 0 (hemiplegia) até 100 pontos (desempenho motor normal), divididos em 66 pontos para a extremidade superior e 34 pontos para a extremidade inferior. Do mesmo modo, existe um máximo de 24 pontos para a sensibilidade, 14 pontos para o equilíbrio sentado e em pé, 44 pontos para a ADM articular e 44 pontos para dores nas articulações (FUGL-MEYER et al., 1975; MAKI et al., 2006; SANFORD et al., 1993). Nesse estudo, utilizamos apenas a parte motora correspondente ao MS e a versão traduzida e validada para o nosso idioma e cultura (MAKI et al., 2006).

\subsubsection{MOTOR ACTIVITY LOG}

Foi aplicado o Motor Activity Log (MAL) com o objetivo de avaliar a utilização do MS parético. O MAL é dividido em 2 partes com 30 itens, uma quantitativa e outra qualitativa, para graduação de cada tarefa. Cada parte possui 6 possibilidades de pontuação, que variam de 0 a 5, para a quantitativa onde 0 = não utiliza o MS parético e 5 = utiliza o MS parético da mesma maneira que utilizava antes do AVE. Para a qualitativa, 0 = o MS parético não foi usado de forma alguma e 5 = o MS parético foi tão bom como era antes do AVE. Também tem possibilidade de pontuação intermediária para descrever a quantidade e a qualidade de utilização do MS parético. A pontuação total é realizada pelo cálculo da média para cada parte da escala, sendo que, quanto mais próxima de 5 a média da pontuação, maior a quantidade de utilização e melhor a qualidade do movimento do MS parético (USWATTE et al., 2005; VAN DER LEE et al., 2004). Foi utilizada a versão traduzida e validada para o nosso idioma e cultura (SALIBA et al., 2010).

\subsubsection{ASHWORTH SCALE}

A Ashworth Scale (AS) foi utilizada para avaliar o grau de espasticidade do MS parético. De acordo com o grau de espasticidade, pode ser pontuada de 0 a 4 , onde 
0 = tônus normal, 1 = aumento do tônus no inicio ou no final do arco de movimento, 2

= aumento do tônus em mais da metade do arco de movimento, 3 = partes em extensão ou em flexão movidas com dificuldade e 4 = partes rígidas em flexão ou extensão (BOHANNON; SMITH, 1987; WOOD et al., 2005).

\subsubsection{AVALIAÇÃO INSTRUMENTAL}

Foram realizadas avaliações instrumentais juntamente com as escalas descritas acima. Para avaliar a força de preensão manual, utilizamos um dinamômetro de mão e para analisar a ativação dos músculos flexores e extensores do punho, a eletromiografia de superfície.

\subsubsection{DINAMOMETRIA DE PREENSÃO MANUAL}

Foi utilizado um dinamômetro digital de mão (Digital Hand Dinamometer, modelo DIGI-II-SH5003, Saehan, Korea). Os sujeitos foram posicionados sentados, com o braço apoiado à $90^{\circ}$ e com a mão livre para executar a preensão, de acordo com as recomendações da American Society of Hand Therapists (ASHT) (ROBERTS et al., 2011) (Figura 3). Com a mão em flexão, posicionada no dinamômetro, os sujeitos realizavam durante 5 segundos uma contração máxima. O procedimento foi repetido 3 vezes. 


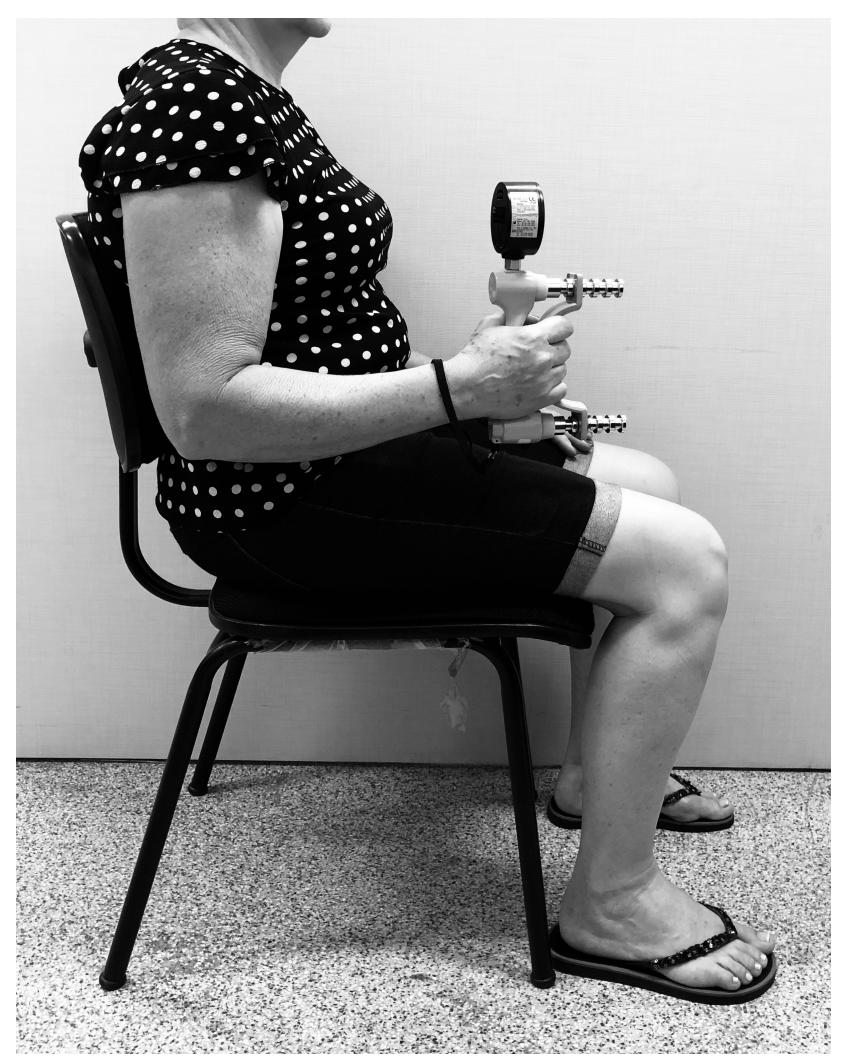

Figura 3 - Posicionamento do paciente durante a coleta de dados da dinamometria de preensão manual de acordo com as recomendações da ASHT (American Society of Hand Therapists).

\subsubsection{ELETROMIOGRAFIA DE SUPERFÍCIE}

A eletromiografia de superfície (EMG), utilizada para avaliar a atividade elétrica muscular, foi realizada por meio de um equipamento de eletromiografia e biofeedback de quatro canais (EMG System do Brasil, modelo CS400AF, São José dos Campos, Brasil), utilizando filtro passa-banda, com frequência de corte entre $20-500 \mathrm{~Hz}$ amplificado a um ganho de 1000 e taxa de rejeição de modo comum $>120 \mathrm{~dB}$. Foram utilizados eletrodos adesivos, bipolares duplos (com distância intereletrodo fixa) e descartáveis.

Para a realização das coletas, utilizando um aparelho de barbear descartável, foi retirado os possíveis pelos na área de colocação dos eletrodos. Ainda, utilizando uma lixa de unha, foi realizada uma abrasão na pele do paciente para a retirada de células mortas. Posteriormente a área foi limpa com álcool a 70\% (KONRAD, 2005). 
Foi colocado um eletrodo entre o ponto motor e o tendão distal dos músculos flexores e outro eletrodo para os extensores de punho. Além desses, foi utilizado um eletrodo dispersivo, fixado no processo estiloide da ulna (PEROTTO, 2011).

Todos os procedimentos de preparação da pele e colocação de eletrodos seguiram as recomendações do projeto da União Europeia de Eletromiografia de Superfície para a Abordagem não Invasiva Muscular ("SENIAM Project”)

Para a aquisição dos dados foi utilizado o software DATAQ Instruments Hardware Manager. Para a aquisição do sinal, o paciente executava o movimento de extensão ou de flexão do punho com o cotovelo posicionado a aproximadamente $90^{\circ}$ contra uma cinta de tecido não elástico (Figura 4). A contração muscular máxima, tinha a duração de 5 segundos. Foram coletados os dados de 3 contrações musculares, com intervalo de 10 segundos, para ambos os grupos musculares. Os dados das avaliações foram normalizados em porcentagem e a avaliação inicial correspondeu a $100 \%$ dos valores de Root Mean Square (RMS).

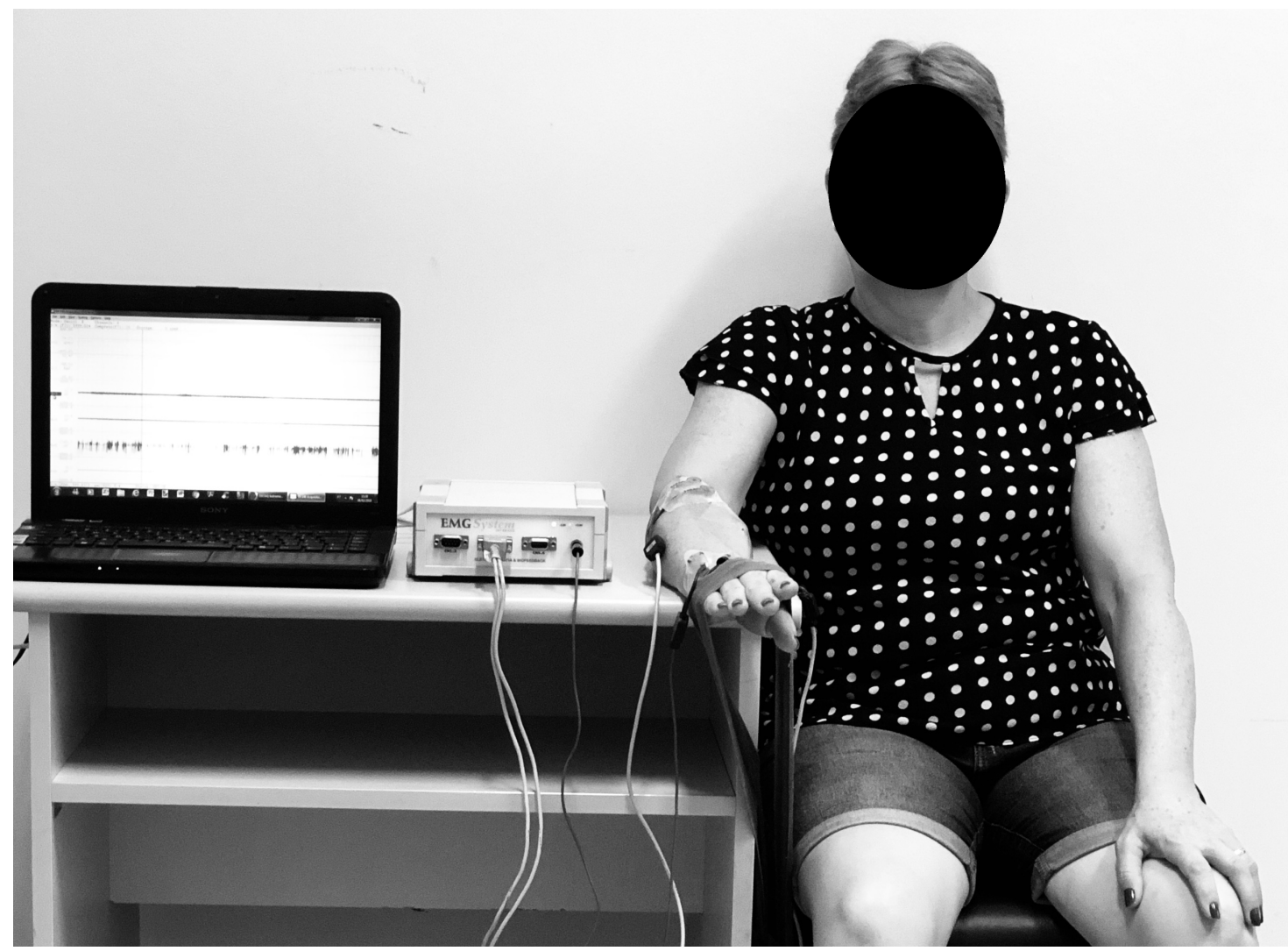

Figura 4 - Figura representativa do posicionamento do paciente durante a coleta de dados dos músculos extensores do punho pela EMG. 


\subsection{ANÁLISE ESTATÍSTICA}

Verificamos a homogeneidade da amostra, após a randomização dos grupos, utilizando o WMFT quantitativo. Com esse fim, foi utilizado o teste t de Student. Uma vez que, os dados estavam adequadamente dentro das curvas de normalidade e variância, utilizamos uma análise de variância de duas vias (ANOVA - Two Way) para a comparação entre os dados dos grupos de tratamento, as diferentes avaliações e suas respectivas interações. Para entendermos se os possíveis resultados sofreram influência do hemisfério lesado, separamos a amostra de acordo com a lesão (HCD ou HCE). Foram considerados significativos os valores de $p<0,05$. A análise estatística foi realizada por meio do software Sigma Plot 11.0. 
RESULTADOS 


\section{RESULTADOS}

Participaram deste estudo 45 sujeitos que sofreram AVE isquêmico, na faixa etária entre 33 e 74 anos, com média de idade entre 58,50 \pm 9,41 anos, de ambos os sexos, sendo $37,26 \%$ dos sujeitos do sexo feminino e $62,74 \%$ do sexo masculino. Os sujeitos da nossa amostra apresentavam lesões encefálicas à $D$ e à $E, 50,98 \%$ no HCD e 49,02\% no HCE e $29,42 \%$ dos sujeitos apresentaram lesão na artéria cerebral média. O tempo médio de lesão foi entre $32,47 \pm 24,60$ meses e $100 \%$ dos sujeitos apresentavam preferência motora para o MSD. A avaliação inicial do WMFT quantitativo revelou a homogeneidade da amostra $(t=-0,41 ; p=0,68)$ (Tabela 1$)$.

A análise dos dados obtidos com a NIHSS revelou uma redução significativa da pontuação no grupo BFCD+AFMD em relação ao grupo BFCD $\left(F_{1,335: 23,33)}\right.$ (Figura 5A). A análise da interação entre os grupos e as avaliações revelou uma diminuição significativa da pontuação do grupo BFCD+AFMD na avaliação 4 e na avaliação final em relação ao grupo BFCD $\left(F_{7,335: 0,21)}\right.$ (Figura 5B). No grupo BFCD, a análise dos resultados dos sujeitos divididos em relação ao hemisfério cerebral lesado não revelou diferenças significativas na comparação entre as avaliações $\left(F_{7,151}: 0,88 ; p=0,52\right)$ (Figura $5 C$ ). Por outro lado, no grupo BFCD+AFMD observamos uma redução significativa da pontuação na avaliação 2 e na avaliação de seguimento 2 dos sujeitos com lesão no HCD em relação aos sujeitos com lesão no HCE $\left(F_{7,335: 0,21)}\right.$ (Figura 5D).

A análise dos dados obtidos com a SS-QOL revelou um aumento significativo da pontuação no grupo BFCD+AFMD em relação ao grupo BFCD $\left(F_{1,335: 22,79}\right)$ (Figura 6A). A análise da interação entre os grupos e as avaliações revelou um aumento significativo da pontuação do grupo BFCD+AFMD na avaliação 3, 4 e na avaliação de seguimento 1 em relação ao grupo BFCD $\left(F_{7,335}: 0,25\right)$ (Figura $\left.6 B\right)$. No grupo BFCD, a análise dos resultados dos sujeitos divididos em relação ao hemisfério cerebral lesado não revelou diferenças significativas na comparação entre as avaliações $\left(F_{7,151}: 0,23 ; p=0,97\right)$ (Figura $\left.6 C\right)$. Na mesma direção, no grupo BFCD+AFMD não observamos diferenças significativas na comparação entre as avaliações $\left(F_{7,168}: 0,33 ; p=0,93\right)$ (Figura $\left.6 D\right)$. 
A análise dos dados obtidos com o WMFT quantitativo revelou uma redução significativa do tempo para execução das tarefas no grupo BFCD+AFMD em relação

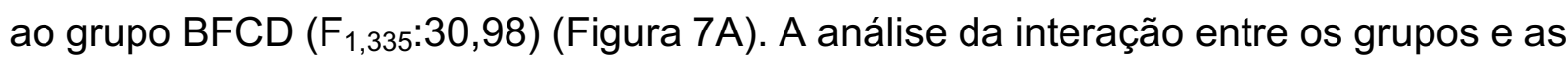
avaliações revelou uma diminuição significativa do tempo para execução das tarefas nas avaliações 2, 3, seguimento 1 e seguimento 3 no grupo BFCD+AFMD em relação ao $\operatorname{BFCD}\left(F_{7,335}: 1,37\right)$. Ainda, no grupo BFCD+AFMD foi revelada uma diminuição significativa da porcentagem de tempo nas avaliações 4, final, seguimento 1, 2 e 3 em comparação com a avaliação inicial. Já, no grupo BFCD não foi encontrado nenhuma diferença significativa entre as avaliações $(p=0,21)$ (Figura 7B). A análise dos resultados dos sujeitos divididos em relação ao hemisfério cerebral lesado, no grupo BFCD, não revelou diferenças significativas na comparação entre as avaliações $\left(F_{7,151}: 0,43 ; p=0,87\right)$ (Figura $7 C$ ). Na mesma direção, no grupo BFCD+AFMD não observamos diferenças significativas na comparação entre as avaliações $\left(F_{7,168}: 0,09\right.$; $\mathrm{p}=0,99$ ) (Figura 7D).

A análise dos dados qualitativos do WMFT não revelou diferenças significativas da pontuação entre os grupos BFCD e BFCD+AFMD $\left(F_{1,335}: 0,04 ; p=0,83\right)$ (Figura 8A). A análise da interação entre os grupos e as avaliações não revelou diferenças significativas na pontuação do grupo BFCD+AFMD em relação ao grupo BFCD $\left(F_{7,335: 0,16 ; p=0,99)}\right.$ (Figura 8B). No grupo BFCD, a análise dos resultados dos sujeitos divididos em relação ao hemisfério cerebral lesado não revelou diferenças significativas entre a comparação das avaliações $\left(F_{7,151}: 0,14 ; p=0,99\right)$ (Figura 8C). Na mesma direção, no grupo BFCD+AFMD não observamos diferenças significativas na comparação entre as avaliações $\left(F_{7,168}: 0,08 ; p=0,99\right)$ (Figura 8D).

A análise dos dados obtidos com a pontuação total da FMA revelou um aumento significativo da pontuação no grupo BFCD+AFMD em relação ao grupo BFCD $\left(F_{1,335: 4,14)}\right.$ (Figura 9A). A análise da interação entre os grupos e as avaliações não revelou diferenças significativas da pontuação do grupo BFCD+AFMD em relação ao grupo BFCD $\left(\mathrm{F}_{7,335}: 0,04 ; \mathrm{p}=1,00\right)$ (Figura $\left.9 \mathrm{~B}\right)$. No grupo $\mathrm{BFCD}$, a análise dos resultados dos sujeitos divididos em relação ao hemisfério cerebral lesado não revelou diferenças significativas na comparação entre as avaliações $\left(F_{7,151}: 0,08 ; p=0,99\right)$ (Figura 9C). Na mesma direção, no grupo BFCD+AFMD não encontramos diferenças significativas na comparação entre as avaliações $\left(F_{7,168}: 0,08 ; p=0,99\right)$ (Figura 9D). 
A análise dos dados obtidos com a pontuação do punho da FMA não revelou diferenças significativas da pontuação entre os grupos BFCD e BFCD+AFMD

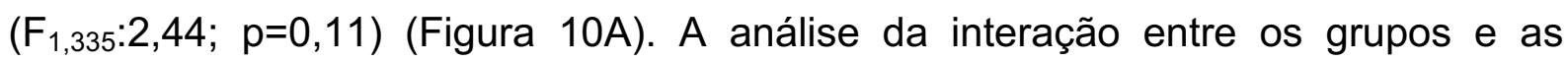
avaliações não revelou diferenças significativas da pontuação do grupo BFCD+AFMD em relação ao grupo BFCD $\left(F_{7,335}: 0,09 ; p=0,99\right)$ (Figura 10B). No grupo BFCD, a análise dos resultados dos sujeitos divididos em relação ao hemisfério cerebral lesado não revelou diferenças significativas na comparação entre as avaliações $\left(F_{7,151}: 0,12\right.$; $p=0,99$ ) (Figura 10C). Na mesma direção, no grupo BFCD+AFMD não encontramos diferenças significativas na comparação entre as avaliações $\left(F_{7,168}: 0,29 ; p=0,95\right)$ (Figura 10D).

A análise dos dados obtidos com a pontuação relacionada a mão da FMA não revelou diferenças significativas da pontuação entre os grupos BFCD e BFCD+AFMD $\left(F_{1,335: 3,30 ; p=0,07)}\right.$ (Figura 11A). A análise da interação entre os grupos e as avaliações não revelou diferenças significativas da pontuação do grupo BFCD+AFMD em relação ao grupo BFCD $\left(F_{7,335}: 0,21 ; p=0,98\right)$ (Figura 11B). No grupo BFCD, a análise dos resultados dos sujeitos divididos em relação ao hemisfério cerebral lesado não revelou diferenças significativas na comparação entre as avaliações $\left(F_{7,151}: 0,68\right.$; $p=0,68$ ) (Figura 11C). Na mesma direção, no grupo BFCD+AFMD não encontramos diferenças significativas entre na comparação entre as avaliações $\left(F_{7,168}: 0,07 ; p=0,99\right)$ (Figura 11D).

A análise dos dados obtidos com o MAL quantitativo revelou um aumento significativo da pontuação no grupo BFCD+AFMD em relação ao grupo BFCD $\left(F_{1,335: 17,81)}\right.$ (Figura 12A). A análise da interação entre os grupos e as avaliações revelou um aumento significativo da pontuação nas avaliações 2 e 3 do grupo $B F C D+A F M D$ em relação ao BFCD $\left(F_{7,335: 3,46}\right)$. Ainda, no grupo BFCD+AFMD foi revelado um aumento significativo da pontuação nas avaliações 3, 4, final e seguimento 1 em comparação com a avaliação inicial. Já, no grupo BFCD não foi encontrado nenhuma diferença significativa entre as avaliações $(p=0,89)$ (Figura 12B). A análise dos resultados dos sujeitos divididos em relação ao hemisfério cerebral lesado, no grupo BFCD, revelou um aumento significativo da pontuação nas avaliações 2, 3, 4 e final dos sujeitos com lesão no HCE em relação aos sujeitos com lesão no HCD $\left(F_{7,151}: 0,44\right)$ (Figura 12C). Por outro lado, no grupo BFCD+AFMD não 
observamos diferenças significativas na comparação entre as avaliações $\left(F_{7,168}: 0,29\right.$; $\mathrm{p}=0,95)$ (Figura 12D).

A análise dos dados obtidos com o MAL qualitativo revelou um aumento significativo da pontuação no grupo BFCD+AFMD em relação ao grupo BFCD $\left(F_{1,335}: 15,80\right)$ (Figura 13A). A análise da interação entre os grupos e as avaliações revelou um aumento significativo da pontuação na avaliação 3 do grupo BFCD+AFMD em relação ao BFCD $\left(F_{7,335}: 2,95\right)$. Ainda, no grupo $B F C D+A F M D$ foi revelado um aumento significativo da pontuação nas avaliações 4 e seguimento 1 em comparação com a avaliação inicial. Já, no grupo BFCD não foi encontrado nenhuma diferença significativa entre as avaliações $(p=0,94)$ (Figura 13B). A análise dos resultados dos sujeitos divididos em relação ao hemisfério cerebral lesado, no grupo BFCD, revelou um aumento significativo da pontuação nas avaliações 2, 3 e 4 dos sujeitos com lesão no HCE em relação aos sujeitos com lesão no HCD $\left(F_{7,151}: 0,41\right)$ (Figura 13C). Por outro lado, no grupo BFCD+AFMD não observamos diferenças significativas na comparação entre as avaliações $\left(F_{7,168}: 0,19 ; p=0,98\right)$ (Figura 13D).

A análise dos dados obtidos com a AS para o cotovelo não revelou diferenças

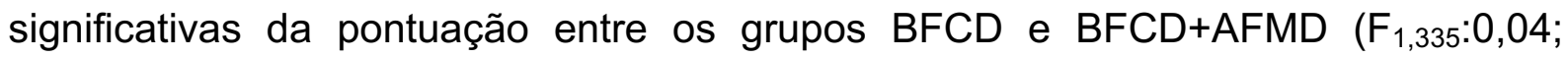
$\mathrm{p}=0$,82) (Figura 14A). A análise da interação entre os grupos e as avaliações não revelou diferenças significativas da pontuação entre os grupos BFCD e BFCD+AFMD $\left(F_{7,335: 0,35 ;} p=0,92\right)$ (Figura 14B). No grupo BFCD, a análise dos resultados dos sujeitos divididos em relação ao hemisfério cerebral lesado não revelou diferenças significativas na comparação entre as avaliações $\left(F_{7,151}: 0,22 ; p=0,98\right)$ (Figura 14C). Na mesma direção, no grupo BFCD+AFMD não encontramos diferenças significativas na comparação entre as avaliações $\left(F_{7,168}: 0,22 ; p=0,98\right)$ (Figura 14D).

A análise dos dados obtidos com a AS para o punho revelou uma redução significativa da pontuação no grupo BFCD+AFMD em relação ao grupo BFCD $\left(F_{1,335: 6,81)}\right.$ (Figura 15A). A análise da interação entre os grupos e as avaliações não revelou diferenças significativas da pontuação entre os grupos BFCD e BFCD+AFMD $\left(F_{7,335: 0,14 ; p=0,99)}\right.$ (Figura 15B). No grupo BFCD, a análise dos resultados dos sujeitos divididos em relação ao hemisfério cerebral lesado não revelou diferenças significativas na comparação entre as avaliações $\left(F_{7,151}: 0,05 ; p=1,00\right)$ (Figura 15C). Na mesma direção, no grupo BFCD+AFMD não encontramos diferenças significativas na comparação entre as avaliações $\left(F_{7,168}: 0,10 ; p=0,99\right)$ (Figura 15D). 
A análise dos dados obtidos com a dinamometria não revelou diferenças significativas na força de preensão manual entre os grupos BFCD e BFCD+AFMD

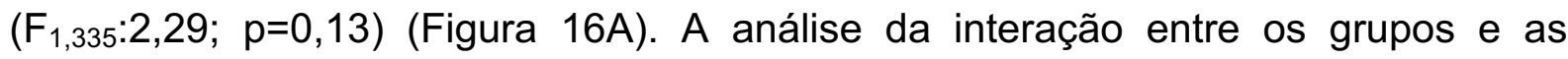
avaliações não revelou diferenças significativas da pontuação entre os grupos BFCD e BFCD+AFMD $\left(F_{7,335}: 0,04 ; p=1,00\right)$ (Figura 16B). No grupo BFCD, a análise dos resultados dos sujeitos divididos em relação ao hemisfério cerebral lesado não revelou diferenças significativas na comparação entre as avaliações $\left(F_{7,151}: 0,02 ; p=1,00\right)$ (Figura 16C). Por outro lado, no grupo BFCD+AFMD, encontramos um aumento significativo da força de preensão manual na avaliação de seguimento 3 dos sujeitos com lesão no HCD em relação aos sujeitos com lesão no $\operatorname{HCE}\left(F_{7,168}: 0,12\right)$ (Figura 16D).

A análise dos dados da EMG para os músculos flexores do punho, não revelou diferenças significativas da atividade RMS entre os grupos BFCD e BFCD+AFMD $\left(F_{1,303: 3,76 ;} p=0,18\right)$ (Figura 17A). A análise da interação entre os grupos e as avaliações não revelou diferenças significativas na atividade RMS do grupo

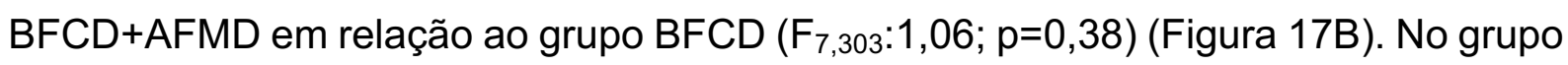
BFCD, a análise dos resultados dos sujeitos divididos em relação ao hemisfério cerebral lesado não revelou diferenças significativas na comparação entre as avaliações $\left(F_{7,143: 1,31 ;} p=0,24\right)$ (Figura 17C). Na mesma direção, no grupo BFCD+AFMD não observamos diferenças significativas na comparação entre as avaliações $\left(F_{7,144: 0,34 ; ~}=0,93\right)$ (Figura 17D).

A análise dos dados da EMG para os músculos extensores do punho, não revelou diferenças significativas da atividade RMS entre os grupos BFCD e BFCD+AFMD $\left(F_{1,303}: 0,21 ; p=0,64\right)$ (Figura 18A). A análise da interação entre os grupos e as avaliações não revelou diferenças significativas na atividade RMS do grupo BFCD+AFMD em relação ao grupo BFCD $\left(F_{7,303}: 1,07 ; p=0,37\right)$ (Figura 18B). No grupo BFCD, a análise dos resultados dos sujeitos divididos em relação ao hemisfério cerebral lesado não revelou diferenças significativas na comparação entre as avaliações $\left(F_{7,143: 0,71 ;} p=0,65\right)$ (Figura 18C). Na mesma direção, no grupo BFCD+AFMD não observamos diferenças significativas na comparação entre as avaliações $\left(F_{7,144: 0,81 ;} p=0,57\right)$ (Figura 18D). 
Tabela 1 - Características clínicas e dados demográficos da amostra.

\begin{tabular}{|c|c|c|c|c|c|c|c|}
\hline Grupos & $\begin{array}{l}\text { Idade } \\
\text { (Anos) }\end{array}$ & Gênero & $\begin{array}{l}\text { Hemisfério } \\
\text { lesado }\end{array}$ & WMFT & $\begin{array}{l}\text { Local da } \\
\text { lesão }\end{array}$ & $\begin{array}{l}\text { Tempo } \\
\text { pós-AVE } \\
\text { (meses) }\end{array}$ & $\begin{array}{c}\text { Preferência } \\
\text { motora }\end{array}$ \\
\hline BFCD & 33 & M & E & 28,64 & $\mathrm{AC}$ & 24 & D \\
\hline BFCD & 61 & $\mathrm{~F}$ & E & 5,59 & AC & 26 & D \\
\hline $\mathrm{BFCD}$ & 57 & $M$ & D & 8,96 & $\mathrm{NI}$ & 24 & D \\
\hline BFCD & 45 & $\mathrm{~F}$ & D & 3,81 & $\mathrm{NI}$ & 24 & D \\
\hline BFCD & 65 & M & E & 2,00 & ACM & 26 & D \\
\hline BFCD & 53 & M & D & 39,22 & LAC & 24 & D \\
\hline BFCD & 66 & $\mathrm{~F}$ & D & 2,31 & $\mathrm{AC}$ & 21 & D \\
\hline BFCD & 74 & M & D & 3,78 & $\mathrm{NI}$ & 24 & D \\
\hline BFCD & 54 & $\mathrm{~F}$ & E & 22,76 & $\mathrm{ACP}$ & 24 & D \\
\hline BFCD & 65 & $\mathrm{~F}$ & D & 3,97 & ACM & 20 & D \\
\hline BFCD & 56 & M & D & 1,96 & $\mathrm{NI}$ & 23 & D \\
\hline BFCD & 52 & M & E & 4,77 & $\mathrm{NI}$ & 15 & D \\
\hline $\mathrm{BFCD}$ & 58 & $\mathrm{~F}$ & D & 58,44 & ACM & 13 & D \\
\hline BFCD & 63 & M & E & 7,24 & $\mathrm{AC}$ & 15 & D \\
\hline BFCD & 69 & $M$ & $\mathrm{D}$ & 4,56 & $\mathrm{ACM}$ & 15 & D \\
\hline BFCD & 66 & M & $\mathrm{E}$ & 2,43 & $\mathrm{NI}$ & 20 & D \\
\hline BFCD & 61 & M & D & 24,14 & $\mathrm{AC}$ & 132 & D \\
\hline $\mathrm{BFCD}$ & 75 & $\mathrm{~F}$ & $\mathrm{E}$ & 5,15 & $\mathrm{NI}$ & 72 & D \\
\hline BFCD & 65 & M & D & 5,94 & CER & 120 & D \\
\hline BFCD & 64 & $\mathrm{~F}$ & $\mathrm{E}$ & 2,11 & $\mathrm{NI}$ & 30 & D \\
\hline BFCD & 71 & $\mathrm{~F}$ & E & 5,89 & $\mathrm{NI}$ & 6 & D \\
\hline BFCD & 53 & $\mathrm{~F}$ & $\mathrm{D}$ & 10,39 & $\mathrm{NI}$ & 36 & D \\
\hline BFCD & 56 & $\mathrm{~F}$ & E & 7,83 & $\mathrm{NI}$ & 38 & D \\
\hline BFCD & 73 & M & E & 2,61 & $\mathrm{NI}$ & 40 & D \\
\hline BFCD+AFMD & 44 & M & D & 4,69 & LAC & 49 & D \\
\hline BFCD+AFMD & 54 & M & D & 2,76 & ACM & 22 & D \\
\hline BFCD+AFMD & 62 & M & D & 2,53 & ACM & 31 & D \\
\hline BFCD+AFMD & 48 & $\mathrm{~F}$ & $\mathrm{E}$ & 4,32 & $\mathrm{ACM}$ & 57 & D \\
\hline BFCD+AFMD & 62 & M & D & 4,25 & $\mathrm{ACM}$ & 23 & D \\
\hline $\mathrm{BFCD}+\mathrm{AFMD}$ & 63 & $\mathrm{~F}$ & E & 53,90 & ACM & 37 & D \\
\hline BFCD+AFMD & 62 & M & $\mathrm{D}$ & 6,18 & $\mathrm{ACM}$ & 36 & D \\
\hline BFCD+AFMD & 60 & M & D & 3,84 & CER & 30 & D \\
\hline $\mathrm{BFCD}+\mathrm{AFMD}$ & 56 & $\mathrm{~F}$ & $\mathrm{E}$ & 2,68 & ACM & 15 & D \\
\hline BFCD+AFMD & 55 & $M$ & E & 23,34 & $\mathrm{ACM}$ & 13 & D \\
\hline $\mathrm{BFCD}+\mathrm{AFMD}$ & 55 & $M$ & D & 3,80 & $\mathrm{ACM}$ & 17 & D \\
\hline BFCD+AFMD & 58 & M & E & 2,27 & $\mathrm{ACM}$ & 24 & D \\
\hline BFCD+AFMD & 70 & $\mathrm{~F}$ & E & 60,37 & $\mathrm{NI}$ & 36 & D \\
\hline$B F C D+A F M D$ & 66 & M & E & 8,80 & $\mathrm{NI}$ & 21 & D \\
\hline BFCD+AFMD & 55 & $M$ & E & 2,99 & $\mathrm{NI}$ & 32 & D \\
\hline BFCD+AFMD & 66 & M & D & 2,11 & $\mathrm{NI}$ & 30 & D \\
\hline BFCD+AFMD & 74 & M & E & 3,20 & AC & 36 & D \\
\hline BFCD+AFMD & 61 & $\mathrm{~F}$ & E & 4,87 & $\mathrm{NI}$ & 24 & D \\
\hline BFCD+AFMD & 56 & $M$ & D & 8,15 & $\mathrm{NI}$ & 21 & $\mathrm{D}$ \\
\hline $\mathrm{BFCD}+\mathrm{AFMD}$ & 68 & M & D & 4,08 & $\mathrm{NI}$ & 23 & D \\
\hline $\mathrm{BFCD}+\mathrm{AFMD}$ & 51 & $M$ & E & 2,34 & $\mathrm{ACM}$ & 26 & D \\
\hline $\mathrm{BFCD}+\mathrm{AFMD}$ & 52 & M & E & 24,86 & $\mathrm{AC}$ & 48 & D \\
\hline BFCD+AFMD & 50 & $\mathrm{~F}$ & D & 2,04 & $\mathrm{NI}$ & 24 & D \\
\hline $\mathrm{BFCD}+\mathrm{AFMD}$ & 56 & $M$ & D & 3,73 & $\mathrm{NI}$ & 25 & D \\
\hline $\mathrm{BFCD}+\mathrm{AFMD}$ & 35 & M & E & 2,40 & $\mathrm{NI}$ & 24 & D \\
\hline $\mathrm{BFCD}+\mathrm{AFMD}$ & 40 & $\mathrm{~F}$ & D & 3,75 & $\mathrm{NI}$ & 36 & D \\
\hline \multirow[t]{3}{*}{$\mathrm{BFCD}+\mathrm{AFMD}$} & 50 & $\mathrm{~F}$ & $\mathrm{D}$ & 4,11 & $\mathrm{NI}$ & 25 & D \\
\hline & & & & & $\begin{array}{l}\text { ACP 1,96\% } \\
\text { LAC 3,92\% }\end{array}$ & & \\
\hline & 58,50 & F $37,26 \%$ & D $50,98 \%$ & 10,13 & АCM $29,42 \%$ & 32,47 & \\
\hline \multirow[t]{3}{*}{ Total } & \pm & M 62,74\% & E $49,02 \%$ & \pm & CER $3,92 \%$ & \pm & D 100\% \\
\hline & 9,41 & & & 14,36 & AC $13,72 \%$ & 24,60 & \\
\hline & & & & & NI $47,06 \%$ & & \\
\hline
\end{tabular}

Legenda: $B F C D=$ Baixa frequência e curta duração, $B F C D+A F M D$ = Baixa frequência e curta duração com adição de alta frequência e média duração, $M=$ Masculino, $F=$ Feminino, $D=$ Direito, $\mathrm{E}=$ Esquerdo, $\mathrm{LAC}=$ Lacunar, $\mathrm{ACM}=$ Artéria Cerebral Média, $\mathrm{ACl}=$ Artéria Cerebral Interna, $\mathrm{ACA}=$ Artéria Cerebral Anterior, $\mathrm{CER}=$ Cerebelar, $\mathrm{AC}=$ Artéria Carótida, $\mathrm{NI}=$ não identificado. 


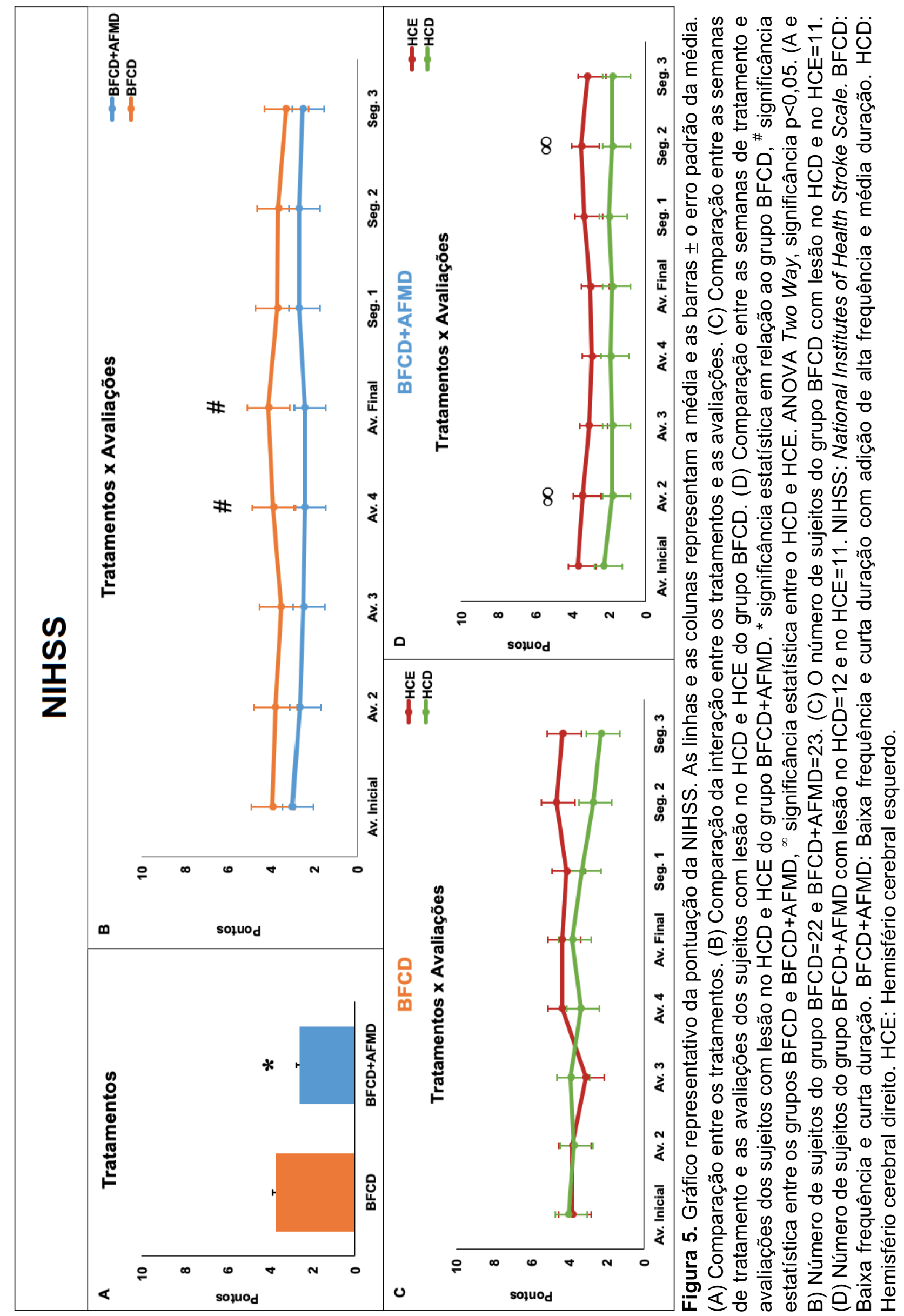




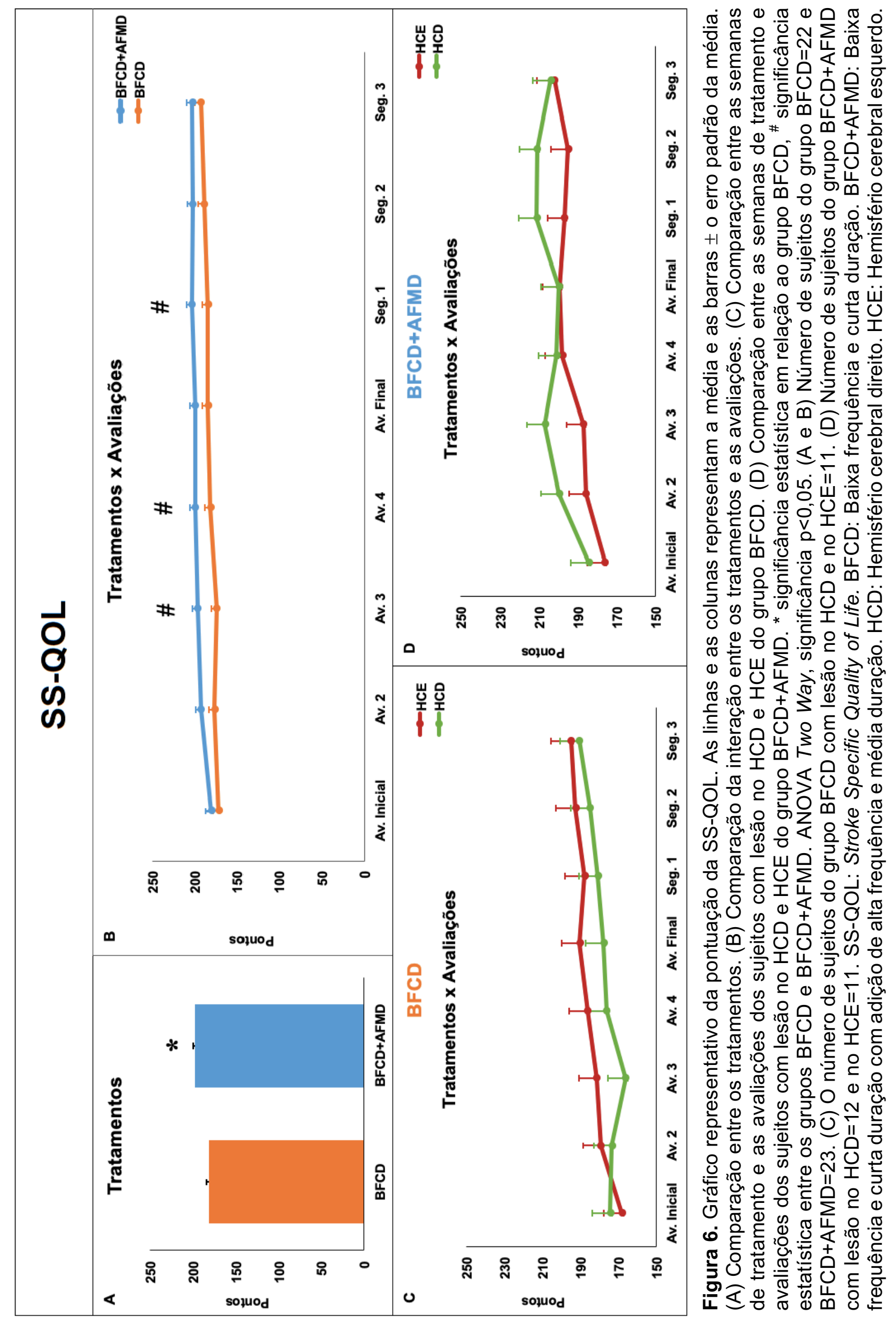




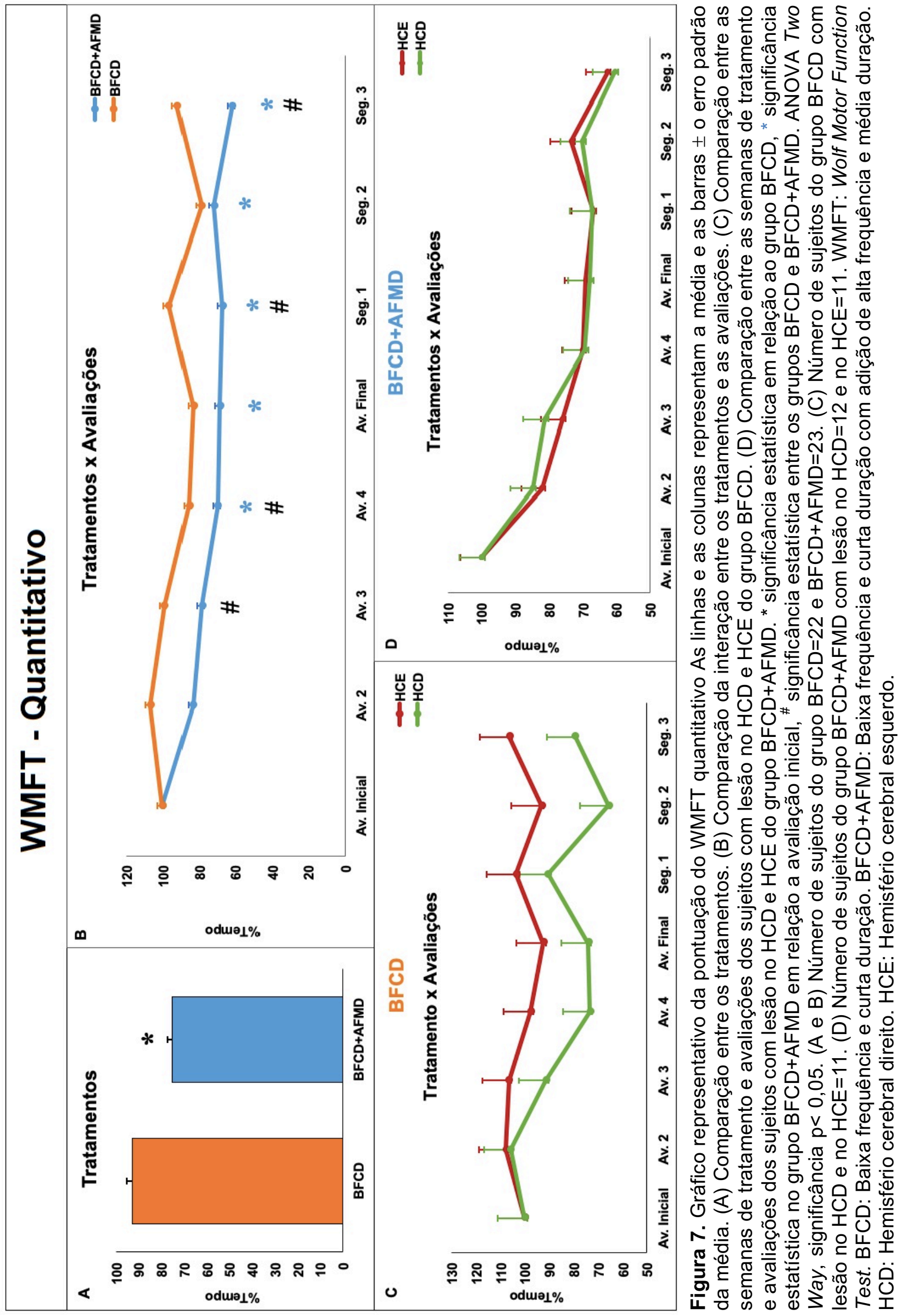




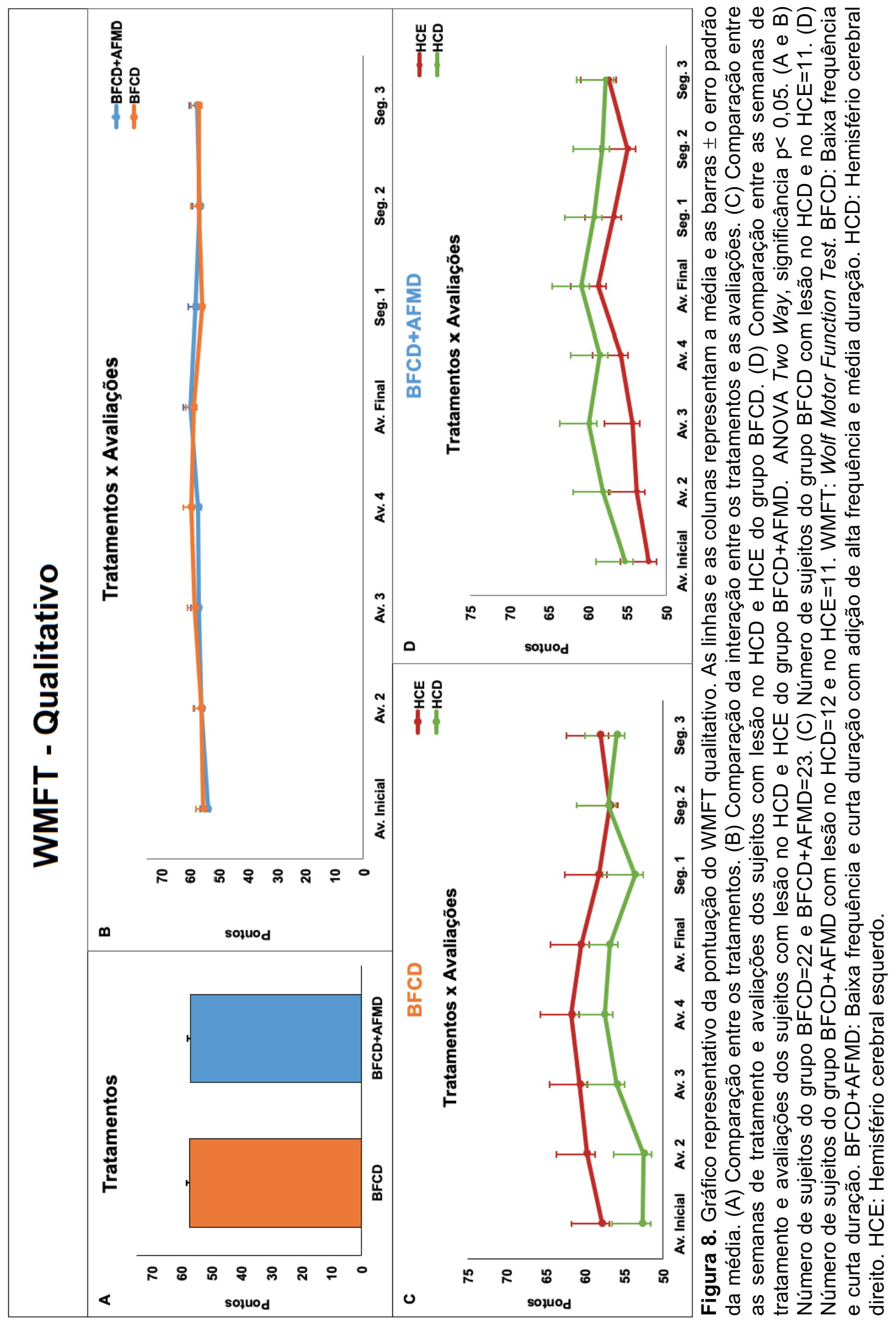




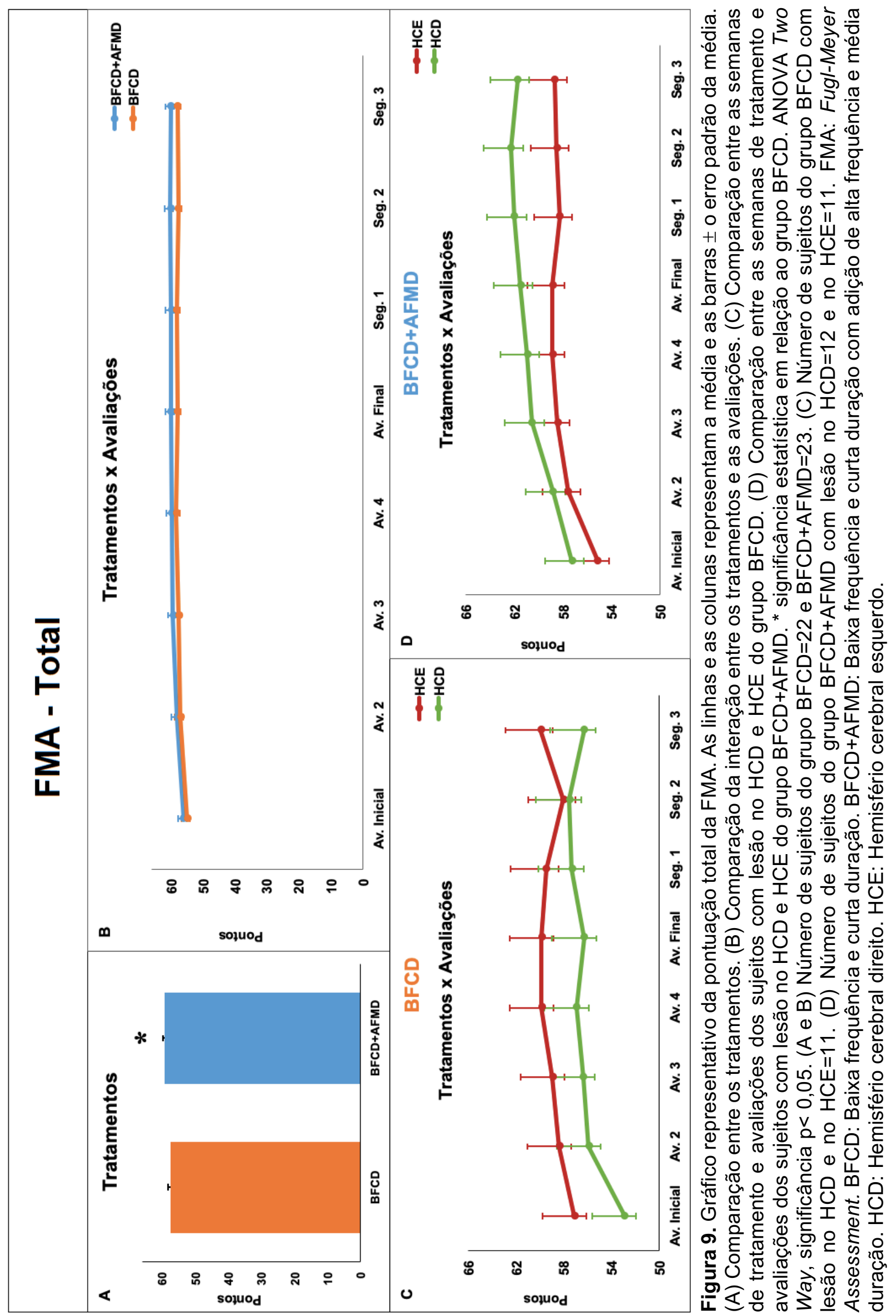




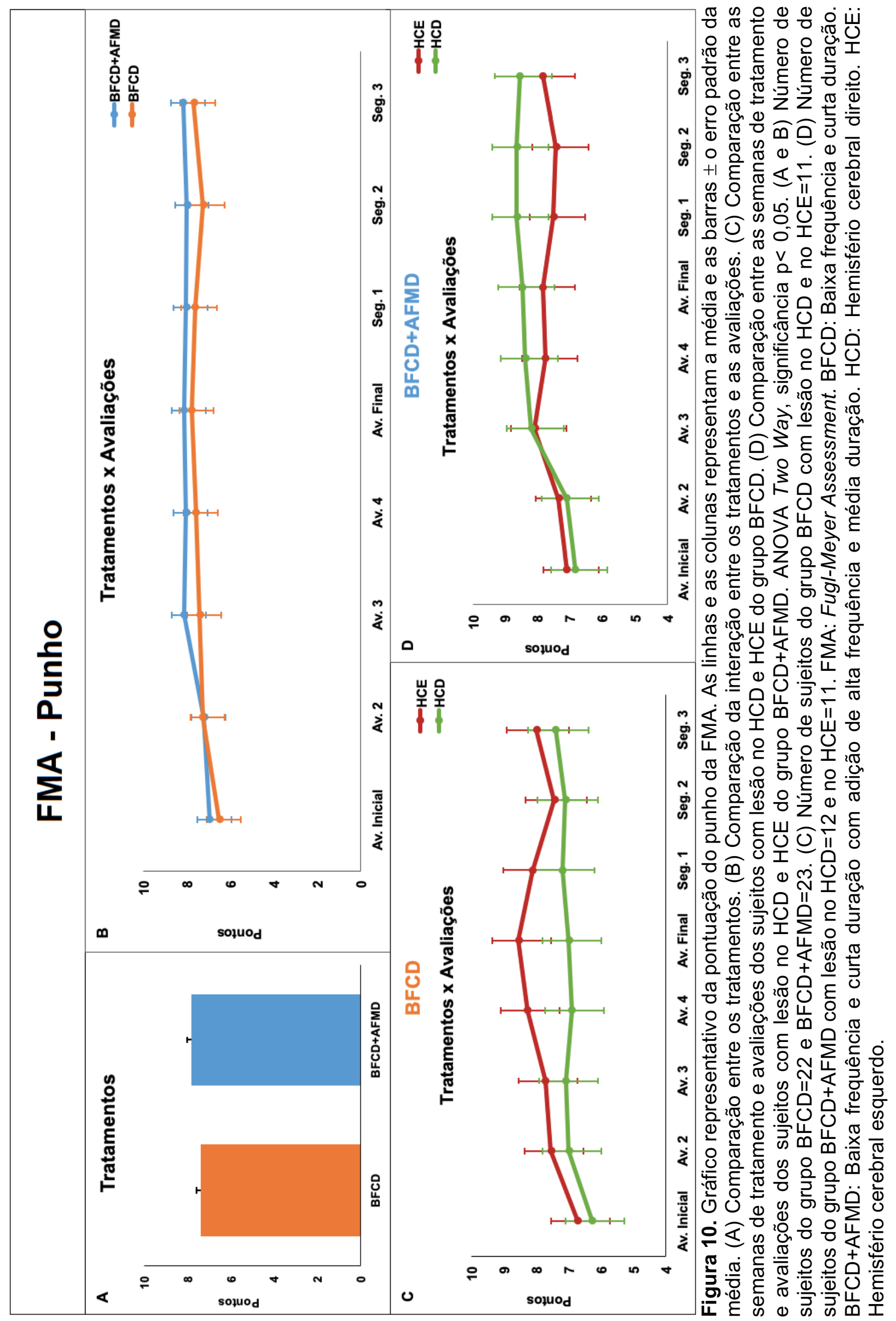




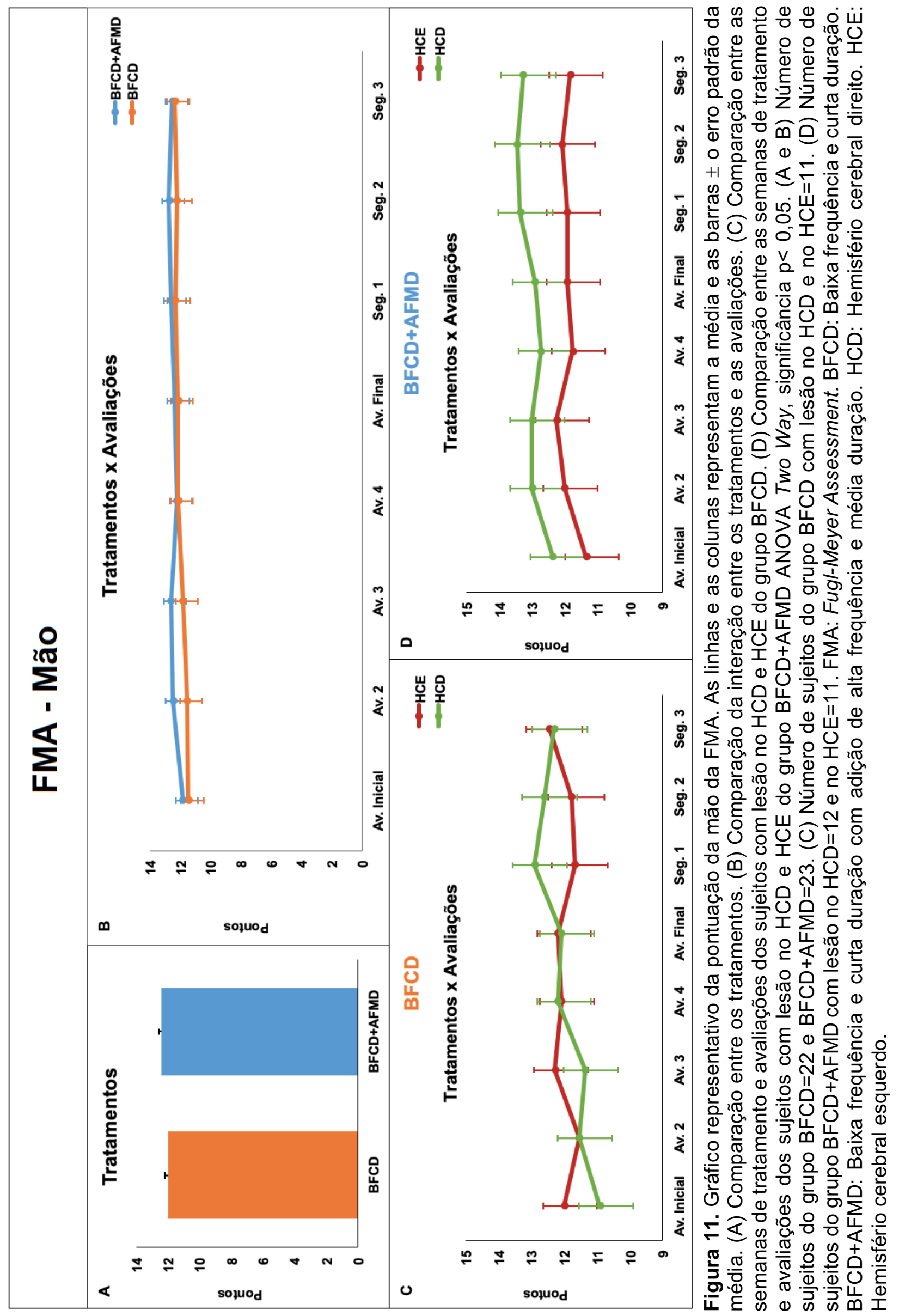




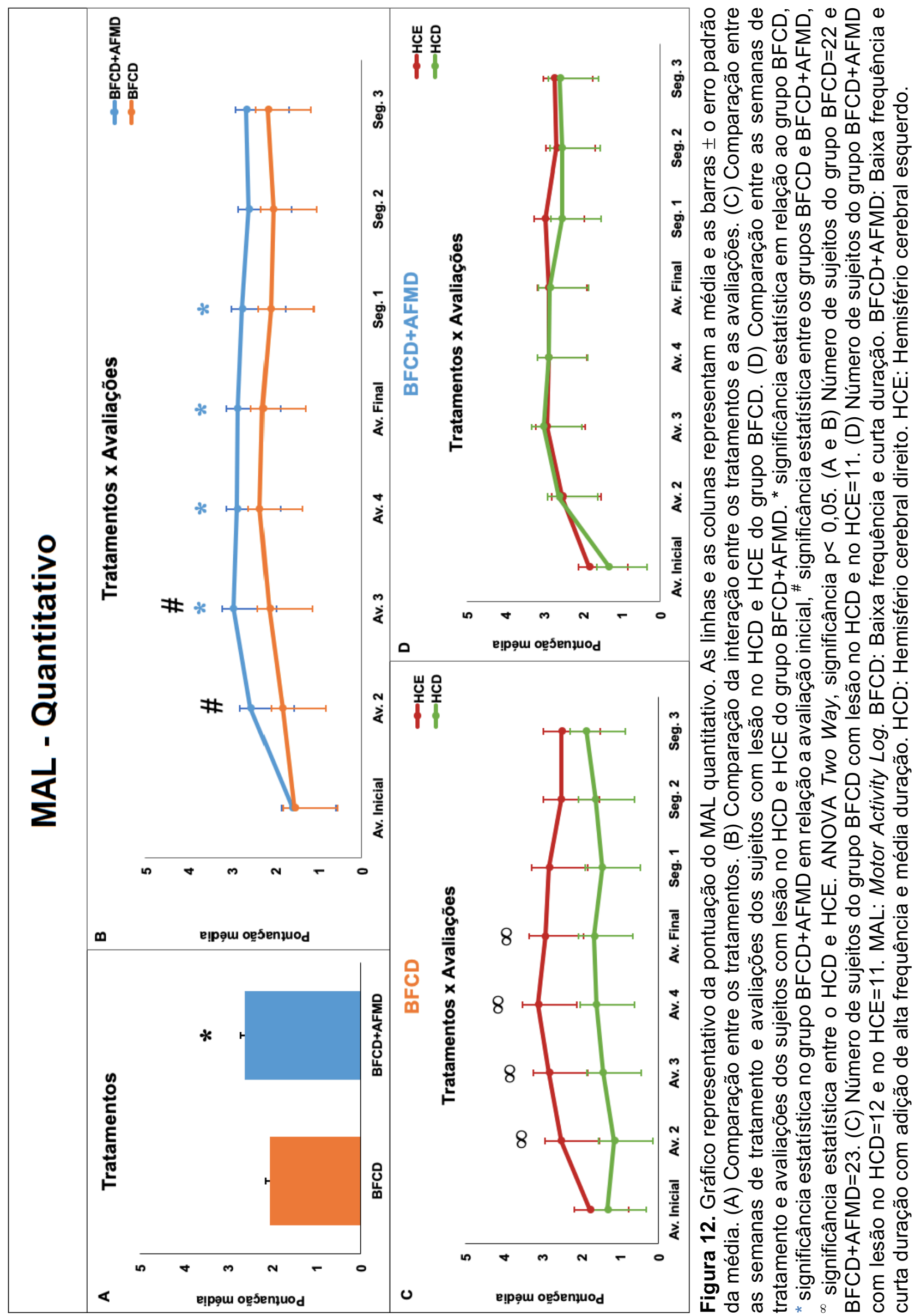




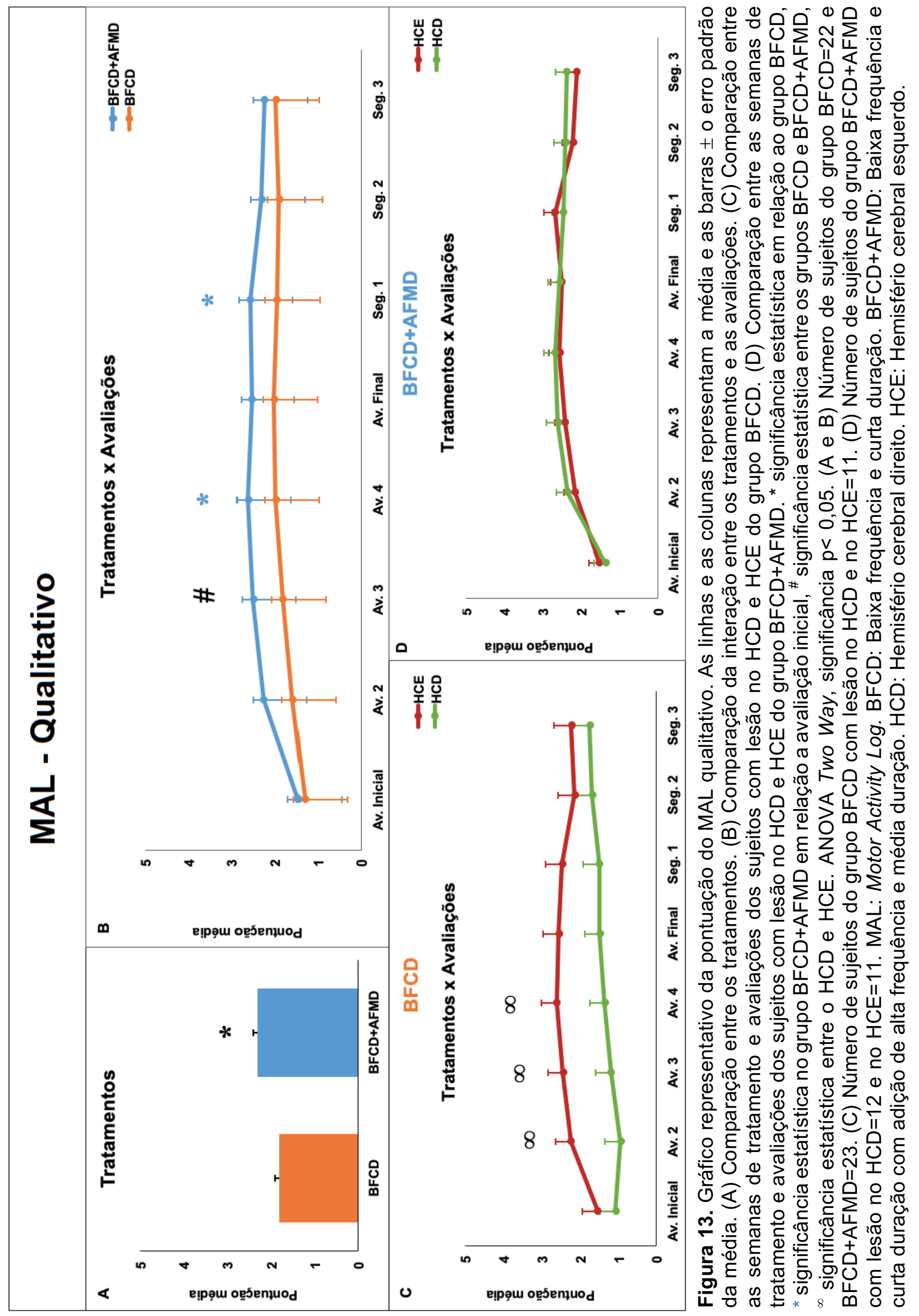




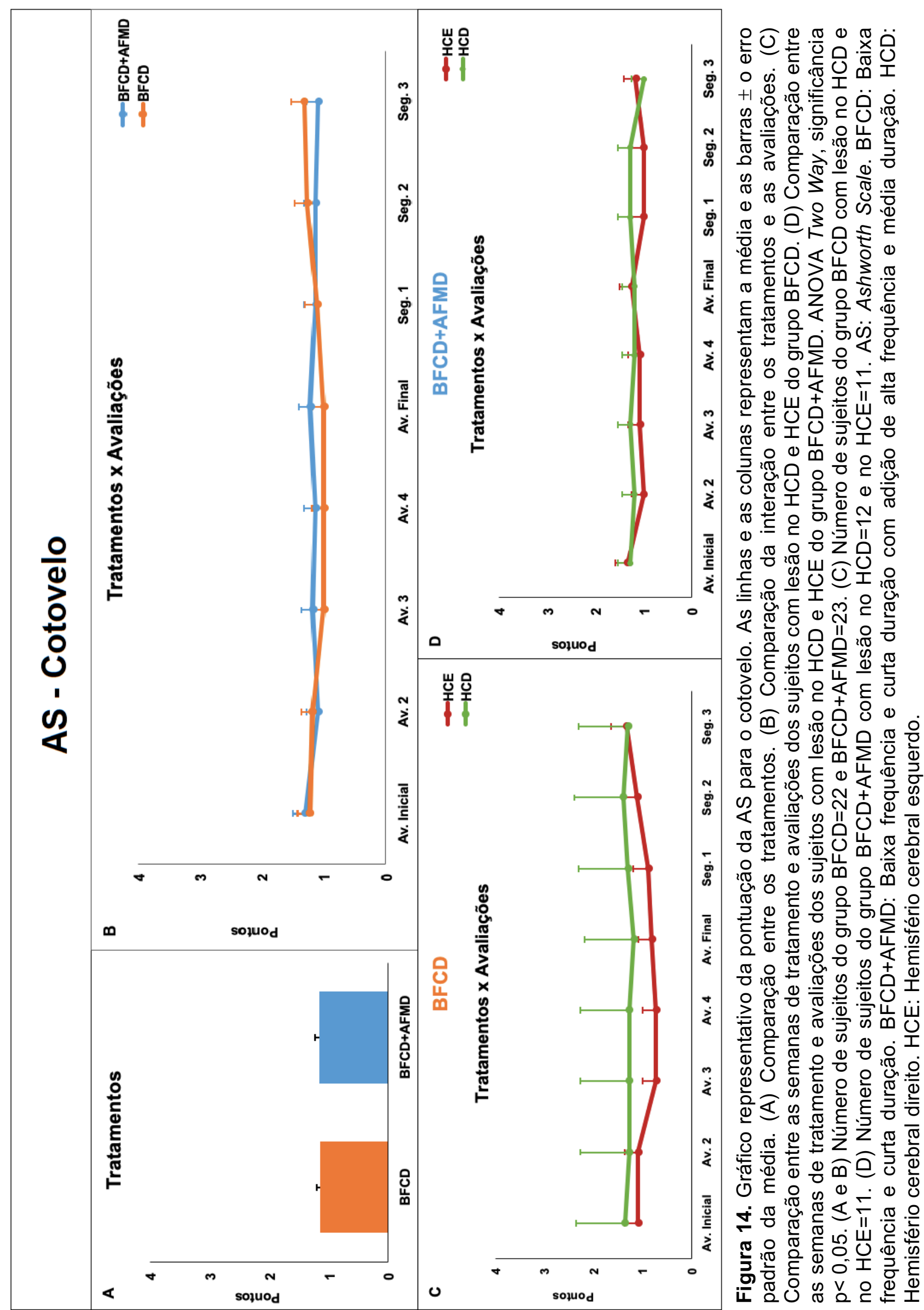




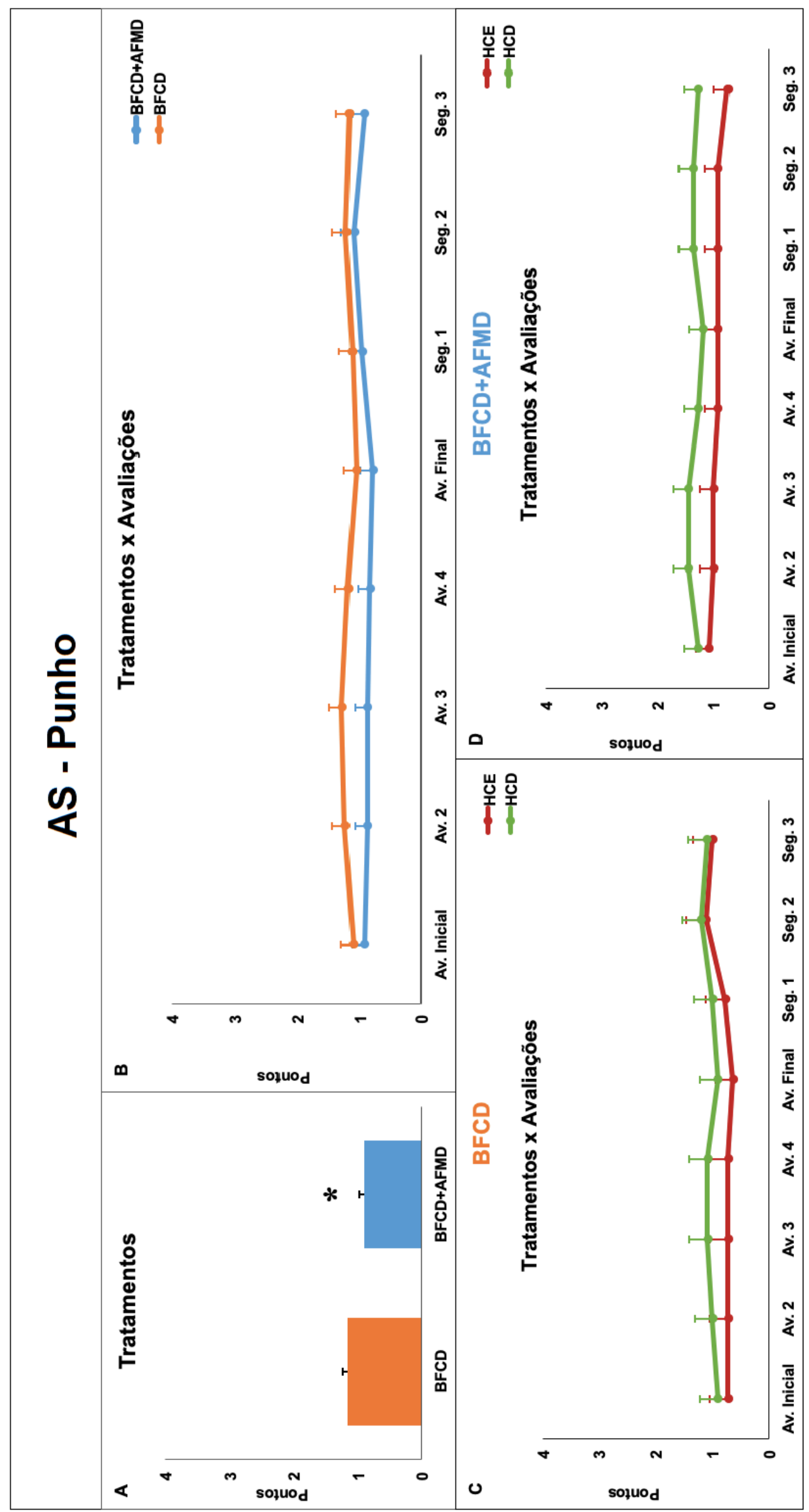

+1 한 ๑ क) . (1) त्र ๙ क ळ \& 0 언 \&

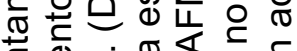
ป क $\frac{1}{0}$ U 힌 ब

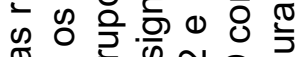
후 Nㅜㅇ

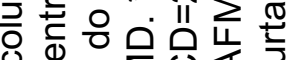
U $\sum 0<0$

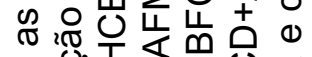

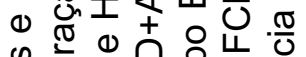
๙ ब

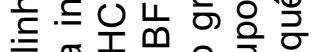

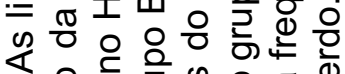

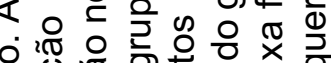

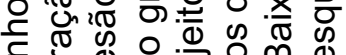
흐응 을 ช

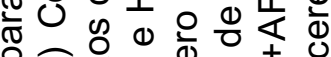

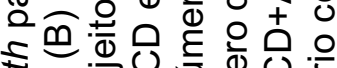

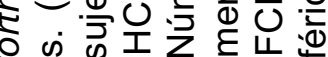
今。 क

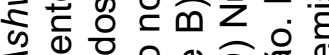
ए (1) क 过 $\frac{\pi}{\pi}=\frac{\pi}{\pi} \varepsilon$ 늄ำ

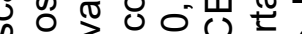

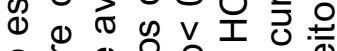

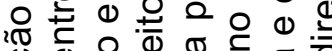
雨 $10 \%$ 责

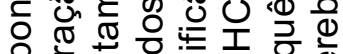

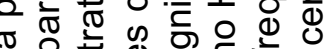

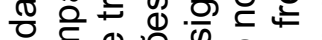
$\circ$ 엉 잉

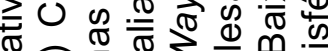
¿ $\frac{1}{\pi} \vec{\sigma} \varepsilon$ ब . Q ¿

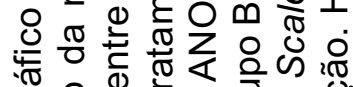
西 0 ब

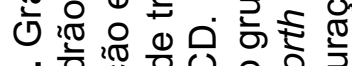
เก

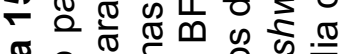
준 유은

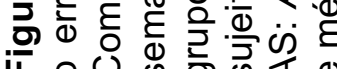




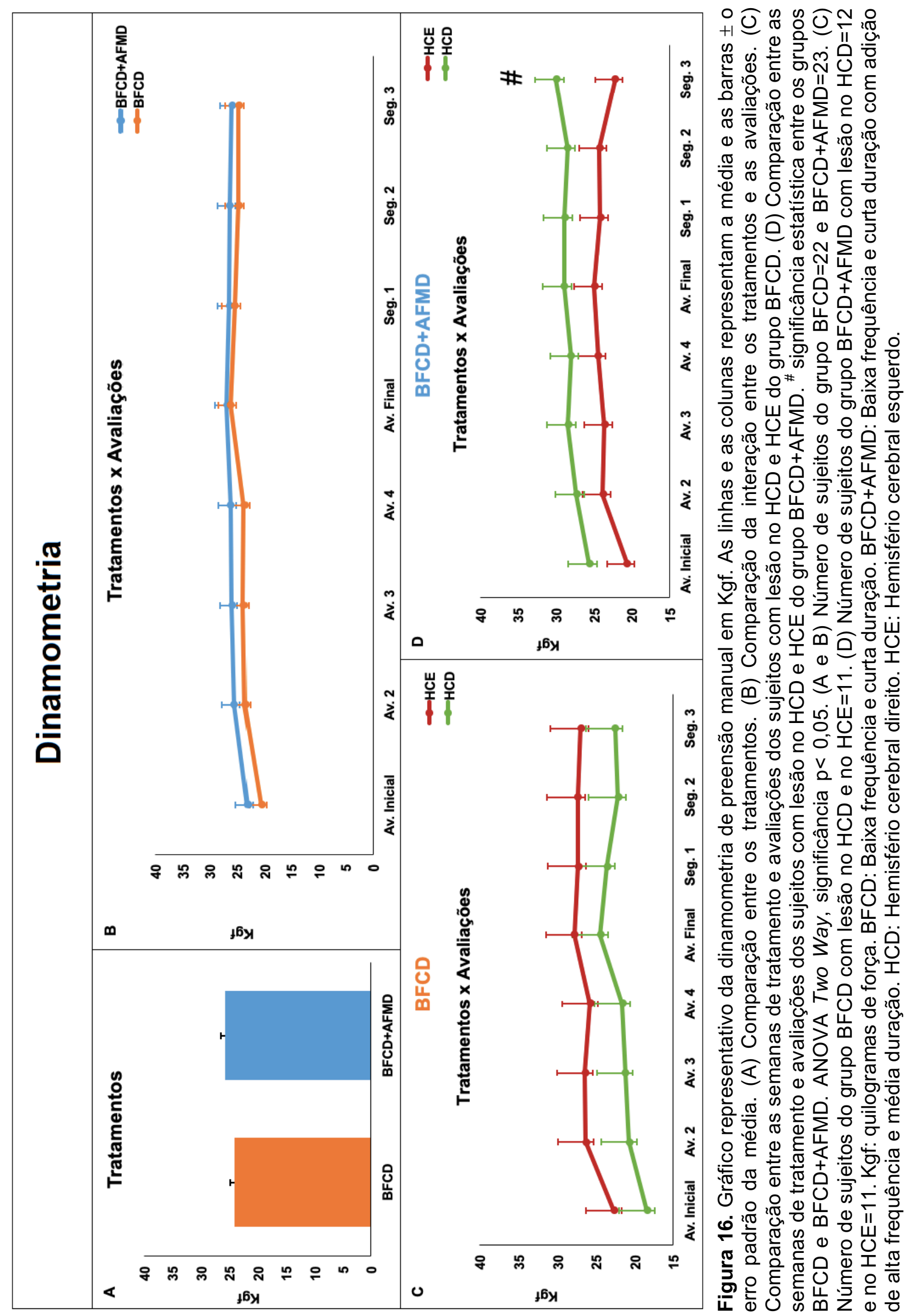




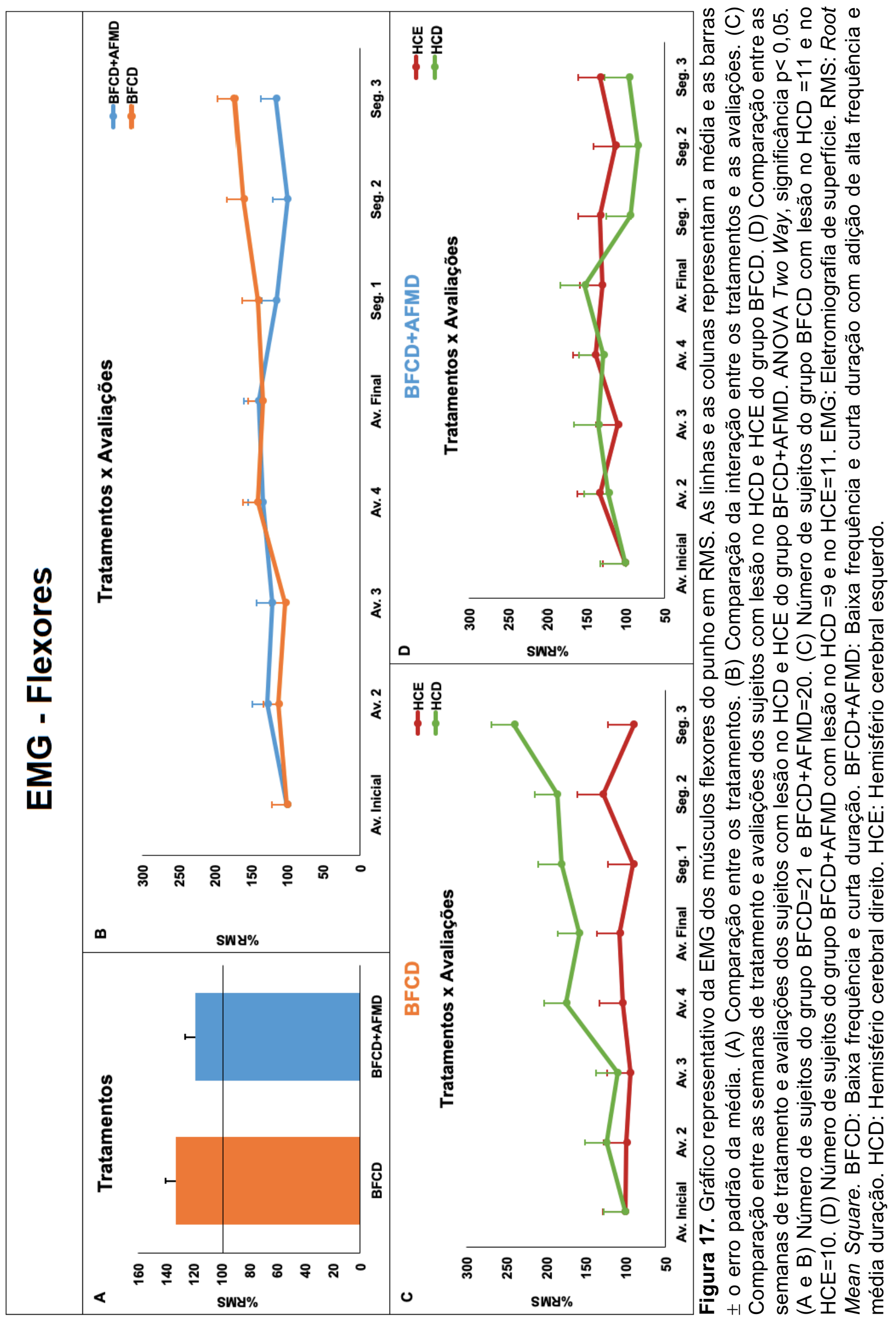




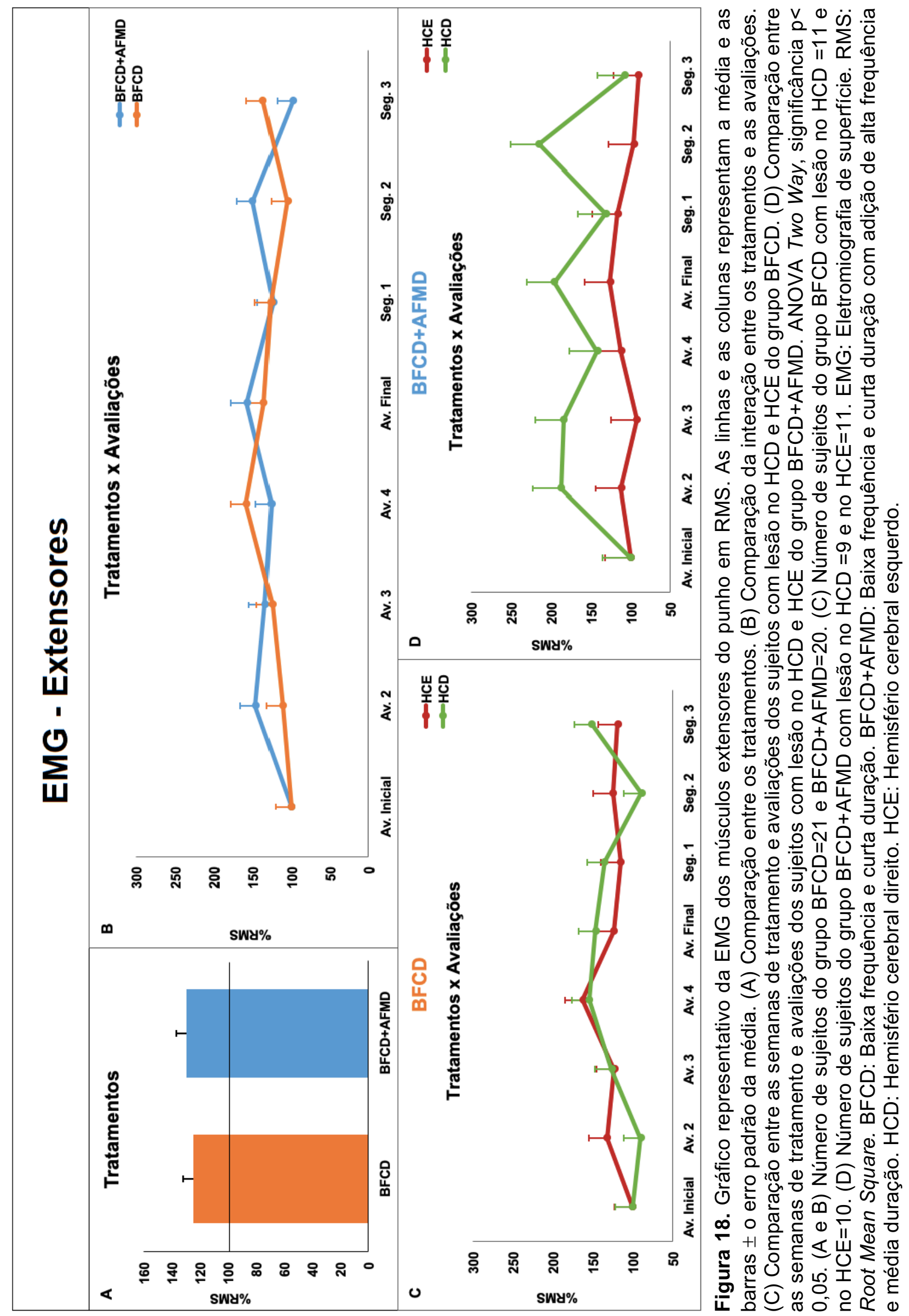




\section{DISCUSSÃO}

Com base nos nossos resultados obtidos com a NIHSS, SS-QOL, WMFT e MAL, os sujeitos submetidos ao protocolo de reabilitação com adição AFMD e livre exploração do MS parético apresentaram desempenho motor e funcional superior, melhor estado geral e melhor qualidade de vida quando comparados aos sujeitos submetidos ao protocolo específico com BFCD.

Após um AVE diferentes mecanismos plásticos no encéfalo se ativam de maneira natural (LANGHORNE; BERNHARDT; KWAKKEL, 2011) e também induzida por diferentes ferramentas de reabilitação (LIEPERT et al., 1998, 2000; MONFILS; PLAUTZ; KLEIM, 2005; SCHAECHTER et al., 2002). Uma das estratégias para a retomada/aquisição de habilidades motoras no MS parético é o aumento do padrão de recrutamento de músculos relacionados com o desempenho motor pretendido (CARSON; RIEK, 2001). Uma possível correlação com o maior recrutamento de músculos é o aumento de áreas corticais ativadas durante o processo de aprendizagem de um novo movimento. Nesse sentido, quando o movimento já foi aprendido, um número menor de áreas corticais são ativadas e os movimentos tornam-se automatizados (FURLAN et al., 2016; WILLINGHAM, 1998).

Em um estudo anterior do nosso laboratório, usando um protocolo de alta frequência e longa duração com livre exploração do MS parético, observamos um aumento da atividade elétrica nos músculos extensores do punho. Nesse estudo nós correlacionamos essa maior atividade elétrica muscular com a ativação de mecanismos relacionados ao aprendizado motor (SANTOS; FUZARO; DE ARAUJO, 2019) de acordo com as evidências que relatamos acima. No entanto, no estudo atual, nós não observamos modificações na atividade elétrica dos músculos extensores e flexores do punho analisados por EMG. Acreditamos que, a sobrecarga muscular presente no protocolo BFCD pode ter impedido o aumento da atividade elétrica muscular, observada no estudo anterior. Nossa hipótese pode ser corroborada pelo estudo de Pousson e cols. (1999), onde o treinamento de flexão do cotovelo reduziu a atividade elétrica do tríceps braquial ipsilateral (POUSSON; AMIRIDIS; COMETTI, 1999), em um padrão de inibição recíproca (DAY et al., 1984). Em nosso trabalho, não observamos redução, entretanto não utilizamos treinamento muscular ipsilateral aos 
músculos analisados. Assim, a inibição agonista e antagonista pode não ter acontecido de maneira intensa (POUSSON; AMIRIDIS; COMETTI, 1999) para reduzir a atividade elétrica, mas pode ter modulado a atividade no MS contralateral (GUERTIN, 2013).

Em nosso trabalho, os músculos flexores do antebraço e do punho também foram avaliados pela escala de Ashworth, já que estão diretamente relacionados com o padrão de espasticidade piramidal (HEFTER et al., 2012; LAUREYS et al., 2013; MARCINIAK, 2011). Nesse sentido, os nossos sujeitos apresentavam em média, grau 1 nessa escala, ou seja, aumento de resistência somente no final da ADM, um fator não limitante para a utilização do MS parético (PUNDIK et al., 2018; SORINOLA et al., 2009). Essa baixa limitação de utilização ganha força em nosso trabalho com os dados da FMA. Nossos sujeitos apresentavam uma pontuação bem próxima da máxima para essa escala, que tem como função detectar a recuperação da paresia pós-AVE (FUGL-MEYER et al., 1975; GLADSTONE; DANELLS; BLACK, 2002). Mesmo nessa situação de recuperação, os sujeitos do grupo com adição de AFMD com livre exploração do MS parético, apresentaram diminuição da espasticidade no punho. Esse padrão de baixa espasticidade encontrada em nossa amostra de pacientes crônicos, está alinhada com o trabalho de Sterr e Freivogel (2004) que relatam padrão semelhante (STERR; FREIVOGEL, 2004).

Os músculos flexores e extensores do antebraço também estão diretamente relacionados com a força de preensão manual (HÄGG; MILERAD, 1997; HOOZEMANS; VAN DIEËN, 2005), algo que em nosso trabalho foi analisado pela dinamometria de preensão manual. A diminuição dessa força, parece não explicar diretamente um mau desempenho na execução das AVDs em atividades uni manuais (HARRIS; ENG, 2007). De fato, quando comparamos os valores normativos de força de preensão manual, de sujeitos saudáveis com as mesmas características de idade e sexo, com a nossa amostra, a diminuição de força média estava em 7 quilogramas (MATHIOWETZ et al., 1985), mais ou menos $25 \%$ da força total. Sendo assim, nosso estudo também reforça essa evidência, já que, não observamos modificações na força de preensão manual dos sujeitos em ambos protocolos, mas obtivemos ganhos funcionais no grupo que teve a adição de AFMD.

Mesmo que os sujeitos da nossa amostra tenham o MS parético recuperado pela avaliação da FMA e pela baixa espasticidade, eles ainda não eram capazes de 
utilizar o braço parético em situações funcionais. Essa afirmação está fundamentada na baixa pontuação encontrada na avaliação inicial dos pacientes no MAL qualitativo. Em relação a qualidade do movimento, a média da pontuação máxima possível é de 5 pontos e nossos sujeitos, obtiveram em média 2 pontos. Apesar do MAL ser um teste de auto percepção do paciente em relação ao MS parético (SALIBA et al., 2010) ele pode retratar a motivação de utilização do MS parético (MACLEAN et al., 2002). Sendo assim, é comum para a investigação sobre os efeitos de técnicas de tratamento em pacientes pós AVE, a utilização do WMFT adicionalmente ao MAL, como fizemos em nosso estudo (WOLF et al., 2001).

O esperado é que os protocolos de reabilitação propostos para pacientes crônicos pós-AVE reestabeleçam o desempenho motor e funcional nesses pacientes (LANGHORNE; BERNHARDT; KWAKKEL, 2011; NAKAYAMA et al., 1994). Entretanto, em nosso estudo, os pacientes crônicos submetidos somente ao protocolo BFCD, não apresentaram a recuperação motora e funcional esperada e a recuperação foi inferior a obtida com a adição de AFMD. Essa afirmação fica evidente quando observamos os dados da velocidade de realização de tarefas funcionais avaliadas pelo WMFT quantitativo. A adição de AFMD claramente tornou o MS parético mais rápido na realização das tarefas.

O aumento da velocidade na realização de tarefas funcionais pode influenciar positivamente o desempenho motor (LUM et al., 2009). Aumentar a velocidade pode ainda, diminuir o reforçamento negativo, assim como, a redução do erro na realização das AVDs. Em nosso trabalho, tanto a qualidade do movimento auto percebido pelo MAL, como a velocidade avaliada pela WMFT aumentaram. Esses dois parâmetros, constituem um importante eixo do conceito do não uso aprendido (TAUB et al., 1994, 2006), onde a punição pela lentidão ou o erro na execução motora leva a punição ou frustação.

Um ponto que precisa ser discutido é a melhor qualidade do movimento auto percebido pelo MAL e a qualidade efetivamente avaliada pelo WMFT. A ferramenta que utilizamos para aumentar a frequência e duração do tratamento do grupo BFCD+AFMD, foi a contensão do MS não parético. Sendo assim, obrigatoriamente, durante o período de 12 horas de contensão, os sujeitos tinham que utilizar o MS parético. Sendo assim, também podemos propor a influência do mecanismo relacionado a plasticidade uso-dependente. A adição de AFMD, aumentou a utilização 
do MS parético e assim, a repetição dos movimentos realizados por esse membro, e possivelmente como relatado por Liepert e cols. (2001), uma excitabilidade cortical aumentada favorecendo mecanismos de aprendizagem (LIEPERT et al., 2001). Entretanto, a qualidade do movimento não foi detectada pela WMFT e assim, acreditamos que a melhora referida pelos sujeitos é uma questão perceptual e não necessariamente motora (SALIBA et al., 2010). A melhor percepção do MS parético, pode ativar outros mecanismos, como por exemplo o motivacional (BALAAM et al., 2011), que por sua vez, mais uma vez nos leva aos mecanismos relacionados ao desuso aprendido.

Considerar a alteração da percepção dos nossos sujeitos em relação ao MS parético e assim justificar os resultados que obtivemos, ganha força quando observamos a qualidade de vida aferida pela SS-QOL. Silva e cols. (2015) relataram que quanto maior o tempo após o AVE, melhor deve ser a qualidade de vida percebida (SILVA et al., 2015), uma vez que, os mecanismos plásticos irão modificar o desempenho do SNC para otimizar as funções acometidas (LANGHORNE; BERNHARDT; KWAKKEL, 2011; LIEPERT et al., 1998; SCHAECHTER et al., 2002). Como os sujeitos da nossa amostra apresentavam em média 30 meses pós-AVE, o protocolo com adição de AFMD pode, além de mecanismos motores, ter ativado mecanismos motivacionais, pela observação que o MS parético pode ser funcional, e assim ter modificado a pontuação da SS-QOL.

Uma das medidas que utilizamos em nosso trabalho, pode ajudar a reforçar o conceito de que além de mecanismos motivacionais também ativamos mecanismos motores pelo protocolo AFMD. Até o presente momento, o WMFT quantitativo, da suporte a um melhor desempenho motor dos nossos sujeitos através da modificação de mecanismos motores. O MAL qualitativo e quantitativo, somado a SS-QOL a modificação de mecanismos perceptuais.

A pontuação da NIHSS geralmente, não esta associada ao estado de saúde do paciente crônico pós-AVE (PETERS et al., 2015). Embora a NIHSS seja um instrumento amplamente utilizado em estudos com pacientes pós-AVE, ela apresenta capacidade limitada para detectar diferenças entre determinados tratamentos (HAND; PAGE; WHITE, 2014). Por outro lado, em nossa amostra com pacientes crônicos, nós encontramos uma redução da pontuação nos sujeitos submetidos a protocolo com adição de AFMD. Nessa escala, o item que pode ser alterado em pacientes crônicos, 
como em nossa amostra, é a motricidade dos membros. Sendo assim, acreditamos que o resultado que obtivemos com essa escala surgiu de um melhor controle motor do MS parético.

Para tentar entender melhor os mecanismos envolvidos com a adição de AFMD, é preciso considerar que os hemisférios cerebrais D e E se especializaram e que existe um grau de lateralização funcional no controle motor dos MMSS. O que já está bem claro na literatura é que, sujeitos com lesão no HCE desenvolvem comprometimentos na coordenação dos movimentos do cotovelo e do ombro (BAGESTEIRO, 2002) e, sujeitos com lesão no HCD perdem a capacidade de atingir posições finais com precisão (BAGESTEIRO, 2003).

Em nosso estudo, todos os sujeitos apresentavam preferência motora prévia ao AVE à D, ou seja, eram destros. Estudos com sujeitos, cuja paresia se relaciona a preferência motora, mostraram que a recuperação é mais adequada quando comparada com a paresia relacionada a preferência motora prévia ao AVE (SARIKAYA et al., 2017). Essa informação, mostra a importância da adição de AFMD em nosso estudo, porque independente do lado da paresia, nossos sujeitos apresentaram recuperação motora semelhante. Por outro lado, o protocolo BFCD sem adição de AFMD somente mostra resultados para os sujeitos com lesão no HCE, ou seja, paréticos a $D$, com o mesmo lado de preferência motora prévia ao AVE. Esses resultados são perceptivos, utilizando o MAL na qualidade do movimento e quantidade de utilização do MS, quando comparados aos sujeitos com lesão no HCD.

Enfatizando ainda mais a importância da lateralização (PROVINS; MAGLIARO, 1993; RINEHART et al., 2009; SARIKAYA et al., 2017), em nosso trabalho, a adição de AFMD, aumentou a força e a resistência isométrica contra a gravidade na NIHSS. Sujeitos destros, apresentam maior força do lado D quando comparados com seu lado E (MATHIOWETZ et al., 1985). Em nosso trabalho a AFMD conseguiu aumentar a utilização de ambos os MMSS paréticos, já que nossos resultados não dependem da lateralidade. Entretanto, ao submeter sujeitos com paresia no MSE a uma maior utilização desse segmento, aumentamos a força dos sujeitos paréticos à $E$ em relação aos sujeitos com paresia no MSD. Esses efeitos de geração de força após 4 semanas de treinamento são conhecidos em sujeitos saudáveis (GOTO et al., 2004). Na mesma linha, com um melhor desempenho isométrico no MS parético à $E$ induzido pelo treinamento, justificamos os resultados obtidos na NIHSS. 
Dessa maneira, com um trabalho randomizado, com 4 semanas de intervenção e 3 meses de seguimento, utilizando escalas e avaliação instrumental, mostramos a importância da adição de alta frequência, média duração e livre exploração na reabilitação do paciente hemiparético crônico pós-AVE. 


\section{CONCLUSÕES}

A adição de alta frequência, média duração e livre exploração do MS parético em um protocolo de baixa frequência, curta duração e alta especificidade torna a reabilitação do MS parético mais eficaz.

A adição de alta frequência, média duração e livre exploração do MS parético melhora o desempenho nas escalas WMFT e no MAL.

A ativação elétrica e a força de preensão manual não se modificam independentemente de se adicionar ou não alta frequência, média duração e livre exploração do MS parético.

A adição de alta frequência, média duração e livre exploração do MS parético melhora a qualidade de vida e o impacto do AVE usando a SS-QOL e a NIHSS.

A lateralização é responsável por modificações distintas na motricidade detectadas pelo MAL, dinamometria e NIHSS. 


\section{REFERÊNCIAS BIBLIOGRÁFICAS}

AARNIO, K. et al. Return to work after ischemic stroke in young adults: A registrybased follow-up study. Neurology, v. 91, n. 20, p. e1909-e1917, 2018.

AKOSILE, C. et al. Effects of Proprioceptive Neuromuscular Facilitation Technique on the Functional Ambulation of Stroke Survivors. Journal of the Nigeria Society of Physiotherapy, v. 18 \& 19, p. 7-12, 2011.

ALAWIEH, A.; ZHAO, J.; FENG, W. Factors affecting post-stroke motor recovery: Implications on neurotherapy after brain injury. Behavioural Brain Research, v. 340, p. 94-101, 2018.

ALLRED, R. P.; JONES, T. A. Maladaptive effects of learning with the less-affected forelimb after focal cortical infarcts in rats. Experimental Neurology, v. 210, n. 1, p. 172-181, 2008.

AMMANN, B. C. et al. Application of principles of exercise training in sub-acute and chronic stroke survivors: A systematic review. BMC Neurology, v. 14, n. 1, p. 1-11, 2014.

ANDERSON, M.; LOUGH, S. A psychological framework for neurorehabilitation. Physiotherapy Theory and Practice, v. 2, n. 2, p. 74-82, 1986.

BAGESTEIRO, L. B. Handedness: Dominant Arm Advantages in Control of Limb Dynamics. Journal of Neurophysiology, v. 88, n. 5, p. 2408-2421, 2002.

BAGESTEIRO, L. B. Nondominant Arm Advantages in Load Compensation During Rapid Elbow Joint Movements. Journal of Neurophysiology, v. 90, n. 3, p. 15031513, 2003.

BALAAM, M. et al. Motivating Mobility: Designing for Lived Motivation in Stroke Rehabilitation. Proceedings of the SIGCHI Conference on Human Factors in Computing Systems, p. 3073-3082, 2011.

BAYONA, N. A. et al. The Role of Task-Specific Training in Rehabilitation Therapies. Topics in Stroke Rehabilitation, v. 12, n. 3, p. 58-65, 2005.

BERNHARDT, J. et al. Prespecified dose-response analysis for A Very Early Rehabilitation Trial (AVERT). Neurology, v. 86, n. 23, p. 2138-2145, 2016.

BILLINGER, S. A. Does Aerobic Exercise and the FITT Principle Fit into Stroke Recovery. Current Neurology and Neuroscience Reports, v. 15, n. 2, p. 1-14, 2016.

BOHANNON, R.; SMITH, M. Interrater Reliability of a Modified Ashworth Scale of Muscle Spasticity. Physical Therapy, v. 67, n. 2, p. 1986-1987, 1987. 
BONITA, R. et al. The global stroke initiative. Lancet Neurology, v. 3, n. 7, p. 391393, 2004.

BORGES, L. R. et al. Action observation for upper limb rehabilitation after stroke. The Cochrane Database of Systematic Reviews, v. 10, n. 10, 2018.

$\mathrm{BOSCH}$, J. et al. Does Task-Oriented Practice Improve Upper Extremity Motor Recovery after Stroke? A Systematic Review, Does Task-Oriented Practice Improve Upper Extremity Motor Recovery after Stroke? A Systematic Review. ISRN Stroke, v. 2014, 2014.

BOYNE, P. et al. Aerobic Exercise Prescription in Stroke Rehabilitation: A Web-Based Survey of United States Physical Therapists. Journal of Neurologic Physical Therapy, v. 41, n. 2, p. 119-128, 2017.

BROCK, K. et al. Does physiotherapy based on the Bobath concept, in conjunction with a task practice, achieve greater improvement in walking ability in people with stroke compared to physiotherapy focused on structured task practice alone? A pilot randomized controlled tr. Clinical Rehabilitation, v. 25, n. 10, p. 903-912, 2011.

BROTT, T. et al. Measurements of acute cerebral infarction: A clinical examination scale. Stroke, v. 20, n. 7, p. 864-870, 1989.

BÜTEFISCH, C. et al. Repetitive training of isolated movements improves the outcome of motor rehabilitation of the centrally paretic hand. Journal of the Neurological Sciences, v. 130, n. 1, p. 59-68, 1995.

BÜTEFISCH, C. M. et al. Mechanisms of use-dependent plasticity in the human motor cortex. Proocedings of the National Academy of Sciences, v. 18, n. 7, p. 36613665, 1998.

CAPRIOTTI, T.; MURPHY, T. Ischemic Stroke. Home Healthcare Now, v. 34, n. 5, p. 259-266, 2016.

CAREY, J. R. et al. Analysis of fMRI and finger tracking training in subjects with chronic stroke. Brain, v. 125, n. 4, p. 773-788, 2002.

CARROLL, T. J. et al. Contralateral effects of unilateral strength training: evidence and possible mechanisms. Journal of Applied Physiology, v. 101, n. 5, p. 1514-1522, 2006.

CARSON, R. G.; RIEK, S. Changes in muscle recruitment patterns during skill acquisition. Experimental Brain Research, v. 138, n. 1, p. 71-87, 2001.

CAURAUGH, J. H.; KIM, S. B.; SUMMERS, J. J. Chronic stroke longitudinal motor improvements: Cumulative learning evidence found in the upper extremity. Cerebrovascular Diseases, v. 25, n. 1-2, p. 115-121, 2008. 
CHAN, B. Effect of Increased Intensity of Physiotherapy on Patient Outcomes After Stroke: An Economic Literature Review and Cost-Effectiveness Analysis. Ontario Health Technology Assessment Series, v. 15, n. 7, p. 1-43, 2015.

CHENG, Y. Y. et al. The Impact of Rehabilitation Frequencies in the First Year after Stroke on the Risk of Recurrent Stroke and Mortality. Journal of Stroke and Cerebrovascular Diseases, v. 26, n. 12, p. 2755-2762, 2017.

CINCURA, C. et al. Validation of the National Institutes of Health Stroke Scale, modified Rankin Scale and Barthel Index in Brazil: The role of cultural adaptation and structured interviewing. Cerebrovascular Diseases, v. 27, n. 2, p. 119-122, 2009.

CLASSEN, J. et al. Rapid Plasticity of Human Cortical Movement Representation Induced by Practice. Journal of Neurophysiology, v. 79, n. 2, p. 1117-1123, 1998.

COHEN, L. G. et al. Plasticity of cortical motor output organization following deafferentation, cerebral lesions, and skill acquisition. Advances in Neurology, v. 63, p. 187-200, 1993.

CORBETTA, D.; IMERI, F.; GATTI, R. Rehabilitation that incorporates virtual reality is more effective than standard rehabilitation for improving walking speed, balance and mobility after stroke: A systematic review. Journal of Physiotherapy, v. 61, n. 3, p. 117-124, 2015.

COUPLAND, A. P. et al. The definition of stroke. Journal of the Royal Society of Medicine, v. 110, n. 1, p. 9-12, 2017.

DAY, B. L. et al. Reciprocal inhibition between the muscles of the human forearm. The Journal of Physiology, v. 349, n. 1, p. 519-534, 1984.

DE ARAUJO, F. L. B. et al. Influence of treadmill training on motor performance and organization of exploratory behavior in Meriones unguiculatus with unilateral ischemic stroke: Histological correlates in hippocampal CA1 region and the neostriatum. Neuroscience Letters, v. 431, n. 2, p. 179-183, 2008.

DEJONG, G. et al. Opening the black box of poststroke rehabilitation: Stroke rehabilitation patients, processes, and outcomes. Archives of Physical Medicine and Rehabilitation, v. 86, n. 12, p. 1-7, 2005.

DICKSTEIN, R. et al. Stroke rehabilitation. Three exercise therapy approaches. Physical Therapy, v. 66, n. 8, p. 1233-1238, 1986.

DIMYAN, M. A.; COHEN, L. G. Neuroplasticity in the context of motor rehabilitation after stroke. Nature Reviews Neurology, v. 7, n. 2, p. 76-85, 2011.

Diretrizes de atenção à reabilitação da pessoa com Acidente Vascular Cerebral. Brasília: 2013. 
DISOTTO-MONASTERO, M. et al. Efficacy of 7 days per week inpatient admissions and rehabilitation therapy. Archives of Physical Medicine and Rehabilitation, v. 93, n. 12, p. 2165-2169, 2012.

DOBKIN, B. H. Rehabilitation after Stroke. New England Journal of Medicine, v. 352, n. 16, p. 1677-1684, 2005.

DUNCAN, P. W. et al. Management of Adult Stroke Rehabilitation Care: A Clinical Practice Guideline. Stroke, v. 36, n. 9, p. 100-143, 2005.

EASTON, J. D. et al. Definition and evaluation of transient ischemic attack: a scientific statement for healthcare professionals from the American Heart Association/American Stroke Association Stroke Council; Council on Cardiovascular Surgery and Anesthesia; Council on Cardio. Stroke, v. 40, n. 6, p. 2276-2293, 2009.

EHRENSBERGER, M. et al. Cross-education of strength has a positive impact on poststroke rehabilitation: a systematic literature review. Topics in Stroke Rehabilitation, v. 23, n. 2, p. 126-135, 2016.

ENGLISH, C. et al. Circuit class therapy or seven-day week therapy for increasing rehabilitation intensity of therapy after stroke (CIRCIT): A randomized controlled trial. International Journal of Stroke, v. 10, n. 4, p. 594-602, 2015.

FARTHING, J. P. Cross-education of strength depends on limb dominance: Implications for theory and application. Exercise and Sport Sciences Reviews, v. 37, n. 4, p. 179-187, 2009.

FRENCH, B. et al. Repetitive task training for improving functional ability after stroke. Cochrane Database of Systematic Reviews, v. 4, n. 4, 2007.

FRENCH, B. et al. A systematic review of repetitive task training with modelling of resource use, costs and effectiveness. Health Technology Assessment, v. 12, n. 30, p. 1-117, 2008.

FUGL-MEYER, A. R. et al. The post-stroke hemiplegic patient. 1. a method for evaluation of physical performance. Scandinavian Journal of Rehabilitation Medicine, v. 7, n. 1, p. 13-31, 1975.

FURLAN, L. et al. Upper Limb Immobilisation: A Neural Plasticity Model with Relevance to Poststroke Motor Rehabilitation. Neural plasticity, v. 2016, 2016.

GALVIN, R. et al. The Impact of Increased Duration of Exercise Therapy on Functional Recovery Following Stroke - What Is the Evidence? Topics in Stroke Rehabilitation, v. 15, n. 4, p. 365-377, 2008.

GERROW, K.; BROWN, C. E. Structural Neural Plasticity During Stroke Recovery. In: The Rewiring Brain, p. 49-70, 2017. 
GLADSTONE, D. J.; DANELLS, C. J.; BLACK, S. E. The Fugl-Meyer assessment of motor recovery after stroke: a critical review of its measurement properties. Neurorehabilitation and Neural Repair, v. 16, n. 3, p. 232-240, 2002.

GOLDSTEIN, L. B. et al. Guidelines for the primary prevention of stroke: A Guideline for Healthcare Professionals from the American Heart Association/American Stroke Association. Stroke, v. 42, n. 2, p. 517-584, 2011.

GOTO, K. A. G. et al. Muscular adaptationsto combinations of high and low-intensity resistance exercises. Journal of Strength and Conditioning Research, v. 18, n. 4, p. 730-737, 2004.

GRAHAM, J. V. et al. The Bobath Concept in Contemporary Clinical Practice. Topics in Stroke Rehabilitation, v. 16, n. 1, p. 57-68, 2009.

GUERTIN, P. A. Central pattern generator for locomotion : anatomical, physiological, and pathophysiological considerations. Frontiers in Neurology, v. 3, p. 183, 2013.

HÄGG, G. M.; MILERAD, E. Forearm extensor and flexor muscle exertion during simulated gripping work - An electromyographic study. Clinical Biomechanics, v. 12, n. 1, p. 39-43, 1997.

HAN, C. et al. Effects of intensity of arm training on hemiplegic upper extremity motor recovery in stroke patients: A randomized controlled trial. Clinical Rehabilitation, v. 27, n. 1, p. 75-81, 2013.

HAND, B.; PAGE, S. J.; WHITE, S. Stroke Survivors Scoring Zero on the NIH Stroke Scale Score Still Exhibit Significant Motor Impairment and Functional Limitation. Stroke Research and Treatment, v. 2014, 2014.

HANKEY, G. J. Stroke. The Lancet, v. 389, n. 10069, p. 641-654, fev. 2017.

HARRIS, J. E.; ENG, J. J. Paretic Upper-Limb Strength Best Explains Arm Activity in People With Stroke. Physical Therapy, v. 87, n. 1, p. 88-97, 2007.

HEFTER, $\mathrm{H}$. et al. Classification of posture in poststroke upper limb spasticity: a potential decision tool for botulinum toxin A treatment? International Journal of Rehabilitation Research, v. 35, n. 3, p. 227-233, 2012.

HENDY, A. M.; SPITTLE, M.; KIDGELL, D. J. Cross education and immobilisation: Mechanisms and implications for injury rehabilitation. Journal of Science and Medicine in Sport, v. 15, n. 2, p. 94-101, 2012.

HOOZEMANS, M. J. M.; VAN DIEËN, J. H. Prediction of handgrip forces using surface EMG of forearm muscles. Journal of Electromyography and Kinesiology, v. 15, n. 4, p. 358-366, 2005.

HORTOBÁGYI, T. et al. Cross-Education of Muscle Strength Is Greater with Stimulated than Voluntary Contractions. Motor Control, v. 3, n. 2, p. 205-219, 1999. HUBBARD, I. J. et al. Task-specific training: evidence for and translation to clinical practice. Occupational Therapy International, v. 16, n. 3-4, p. 175-189, 2009. 
INTERCOLLEGIATE STROKE WORKING PARTY. National clinical guideline for stroke. National clinical guideline for stroke, 2016.

JOHNSTON, M. V. Clinical disorders of brain plasticity. Brain and Development, v. 26, n. 2, p. 73-80, 2004.

JOHNSTON, M. V; MILLER, L. S. Cost-effectiveness of the Medicare three-hour regulation. Archives of Physical Medicine and Rehabilitation, v. 67, n. 9, p. 5815,1986 .

JONES, T. A. et al. Motor System Plasticity in Stroke Models: Intrinsically Usedependent, Unreliably Useful. Stroke, v. 44, n. 6, p. S104-S106, 2013.

KABAT, $\mathrm{H}$. Studies on neuromuscular dysfunction. XV. The role of central facilitation in restoration of motor function in paralysis. Archives of physical medicine, v. 33, $n$. 9, p. 521-33,1952.

KARGES, J.; SMALLFIED, S. A description of the outcomes, frequency, duration, and intensity of occupational, physical, and speech therapy in inpatient stroke rehabilitation. Journal of Alied Health, v. 38, n. 1, p. E1-10, 2009.

KAWAHIRA, K. et al. Addition of intensive repetition of facilitation exercise to multidisciplinary rehabilitation promotes motor functional recovery of the hemiplegic lower limb. Journal of Rehabilitation Medicine, v. 36, n. 4, p. 159-164, 2004.

KERR, A. L. et al. Post-stroke protection from maladaptive effects of learning with the non-paretic forelimb by bimanual home cage experience in C57BL / 6 mice. Behavioural Brain Research, v. 252, p. 180-187, 2013.

KINOSHITA, S. et al. Association Between 7 Days Per Week Rehabilitation and Functional Recovery of Patients With Acute Stroke: A Retrospective Cohort Study Based on the Japan Rehabilitation Database. Archives of Physical Medicine and Rehabilitation, v. 98, n. 4, p. 701-706, 2017.

KITABATAKE, T. T. et al. Behavioral effects and neural changes induced by continuous and not continuous treadmill training, post bilateral cerebral ischemia in gerbils. Behavioural Brain Research, v. 291, p. 20-25, 2015.

KLEIM, J. A.; JONES, T. A. Principles of Experience-Dependent Neural Plasticity: Implications for Rehabilitation After Brain Damage. Journal of Speech Language and Hearing Research, v. 51, n. 1, p. S225, 2008.

KOLLEN, B. J. et al. The effectiveness of the bobath concept in stroke rehabilitation what is the evidence? Stroke, v. 40, n. 4, 2009.

KONRAD, $P$. The ABC of EMG. A Practical Introduction to Kinesiological Electromyography, v. 1, p. 30-35, 2005. 
KRAKAUER, J. W. Motor learning: its relevance to stroke recovery and neurorehabilitation. Current opinion in neurology, v. 19, n. 1, p. 84-90, 2006.

KREISEL, S. H.; HENNERICI, M. G.; BÄZNER, H. Pathophysiology of stroke rehabilitation: The natural course of clinical recovery, use-dependent plasticity and rehabilitative outcome. Cerebrovascular Diseases, v. 23, n. 4, p. 243-255, 2007.

KWAH, L. K.; DIONG, J. National Institutes of Health Stroke Scale (NIHSS). Journal of Physiotherapy, v. 60, n. 1, p. 61, 2014.

KWAKKEL, G. et al. Effects of intensity of rehabilitation after stroke. A research synthesis. Stroke, v. 28, n. 8, p. 1550-6, ago. 1997.

KWAKKEL, G. et al. Intensity of leg and arm training after primary middle-cerebralartery stroke: a randomised trial. The Lancet, v. 354, n. 9174, p. 191-196, 1999.

KWAKKEL, G. et al. Probability of regaining dexterity in the flaccid upper limb: Impact of severity of paresis and time since onset in acute stroke. Stroke, v. 34, n. 9, p. 21812186, 2003.

KWAKKEL, G. et al. Effects of augmented exercise therapy time after stroke: A metaanalysis. Stroke, v. 35, n. 11, p. 2529-2536, 2004.

KWAKKEL, G. Impact of intensity of practice after stroke: Issues for consideration. Disability and Rehabilitation, v. 28, n. 13-14, p. 823-830, 2006.

KWAKKEL, G. et al. Constraint-induced movement therapy after stroke. The Lancet Neurology, v. 14, n. 2, p. 224-234, 2015.

KWAKKEL, G.; KOLLEN, B. J.; WAGENAAR, R. C. Long term effects of intensity of upper and lower limb training after stroke: A randomised trial. Journal of Neurology Neurosurgery and Psychiatry, v. 72, n. 4, p. 473-479, 2002.

KWAKKEL, G.; WAGENAAR, R. C. Effect of duration of upper-and lower-extremity rehabilitation sessions and walking speed on recovery of interlimb coordination in hemiplegic gait. Physical Therapy, v. 82, n. 5, p. 432-448, 2002.

LAGERQUIST, O. Increased spinal reflex excitability is not associated with neural plasticity underlying the cross-education effect. Journal of Applied Physiology, v. 100 , n. 1, p. 83-90, 2006.

LANG, C. E. et al. Assessment of upper extremity impairment, function , and activity after stroke: foundations for clinical decision making. Journal of Hand Therapy, v. 26, n. 2, p. 104-115, 2013.

LANG, C. E.; LOHSE, K. R.; BIRKENMEIER, R. L. Dose and timing in neurorehabilitation: prescribing motor therapy after stroke. Current Opinion in Neurology, v. 28, n. 6, p. 549-555, 2015. 
LANGHAMMER, B.; STANGHELLE, J. K. Can Physiotherapy after Stroke Based on the Bobath Concept Result in Improved Quality of Movement Compared to the Motor Relearning Programme. Physiotherapy Research International, v. 16, n. 2, p. 6980, 2011.

LANGHORNE, P.; BERNHARDT, J.; KWAKKEL, G. Stroke rehabilitation. The Lancet, v. 377, n. 9778, p. 1693-1702, 2011.

LAUREYS, S. et al. Spasticity after stroke: Physiology, assessment and treatment. Brain Injury, v. 27, n. 10, p. 1093-1105, 2013.

LIEPERT, J. et al. Motor cortex plasticity during constraint-induced movement therapy in stroke patients. Neuroscience Letters, v. 250, n. 1, p. 5-8, 1998.

LIEPERT, J. et al. Treatment-induced cortical reorganization after stroke in humans. Stroke, v. 31, n. 6, p. 1210-1216, 2000.

LIEPERT, J. et al. Motor cortex plasticity during forced-use therapy in stroke patients: A preliminary study. Journal of Neurology, v. 248, n. 4, p. 315-321, 2001.

LIMA, R. et al. Psychometric properties of the Brazilian version of the Stroke Specific Quality of Life Scale: application of the Rasch model. Brazilian Journal of Physical Therapy, v. 12, n. 2, p. 149-56, 2008.

LO, C.-L.; TSENG, H.-T. Predicting rehabilitation treatment helpfulness to stroke patients: A supervised learning approach. Artificial Intelligence Research, v. 6, n. 2, p. 1, 2017.

LOHSE, K. R.; LANG, C. E.; BOYD, L. A. Is More Better? Using Metadata to Explore Dose-Response Relationships in Stroke Rehabilitation. Stroke, v. 45, n. 7, p. 20532058, jul. 2014.

LÖVDÉN, M. et al. A Theoretical Framework for the Study of Adult Cognitive Plasticity. Psychological Bulletin, v. 136, n. 4, p. 659-676, 2010.

LUM, P. S. et al. Gains in Upper Extremity Function After Stroke via Recovery or Compensation: Potential Differential Effects on Amount of Real-World Limb Use. Topics in Stroke Rehabilitation, v. 16, n. 4, p. 237-253, 2009.

MACKEY, F. et al. Stroke rehabilitation: Are highly structured units more conducive to physical activity than less structured units? Archives of Physical Medicine and Rehabilitation, v. 77, n. 10, p. 1066-1070, 1996.

MACLEAN, N. et al. The Concept of Patient Motivation A Qualitative Analysis of Stroke Professionals ' Attitudes. Stroke, v. 33, p. 444-448, 2002.

MAKI, T. et al. Reliability Study on the Application of the Fugl-Meyer Scale in Brazil. Brazilian Journal of Physical Therapy, v. 10, n. 2, p. 177-183, 2006. 
MARCINIAK, C. Poststroke Hypertonicity: Upper Limb Assessment and Treatment. Topics in Stroke Rehabilitation, v. 18, n. 3, p. 179-194, 2011.

MARK, V.; TAUB, E.; MORRIS, D. Neuroplasticity and constraint-induced movement therapy. Europa Medicophysica, v. 42, n. 3, p. 269-284, 2006.

MATHIOWETZ, V. et al. Grip and Pinch Strength : Normative Data for Adults. Archives of Physical Medicine and Rehabilitation, v. 66, n. 2, p. 69-74, 1985.

MAWASE, F. et al. Motor Learning Enhances Use-Dependent Plasticity. The Journal of Neuroscience, v. 37, n. 10, p. 2673-2685, 2017.

MEHRHOLZ, J.; POHL, M.; ELSNER, B. Treadmill training and body weight support for walking after stroke. The Cochrane Library, 2014.

MILLER, E. L. et al. Comprehensive overview of nursing and interdisciplinary rehabilitation care of the stroke patient: A scientific statement from the American heart association. Stroke, v. 41, n. 10, p. 2402-2448, 2010.

MONFILS, M. H.; PLAUTZ, E. J.; KLEIM, J. A. In search of the motor engram: Motor map plasticity as a mechanism for encoding motor experience. The Neuroscientist, v. 11, n. 5, p. 471-483, 2005.

MORRIS, D. M. et al. Constraint-induced movement therapy for motor recovery after stroke. NeuroRehabilitation, v. 9, n. 1, p. 29-43, 1997.

MORRIS, D. M. et al. The reliability of the wolf motor function test for assessing upper extremity function after stroke. Archives of Physical Medicine and Rehabilitation, v. 82 , n. 6 , p. 750-755, 2001.

MOZAFFARIAN, D. et al. Heart disease and stroke statistics--2015 update: a report from the American Heart Association. Circulation, v. 131, n. 4, p. e29-322, 2015.

MUDIE, M. H.; MATYAS, T. A. Can simultaneous bilateral movement involve the undamaged hemisphere in reconstruction of neural networks damaged by stroke? Disability and Rehabilitation, v. 22, n. 1-2, p. 23-37, 2000.

MURPHY, T. H.; CORBETT, D. Plasticity during stroke recovery: From synapse to behaviour. Nature Reviews Neuroscience, v. 10, n. 12, p. 861-872, 2009.

NAKAYAMA, $\mathrm{H}$. et al. Recovery of upper extremity function in stroke patients: The Copenhagen stroke study. Archives of Physical Medicine and Rehabilitation, v. 75, n. 4, p. 394-398, 1994.

NUDO, R. J. et al. Neural Substrates for the Effects of Rehabilitative Training on Motor Recovery After Ischemic Infarct. Science, v. 272, n. 5269, p. 1791-1794, 21 jun. 1996.

NUDO, R. J.; FRIEL, K. M.; DELIA, S. W. Role of sensory deficits in motor impairments after injury to primary motor cortex. Neuropharmacology, v. 39, n. 5, p. 733-742, 2000. 
OTTERMAN, N. M. et al. Physical therapists' guideline adherence on early mobilization and intensity of practice at dutch acute stroke units: A country-wide survey. Stroke, v. 43, n. 9, p. 2395-2401, 2012.

OUTERMANS, J. C. et al. Effects of a High-Intensity Task-Oriented Training on Gait Performance. Clinical rehabilitation, v. 24, n. 11, p. 979-987, 2010.

PAGE, S. J. Intensity versus task-specificity after stroke: How important is intensity? American Journal of Physical Medicine and Rehabilitation, v. 82, n. 9, p. 730-732, 2003.

PAGE, S. J.; SCHMID, A.; HARRIS, J. E. Optimizing terminology for stroke motor rehabilitation: Recommendations from the american congress of rehabilitation medicine stroke movement interventions subcommittee. Archives of Physical Medicine and Rehabilitation, v. 93, n. 8, p. 1395-1399, 2012.

PAGE, S.; SISTO, S. Modified constraint induced therapy: a randomized feasibility and efficacy study. Journal of Rehabilitation Research and Development, v. 38, n. 5, p. 583-90, 2001.

PEREIRA, N. D. et al. Reliability of the brazilian version of the Wolf Motor Function Test in adults with hemiparesis. Revista Brasileira de Fisioterapia, v. 15, n. 3, p. 257-265, 2011.

PEROTTO, A. O. Anatomical guide for the electromyographer: the limbs and trunk. Charles C. Thomas, 2011.

PERSSON, J.; FERRAZ-NUNES, J.; KARLBERG, I. Economic burden of stroke in a large county in Sweden. BMC Health Services Research, v. 12, n. 1, p. 1-8, 2012.

PETERS, H. T. et al. The National Institutes of Health Stroke Scale Lacks Validity in Chronic Hemiparetic Stroke. Journal of Stroke and Cerebrovascular Diseases, v. 24, n. 10, p. 2207-2212, 2015.

PLATZ, T. et al. Best Conventional Therapy Versus Modular Impairment-Oriented Training for Arm Paresis After Stroke: A Single-Blind, Multicenter Randomized Controlled Trial. Neurorehabilitation and Neural Repair, v. 23, n. 7, p. 706-716, 2009.

PLAUTZ, E. J.; MILLIKEN, G. W.; NUDO, R. J. Effects of repetitive motor training on movement representations in adult squirrel monkeys: Role of use versus learning. Neurobiology of Learning and Memory, v. 74, n. 1, p. 27-55, 2000.

PLUMMER, P. et al. Effects of stroke severity and training duration on locomotor recovery after stroke: A pilot study. Neurorehabilitation and Neural Repair, v. 21, n. 2, p. 137-151, 2007.

POLLOCK, A. et al. Physiotherapy treatment approaches for the recovery of postural control and lower limb function following stroke: A systematic review. Clinical 
Rehabilitation, v. 21, n. 5, p. 395-410, 2007.

PONTES-NETO, O. M. et al. Brazilian guidelines for the manegement of intracerebral hemorrhage. Archives of Neuropsychiatry, v. 67, n. 3 B, p. 940-950, 2009.

POUSSON, M.; AMIRIDIS, I. G.; COMETTI, G. Velocity-specific training in elbow flexors. European Journal of Applied Physiology, p. 367-372, 1999.

PROVINS, K. A.; MAGLIARO, J. The measurement of handedness by preference and performance tests. Brain and Cognition, v. 22, n. 2, p. 171-181, 1993.

PRZYBYLA, A.; GOOD, D. C.; SAINBURG, R. L. Dynamic dominance varies with handedness: Reduced interlimb asymmetries in left-handers. Experimental Brain Research, v. 216, n. 3, p. 419-431, 2012.

PUNDIK, S. et al. Association of spasticity and motor dysfunction in chronic stroke. Annals of Physical and Rehabilitation Medicine, 2018.

RAPOPORT, J.; JUDD-VAN EERD, M. Impact of physical therapy weekend coverage on length of stay in an acute care community hospital. Physical therapy, v. 69, n. 1, p. 32-7, 1989.

RIBEIRO, T. S. et al. Effects of a training program based on the Proprioceptive Neuromuscular Facilitation method on post-stroke motor recovery: A preliminary study. Journal of Bodywork and Movement Therapies, v. 18, n. 4, p. 526-532, 2014.

RICHARDS, L. G. et al. Movement-dependent stroke recovery: A systematic review and meta-analysis of TMS and fMRI evidence. Neuropsychologia, v. 46, n. 1, p. 311, 2008.

RINEHART, J. K. et al. Arm Use After Left or Right Hemiparesis Is Influenced by Hand Preference. Stroke, v. 40, p. 545-550, 2009.

ROBERTS, H. C. et al. A review of the measurement of grip strength in clinical and epidemiological studies: Towards a standardised approach. Age and Ageing, v. 40, n. 4, p. 423-429, 2011.

ROSE, D. K. et al. Locomotor Training and Strength and Balance Exercises for Walking Recovery Post Stroke: Response to Number of Training Sessions. Physical Therapy, v. 97, n. 11, p. 1066-1074, 2017.

ROSSI, F.; GIANOLA, S.; CORVETTI, L. Regulation of intrinsic neuronal properties for axon growth and regeneration. Progress in Neurobiology, v. 81, n. 1, p. 1-28, 2007. SACCO, R. L. et al. An updated definition of stroke for the 21st century: A statement for healthcare professionals from the American heart association/American stroke association. Stroke, v. 44, n. 7, p. 2064-2089, 2013.

SALIBA, V. A. et al. Cross-cultural adaptation and analysis of the psychometric properties of the Brazilian version of the Motor Activity Log. Pan American Journal of Public Health, v. 30, n. 3, p. 182, 2010. 
SANFORD, J. et al. Reliability of the Fugl-Meyer Assessment for Testing MotorPerformance. Physical Therapy, v. 73, n. 7, p. 447-454, 1993.

SANTOS, T. P.; FUZARO, A. C.; DE ARAUJO, J. E. High frequency and long duration non-specific paretic arm protocol is more effective than low frequency and short duration specific motor protocol in post-stroke rehabilitation. Submetido para o Journal of Exercise Rehabilitation, 2019.

SARIKAYA, P. M. et al. Effect of Hand Dominance on Functional Status and Recovery of Hand in Stroke Patients. Science, v. 6, n. 3, p. 39-45, 2017.

SCHAECHTER, J. D. et al. Motor recovery and cortical reorganization after constraintinduced movement therapy in stroke patients: A preliminary study. Neurorehabilitation and Neural Repair, v. 16, p. 326-338, 2002.

SCHAECHTER, J. D. Motor rehabilitation and brain plasticity after hemiparetic stroke. Progress in Neurobiology, v. 73, n. 1, p. 61-72, 2004.

SCHNEIDER, E. J. et al. Increasing the amount of usual rehabilitation improves activity after stroke: a systematic review. Journal of Physiotherapy, v. 62, n. 4, p. 182-187, 2016.

SENIAM Project. Disponível em www.seniam.org. Acesso em 05 jan. 2015.

SILVA, S. M. et al. Evaluation of post-stroke functionality based on the International Classification of Functioning, Disability , and Health : a proposal for use of assessment tools. Journal of Physical Therapy Science, v. 27, n. 6, p. 1665-1670, 2015.

SONODA, S. et al. Full-Time Integrated Treatment Program, a New System for Stroke Rehabilitation in Japan: Comparison with Conventional Rehabilitation. American Journal of Physical Medicine and Rehabilitation, v. 83, n. 2, p. 88-93, 2004.

SORINOLA, I. O. et al. Electromyographic Response to Manual Passive Stretch of the Hemiplegic Wrist: Accuracy, Reliability, and Correlation With Clinical. Neurorehabilitation and Neural Repair, v. 23, n. 3, p. 287-294, 2009.

STERR, A.; FREIVOGEL, S. Intensive training in chronic upper limb hemiparesis does not increase spasticity or synergies. Neurology, v. 63, n. 11, p. 2176-2177, 2004.

STINEAR, C. M. et al. Priming the motor system enhances the effects of upper limb therapy in chronic stroke. Brain, v. 131, n. 5, p. 1381-1390, 2008.

TAUB E, USWATTE G, P. R. Constraint-induced movement therapy: a new family of techniques with broad application to physical rehabilitation - a clinical review. Journal of Rehabilitation Research and Development, v. 36, n. 3, p. 237-51, 1999.

TAUB, E. et al. An operant approach to rehabilitation medicine: overcoming learned nonuse by shaping. Journal of the Experimental Analysis of Behavior, v. 61, n. 2, p. 281-293, 1994. 
TAUB, E. New discovery equals change in clinical practice. Journal of Rehabilitation Research and Development, v. 36, n. 3, p. 7, 1999.

TAUB, E. et al. The learned nonuse phenomenon: implications for rehabilitation. Europa Medicophysica, v. 42, n. 3, p. 241-56, 2006.

TAUB, E. et al. Method for Enhancing Real-World Use of a More Affected Arm in Chronic Stroke. Stroke, v. 44, n. 5, p. 1383-1388, 2013.

TAUB, E.; CRAGO, J. E.; USWATTE, G. Constraint-induced movement therapy: A new approach to treatment in physical rehabilitation. Rehabilitation Psychology, $v$. 43, n. 2, p. 152-170, 1998.

TAUB, E.; USWATTE, G. Constraint-Induced Movement therapy: Bridging from the primate laboratory to the stroke rehabilitation laboratory. Journal of Rehabilitation Medicine, v. 41, p. 34-40, 2003.

TOOLE, T. et al. The effects of loading and unloading treadmill walking on balance, gait, fall risk, and daily function in Parkinsonism. NeuroRehabilitation, v. 20, n. 4, p. 307-322, 2005.

USWATTE, G. et al. Reliability and validity of the upper-extremity motor activity log-14 for measuring real-world arm use. Stroke, v. 36, n. 11, p. 2493-2496, 2005.

VAN DER LEE, J. H. et al. Clinimetric properties of the motor activity log for the assessment of arm use in hemiparetic patients. Stroke, v. 35, n. 6, p. 1410-1414, 2004.

VEERBEEK, J. M. et al. What is the evidence for physical therapy poststroke? A systematic review and meta-analysis. PLoS ONE, v. 9, n. 2, 2014.

WANG, H. et al. Daily Treatment Time and Functional Gains of Stroke Patients During Inpatient Rehabilitation. PM\&R, v. 5, n. 2, p. 122-128, 2013.

WEISS, P.; KIZONY, R. Virtual reality in neurorehabilitation. Textbook of Neural Repair and Rehabilitation, v. 51, n. 8, p. 182-197, 2006.

WILLIAMS, L. S. et al. Development of a stroke-specific quality of life scale. Stroke, v. 30, n. 7, p. 1362-1369, 1999.

WILLINGHAM, D. A Neuropsychological Theory of Motor Skill Learning* 1. Psychological Review, v. 105, n. 3, p. 558-584, 1998.

WINSTEIN, C. J. et al. Guidelines for Adult Stroke Rehabilitation and Recovery. Stroke, v. 47, n. 6, p. 98-169, 2016.

WINSTEIN, C. J.; STEWART, J. C. Conditions of task practice for individuals with neurologic impairments. In: SELZER, M. et al. (Eds.). . Neural Repair and Rehabilitation. Cambridge: Cambridge University Press, v. 2, p. 89-102, 2005. 
WOLDAG, H.; STUPKA, K.; HUMMELSHEIM, H. Repetitive training of complex hand and arm movements with shaping is beneficial for motor improvement in patients after stroke. Journal of Rehabilitation Medicine, v. 42, n. 6, p. 582-587, 2010.

WOLF, S. L. et al. The EXCITE trial: Attributes of the Wolf Motor Function Test in patients with subacute stroke. Neurorehabilitation and Neural Repair, v. 19, n. 3, p. 194-205, 2005.

WOLF, S. L. et al. Forced use of hemiplegic upper extremities to reverse the effect of learned nonuse among chronic stroke and head-injured patients. Experimental neurology, v. 104, n. 2, p. 125-32, 1989.

WOLF, S. L. et al. Assessing Wolf Motor Function Test as outcome measure for research in patients after stroke. Stroke, v. 32, n. 7, p. 1635-1639, 2001.

WOLF, S. L. et al. Repetitive Task Practice: A Critical Review of Constraint-Induced Movement Therapy in Stroke. The Neurologist, v. 8, n. 6, p. 325-338, nov. 2002.

WOLF, S. L. et al. Effect of constraint-induced movement therapy on upper extremity function 3 to 9 months after stroke: the EXCITE randomized clinical trial. Jama, v. 296, n. 17, p. 2095-2104, 2006.

WOOD, D. E. et al. Biomechanical approaches applied to the lower and upper limb for the measurement of spasticity: A systematic review of the literature. Disability and Rehabilitation, v. 27, n. 1-2, p. 19-32, 2005. 
ANEXOS 
ANEXO A - Aprovação do Comitê de Ética

HOSPITAL DAS CLINICAS DA FACULDADE DE MEDICINA DE RIBEIRÃO PRETO DA UNIVERSIDADE DE SÃO PAULO

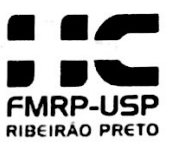

Ribeirão Preto, 25 de junho de 2015.

Oficio $n^{\circ} 2248 / 2015$

CEP/MGV

\section{PROCESSO HCRP n $n^{\circ}$ 6663/2015}

Prezados Pesquisadores,

O trabalho intitulado "VERIFICAÇÃO DA EFICÁCIA E ACEITAÇÃo dE UM NOVO PROTOCOLO DE TERAPIA DE USO FORÇADO COM 12 HORAS DIÁRIAS DE CONSTRIÇÃo DE MOVIMENTO", foi analisado pelo Comitê de Ética em Pesquisa, em sua $410^{a}$ Reunião Ordinária realizada em 22/06/2015, e enquadrado na categoria: APROVADO, bem como o Termo de Consentimento Livre e Esclarecido.

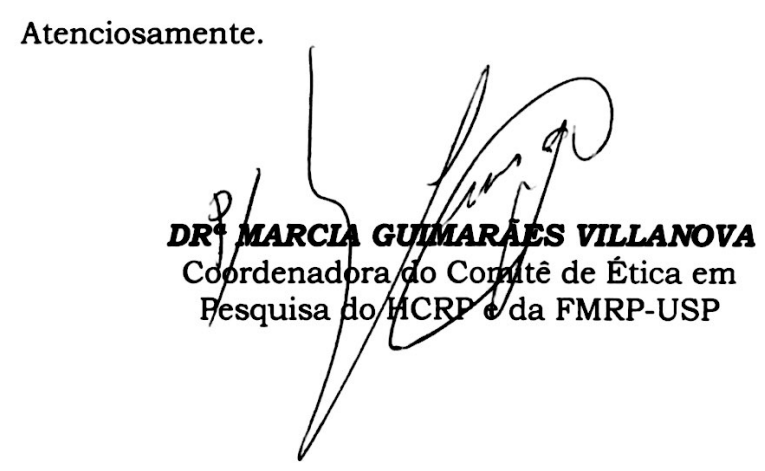

Ilustrissimos Senhores

TAMYRIS PADOVANI DOS SANTOS

PROF. DR. JOÃO EDUARDO DE ARAÚJO

Depto. de Biomecânica, Medicina e Reabilitação do Aparelho Locomotor

HOSPITAL DAS CLINICAS DA FACULDADE DE MEDICINA DE RIBEIRAO PRETO DA UNIVERSIDADE DE SAO PAULO Campus Universitário - Monte Alegre

: $048-900$ Ribeirão Preto SP

Comité de Ética em Pesquisa do HCRP e FMRP-USP FWA-00002733; IRB-00002186 e Registro Plataforma Brasil /CONEP n० 5440 (016) $3602-2228$

wuw.hcrp.usp.br cep@hcrp.usp.br 
ANEXO B - NIHSS - "National Institute of Health Stroke Scale"

\begin{tabular}{|c|c|c|}
\hline Itens & Pontuação & Descrição \\
\hline 1 A. Nível de consciência & & $\begin{array}{ll}0=\text { alerta } & 1=\text { sonolento } \\
2=\text { estuporoso } & 3=\text { comatoso }\end{array}$ \\
\hline $\begin{array}{l}1 \text { B. Perguntas de Nível de } \\
\text { consciência } \\
\text { (mês, idade) }\end{array}$ & & $\begin{array}{l}0=\text { ambas corretas } \\
1=\text { uma correta } \\
2=\text { ambas incorretas }\end{array}$ \\
\hline $\begin{array}{l}\text { 1 C. Comandos } \\
\text { (fechar olhos, fechar a mão) }\end{array}$ & & $\begin{array}{l}0=\text { ambas corretas } \\
1=\text { uma correta } \\
2=\text { nenhuma correta }\end{array}$ \\
\hline Melhor olhar conjugado & & $\begin{array}{l}0=\text { normal } \\
1=\text { paresia parcial do olhar } \\
2 \text { =desvio tônico do olhar }\end{array}$ \\
\hline Campos visuais & & $\begin{array}{l}0=\text { sem perda visual } \\
1=\text { hemianopsia parcial } \\
2=\text { hemianopsia completa } \\
3=\text { hemianopsia bilateral }\end{array}$ \\
\hline Paralisia facial & & $\begin{array}{l}0=\text { movimentos normais simétricos } \\
1=\text { paralisia leve } \\
2=\text { paralisia parcial } \\
3=\text { paralisia completa }\end{array}$ \\
\hline $\begin{array}{l}\text { Motricidade de membros } \\
\text { MS } \\
\text { MI }\end{array}$ & & $\begin{array}{l}0=\text { sem quedas } \\
1 \text { = com queda } \\
2 \text { = esforço vence a gravidade } \\
3 \text { = esforço não vence a gravidade } \\
4=\text { sem movimento }\end{array}$ \\
\hline Ataxia nos membros & & $\begin{array}{l}0=\text { ausente } \\
1=\text { presente em um membro. Qual } ? \\
2=\text { presente em } 2 \text { ou mais membros }\end{array}$ \\
\hline Sensibilidade & & $\begin{array}{l}0=\text { normal } \\
1=\text { perda parcial } \\
2=\text { perda total }\end{array}$ \\
\hline Melhor linguagem & & $\begin{array}{l}0=\text { sem afasia } \\
1=\text { afasia leve a moderada } \\
2=\text { afasia severa }\end{array}$ \\
\hline Disartria & & $\begin{array}{l}0=\text { articulação normal } \\
1 \text { = disartria leve a moderada } \\
2=\text { disartria grave }\end{array}$ \\
\hline Extinção e Desatenção & & $\begin{array}{l}0=\text { ausência } \\
1 \text { = desatenção em uma modalidade } \\
2 \text { = desatenção em mais de uma modalidade }\end{array}$ \\
\hline Total & & \\
\hline
\end{tabular}


ANEXO C - AS - "Ashworth Scale"

MS

Pontuação*

\begin{tabular}{|l|lllll|}
\hline Punho & 0 & 1 & 2 & 3 & 4 \\
\hline Cotovelo & 0 & 1 & 2 & 3 & 4 \\
\hline
\end{tabular}

* $0=$ Normal

$1=$ Resistência aumenta no final da ADM

$2=$ Resistência aumenta do meio para o final da ADM

$3=$ Resistência aumenta em toda a ADM

4 = Rigidez a flexão ou extensão 


\section{ANEXO D - SS-QOL - "Stroke Specific Quality of Life"}

\section{- Durante a semana passada...}

\section{TESTE}

\section{Energia}

1. Eu me senti cansado a maior parte do tempo.

2. Eu tive que parar e descansar durante o dia.

3. Eu estava cansado demais para fazer o que eu queria.

\section{PONTUAÇÃO}

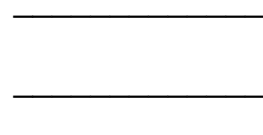

2. Papéis familiares

1. Eu não participei em atividades apenas por lazer/diversão com minha família.

2. Eu senti que era um fardo/peso para minha família.

3. Minha condição física interferiu com minha vida pessoal.

\section{Linguagem}

1. Você teve dificuldade para falar? Por exemplo, não achar a palavra certa, gaguejar, não conseguir se expressar, ou embolar as palavras?

2. Você teve dificuldade para falar com clareza suficiente para usar o telefone?

3. Outras pessoas tiveram dificuldade de entender o que você disse?

4. Você teve dificuldade em encontrar a palavra que queria dizer?

5. Você teve que se repetir para que os outros pudessem entendê-lo?

\section{Mobilidade}

1. Você teve dificuldade para andar? (Se o paciente não pode andar, vá para questão 4 e pontue as questões 2 e 3 com 1 ponto.)

2. Você perdeu o equilíbrio quando se abaixou ou tentou alcançar algo?

3. Você teve dificuldade para subir escadas?

4. Ao andar ou usar a cadeira de rodas você teve que parar e descansar mais do que gostaria?

5. Você teve dificuldade para permanecer de pé?

6. Você teve dificuldade para se levantar de uma cadeira?

\section{Humor}

1. Eu estava desanimado sobre meu futuro.

2. Eu não estava interessado em outras pessoas ou em outras atividades.

3. Eu me senti afastado/isolado das outras pessoas.

4. Eu tive pouca confiança em mim mesmo. 
5. Eu não estava interessado em comida.

\section{Personalidade}

1. Eu estava irritável/irritado. ("Com os nervos à flor da pele")

2. Eu estava impaciente com os outros.

3. Minha personalidade mudou.

\section{Autocuidado}

1. Você precisou de ajuda para preparar comida?

2. Você precisou de ajuda para comer? Por exemplo, para cortar ou preparar a comida?

3. Você precisou de ajuda para se vestir? Por exemplo, para calçar meias ou sapatos, abotoar roupas ou usar um zíper?

4. Você precisou de ajuda para tomar banho de banheira ou chuveiro?

5. Você precisou de ajuda para usar o vaso sanitário?

8. Papéis sociais

1. Eu não saí com a frequência que eu gostaria.

2. Eu dediquei menos tempo aos meus hobbies e lazer do que eu gostaria.

3. Eu não encontrei tantos amigos meus quanto eu gostaria.

4. Eu tive relações sexuais com menos frequência do que gostaria.

5. Minha condição física interferiu com minha vida social.

\section{Memória/concentração}

1. Foi difícil para eu me concentrar.

2. Eu tive dificuldade para lembrar as coisas.

3. Eu tive que anotar as coisas para me lembrar delas.

10. Função da extremidade superior

1. Você teve dificuldade para escrever ou digitar?

2. Você teve dificuldade para colocar meias?

3. Você teve dificuldade para abotoar a roupa?

4. Você teve dificuldade para usar o zíper?

5. Você teve dificuldade para abrir uma jarra?

\section{Visão}

1. Você teve dificuldade em enxergar a televisão o sufi ciente para apreciar um programa? 
2. Você teve dificuldade para alcançar as coisas devido à visão fraca?

3. Você teve dificuldade em ver coisas nas suas laterais/de lado?

12. Trabalho/produtividade

1. Você teve dificuldade para fazer o trabalho caseiro diário?

2. Você teve dificuldade para terminar trabalhos ou tarefas que havia começado?

3. Você teve dificuldade para fazer o trabalho que costumava fazer?

\section{Pontuação total:}

Pontuação: cada item será pontuado com o seguinte critério:

$1=$ Ajuda Total - Não pude fazer de modo algum - Concordo inteiramente

2 = Muita ajuda - Muita dificuldade - Concordo mais ou menos

3 = Alguma ajuda - Alguma dificuldade - Nem concordo nem discordo

$4=$ Um pouco de ajuda - Um pouco de dificuldade - Discordo mais ou menos

$\underline{5}=$ Nenhuma ajuda necessária - Nenhuma dificuldade mesmo - Discordo inteiramente 


\section{ANEXO E - WMFT - "Wolf Motor Function Test"}

TESTE

1. Antebraço na mesa:

2.Antebraço na caixa:

3.Extensão de cotovelo:

4.Extensão do cotovelo (com peso):

5.Mão na mesa:

6.Mão na caixa:

7.Com peso na caixa:

8.Alcançar e retroceder:

9.Levantar lata:

10.Levantar lápis:

11.Levantar clipe de papel:

12.Empilhar peças:

13. Virar cartas:

14.Força de preensão:

15.Virar chave:

16.Dobrar toalha:

17.Levantar cesta:
TEMPO
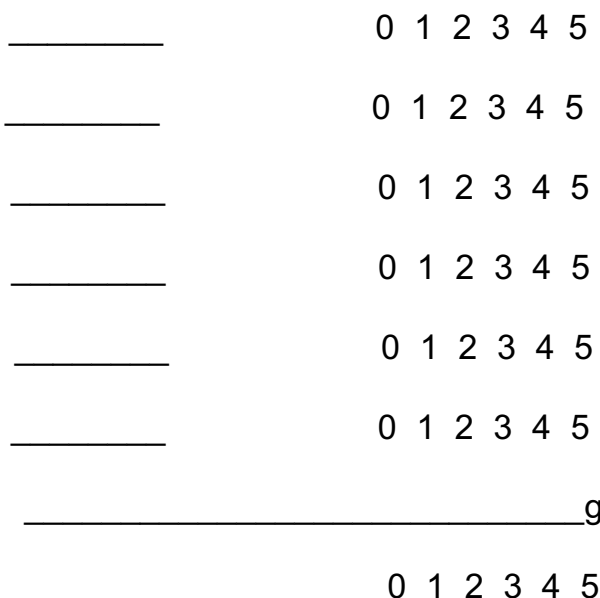

$0 \begin{array}{lllll}0 & 1 & 2 & 3 & 4\end{array}$

012345

012345

012345

012345

012345

Kgf

012345

012345

012345

$0=$ Não tenta com o membro superior (MS) testado.

1= MS testado não participa funcionalmente; no entanto, uma tentativa é feita para usar esse MS. Em teste unilateral, o

MS não testado deve ser usada para mover o MS testado.

2= Faz, mas requer assistência do MS não testado para pequenos reajustes ou trocas de posição, ou requer mais de 2 tentativas para completar, ou realiza muito devagar. Em teste bilateral, o MS testado deve servir somente como auxiliar. 3= Faz, mas o movimento é influenciado em alguns graus por sinergia ou é realizado devagar ou com esforço.

4= Faz, o movimento é próximo do normal* ${ }^{*}$ mas levemente mais vagaroso; pode perder precisão, coordenação fina, ou fluidez.

5=Faz, o movimento aparenta o normal*.

*Para determinar o normal, o MS menos afetado pode ser utilizado como um índice de avaliação para comparação, com dominância_do MS antes do AVC levada em consideração.

$>$ Todos os itens são realizados o mais rápido possível e devem ser realizados em 120 segundos. 
ANEXO F - FMA - "Fugl-Meyer Assessment"

A.Ombro/cotovelo/antebraço

\begin{tabular}{|c|c|c|c|}
\hline $\begin{array}{l}\text { I.Atividade reflexa elicitada } \\
\text { (bíceps, tríceps) }\end{array}$ & $\begin{array}{c}\text { Reflexo } \\
\text { ausente } \\
0\end{array}$ & 1 & $\begin{array}{c}\text { Reflexo } \\
\text { presente } \\
2\end{array}$ \\
\hline $\begin{array}{l}\text { II. Atividade voluntária } \\
\text { a) Sinergia flexora } \\
\text { b) Sinergia extensora }\end{array}$ & $\begin{array}{c}\text { Não realiza } \\
\begin{array}{c}0 \\
0\end{array}\end{array}$ & $\begin{array}{l}1 \\
1\end{array}$ & $\begin{array}{c}\text { Realiza } \\
\text { perfeitamente } \\
2 \\
2\end{array}$ \\
\hline $\begin{array}{l}\text { III. Atividade voluntária associada a } \\
\text { sinergismos } \\
\text { a) posicionar mão afetada na coluna } \\
\text { lombar } \\
\text { b) flexão pura do ombro a } 90^{\circ} \\
\text { c) prono/supinação do antebraço }\end{array}$ & $\begin{array}{c}\text { Não realiza } \\
0 \\
0 \\
0\end{array}$ & $\begin{array}{l}1 \\
1 \\
1\end{array}$ & $\begin{array}{c}\begin{array}{c}\text { Realiza } \\
\text { perfeitamente }\end{array} \\
2 \\
2 \\
2\end{array}$ \\
\hline $\begin{array}{l}\text { IV. Atividade voluntária sem sinergias } \\
\text { a) abdução pura do ombro a } 90^{\circ} \\
\text { b) flexão pura do ombro a } 90^{\circ} \\
\text { c) prono/supinação do antebraço }\end{array}$ & $\begin{array}{l}\text { Não realiza } \\
\qquad \begin{array}{c}0 \\
0 \\
0\end{array}\end{array}$ & $\begin{array}{l}1 \\
1 \\
1\end{array}$ & $\begin{array}{c}\text { Realiza } \\
\text { perfeitamente } \\
2 \\
2 \\
2\end{array}$ \\
\hline V. Atividade reflexa normal & $\begin{array}{c}2 \text { a } 3 \text { reflexos } \\
\text { exacerbados } \\
0\end{array}$ & $\begin{array}{c}1 \text { reflexo } \\
\text { exacerbado } \\
\text { e } 2 \text { vivos } \\
1\end{array}$ & $\begin{array}{l}\text { Nenhum } \\
\text { reflexo } \\
\text { exacerbado e } \\
1 \text { vivo } \\
2\end{array}$ \\
\hline
\end{tabular}

B. Punho

\begin{tabular}{|c|c|c|c|}
\hline I. Extensão em $15^{\circ}$ com leve resistência & $\begin{array}{c}\text { Não realiza } \\
0\end{array}$ & $\begin{array}{c}\text { Realiza sem } \\
\text { resistência } \\
1\end{array}$ & $\begin{array}{c}\text { Realiza } \\
\text { perfeitamente } \\
2\end{array}$ \\
\hline II. Extensão máxima para flexão máxima & $\begin{array}{c}\text { Não realiza } \\
0\end{array}$ & $\begin{array}{c}\text { Realiza com } \\
\text { assistência } \\
1\end{array}$ & $\begin{array}{c}\text { Realiza } \\
\text { perfeitamente } \\
2\end{array}$ \\
\hline $\begin{array}{l}\text { III. Flexão e extensão alternadas com ombro } \\
\text { fletido e/ou abduzido }\end{array}$ & $\begin{array}{c}\text { Não realiza } \\
0\end{array}$ & 1 & $\begin{array}{c}\text { Realiza } \\
\text { perfeitamente } \\
2\end{array}$ \\
\hline $\begin{array}{l}\text { IV. Extensão de } 15^{\circ} \text { com ombro semi-fletido } \\
\text { e/ou abduzido com resistência }\end{array}$ & $\begin{array}{c}\text { Não realiza } \\
0\end{array}$ & 1 & $\begin{array}{c}\text { Realiza } \\
\text { perfeitamente } \\
2\end{array}$ \\
\hline
\end{tabular}




\begin{tabular}{|l|c|c|c|}
\hline V. Circundução do punho & Não realiza & Realiza \\
perfeitamente \\
2
\end{tabular}

C. Mão

\begin{tabular}{|c|c|c|c|}
\hline I. Flexão dos dedos & $\begin{array}{c}\text { Não realiza } \\
0\end{array}$ & 1 & $\begin{array}{c}\text { Realiza } \\
\text { perfeitamente } \\
2\end{array}$ \\
\hline II. Extensão dos dedos & $\begin{array}{c}\text { Não realiza } \\
0\end{array}$ & 1 & $\begin{array}{c}\text { Realiza } \\
\text { perfeitamente } \\
2\end{array}$ \\
\hline III. Preensão resistida em garra & $\begin{array}{c}\text { Não realiza } \\
0\end{array}$ & 1 & $\begin{array}{c}\text { Realiza } \\
\text { perfeitamente } \\
2\end{array}$ \\
\hline IV. Pinça de papel & $\begin{array}{c}\text { Não realiza } \\
0\end{array}$ & 1 & $\begin{array}{c}\text { Realiza } \\
\text { perfeitamente } \\
2\end{array}$ \\
\hline V. Pinça de lápis & $\begin{array}{c}\text { Não realiza } \\
0\end{array}$ & 1 & $\begin{array}{c}\text { Realiza } \\
\text { perfeitamente } \\
2\end{array}$ \\
\hline VI. Segurar lata & $\begin{array}{c}\text { Não realiza } \\
0\end{array}$ & 1 & $\begin{array}{c}\text { Realiza } \\
\text { perfeitamente } \\
2\end{array}$ \\
\hline VII. Segurar bola pequena & $\begin{array}{c}\text { Não realiza } \\
0\end{array}$ & 1 & $\begin{array}{c}\text { Realiza } \\
\text { perfeitamente } \\
2\end{array}$ \\
\hline
\end{tabular}

D. Coordenação / velocidade

I.Teste índex-nariz

a) Tremor

b) Dismetria

c) Velocidade comparada ao membro não afetado

\begin{tabular}{|c|c|c|}
\hline Acentuado & Sutil & Ausente \\
0 & 1 & 2 \\
0 & 1 & 2 \\
6s mais lento & 2 a $5 \mathrm{~s}$ & menos que 2s \\
0 & 1 & 2 \\
\hline
\end{tabular}

\section{H. Sensibilidade}

I. Estímulo de leve toque

a) Braço

b) Superfície palmar da mão

Ausência

\begin{tabular}{|c|c|}
\hline Hipoestesia & Hiperestesia \\
1 & 2 \\
1 & 2 \\
\hline
\end{tabular}


II. Sensação de posição das articulações
a) Ombro
b) Cotovelo
c) Punho
d) Polegar

\begin{tabular}{|l|l|l|}
\hline & & \\
0 & 1 & 2 \\
0 & 1 & 2 \\
0 & 1 & 2 \\
0 & 1 & 2 \\
\hline
\end{tabular}

\section{J. Articulações}

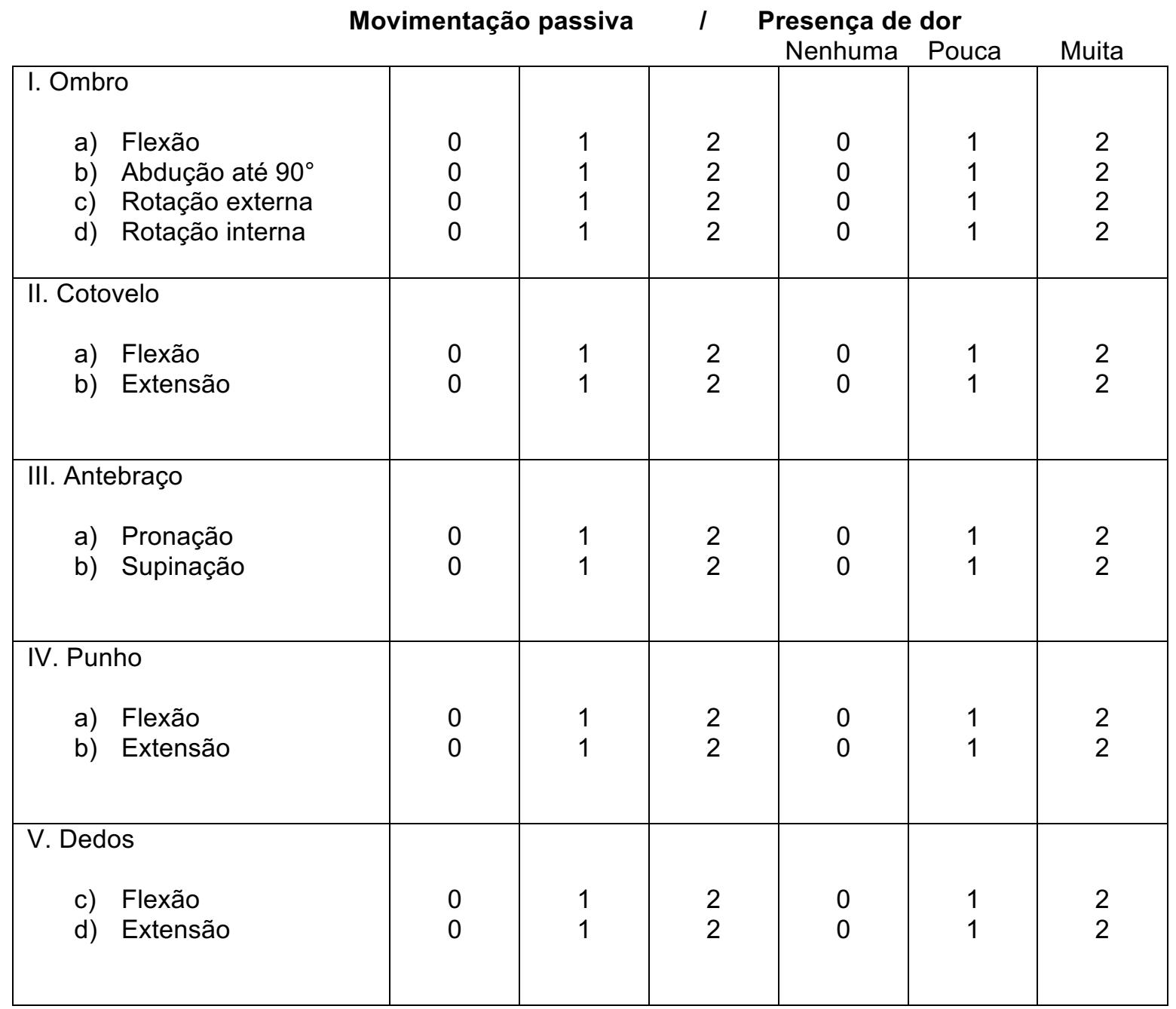


ANEXO G - MAL- "Motor Activity Log"

\begin{tabular}{|c|c|c|c|}
\hline & $\begin{array}{c}\text { Escala } \\
\text { Quantitativa }\end{array}$ & $\begin{array}{c}\text { Escala } \\
\text { Qualitativa }\end{array}$ & \\
\hline 1) Acender a luz pelo interruptor & & & $\begin{array}{l}\text { Se não, por quê? } \\
\text { Comentários: }\end{array}$ \\
\hline 2) Abrir uma gaveta & & & $\begin{array}{l}\text { Se não, por quê? } \\
\text { Comentários: }\end{array}$ \\
\hline $\begin{array}{l}\text { 3) Tirar uma peça de roupa da } \\
\text { gaveta }\end{array}$ & & & $\begin{array}{l}\text { Se não, por quê? } \\
\text { Comentários: }\end{array}$ \\
\hline 4) Tirar o telefone do gancho & & & $\begin{array}{l}\text { Se não, por quê? } \\
\text { Comentários: }\end{array}$ \\
\hline $\begin{array}{l}\text { 5) Passar um pano (limpar) na } \\
\text { bancada da cozinha }\end{array}$ & & & $\begin{array}{l}\text { Se não, por quê? } \\
\text { Comentários: }\end{array}$ \\
\hline $\begin{array}{l}\text { 6) Sair do carro (inclui apenas o } \\
\text { movimento necessário para } \\
\text { levantar do banco e ficar em pé } \\
\text { fora do carro depois que a porta } \\
\text { estiver aberta) }\end{array}$ & & & $\begin{array}{l}\text { Se não, por quê? } \\
\text { Comentários: }\end{array}$ \\
\hline 7) Abrir a geladeira & & & $\begin{array}{l}\text { Se não, por quê? } \\
\text { Comentários: }\end{array}$ \\
\hline $\begin{array}{l}\text { 8) Abrir uma porta girando a } \\
\text { maçaneta }\end{array}$ & & & $\begin{array}{l}\text { Se não, por quê? } \\
\text { Comentários: }\end{array}$ \\
\hline $\begin{array}{l}\text { 9) Utilizar o controle remoto da } \\
\text { TV }\end{array}$ & & & $\begin{array}{l}\text { Se não, por quê? } \\
\text { Comentários: }\end{array}$ \\
\hline $\begin{array}{l}\text { 10) Lavar as mãos (inclui } \\
\text { ensaboar e enxaguar as mãos; } \\
\text { não inclui abrir/fechar uma } \\
\text { torneira manual) }\end{array}$ & & & $\begin{array}{l}\text { Se não, por quê? } \\
\text { Comentários: }\end{array}$ \\
\hline $\begin{array}{l}\text { 11) Abrir e fechar uma torneira } \\
\text { de rosca ou alavanca }\end{array}$ & & & $\begin{array}{l}\text { Se não, por quê? } \\
\text { Comentários: }\end{array}$ \\
\hline 12) Secar as mãos & & & $\begin{array}{l}\text { Se não, por quê? } \\
\text { Comentários: }\end{array}$ \\
\hline 13) Colocar as meias & & & $\begin{array}{l}\text { Se não, por quê? } \\
\text { Comentários: }\end{array}$ \\
\hline 14) Tirar as meias & & & $\begin{array}{l}\text { Se não, por quê? } \\
\text { Comentários: }\end{array}$ \\
\hline $\begin{array}{l}\text { 15) Calçar os sapatos (inclui } \\
\text { amarrar os cadarços e ajustar os } \\
\text { velcros ou as tiras) }\end{array}$ & & & $\begin{array}{l}\text { Se não, por quê? } \\
\text { Comentários: }\end{array}$ \\
\hline $\begin{array}{l}\text { 16) Tirar os sapatos (inclui } \\
\text { desamarrar cadarços e soltar os } \\
\text { velcros ou as tiras) }\end{array}$ & & & $\begin{array}{l}\text { Se não, por quê? } \\
\text { Comentários: }\end{array}$ \\
\hline $\begin{array}{l}\text { 17) Levantar-se de uma cadeira } \\
\text { com apoio de braço }\end{array}$ & & & $\begin{array}{l}\text { Se não, por quê? } \\
\text { Comentários: }\end{array}$ \\
\hline $\begin{array}{l}\text { 18) Afastar a cadeira da mesa } \\
\text { antes de se assentar }\end{array}$ & & & $\begin{array}{l}\text { Se não, por quê? } \\
\text { Comentários: }\end{array}$ \\
\hline $\begin{array}{l}\text { 19) Puxar a cadeira em direção } \\
\text { à mesa após estar assentado }\end{array}$ & & & $\begin{array}{l}\text { Se não, por quê? } \\
\text { Comentários: }\end{array}$ \\
\hline $\begin{array}{l}\text { 20) Levantar um copo, garrafa } \\
\text { (de vidro ou plástico) ou lata }\end{array}$ & & & $\begin{array}{l}\text { Se não, por quê? } \\
\text { Comentários: }\end{array}$ \\
\hline $\begin{array}{l}\text { 21) Escovar os dentes (não } \\
\text { inclui a preparação da escova de } \\
\text { dente ou escovar a dentadura, a } \\
\text { menos que esta seja escovada } \\
\text { dentro da boca) }\end{array}$ & & & $\begin{array}{l}\text { Se não, por quê? } \\
\text { Comentários: }\end{array}$ \\
\hline
\end{tabular}




\begin{tabular}{|c|c|}
\hline $\begin{array}{l}\text { 22) Colocar base de } \\
\text { maquiagem, loção ou creme de } \\
\text { barbear no rosto }\end{array}$ & $\begin{array}{l}\text { Se não, por quê? } \\
\text { Comentários: }\end{array}$ \\
\hline $\begin{array}{l}\text { 23) Usar uma chave para } \\
\text { destrancar uma porta }\end{array}$ & $\begin{array}{l}\text { Se não, por quê? } \\
\text { Comentários: }\end{array}$ \\
\hline $\begin{array}{l}\text { 24) Escrever no papel (se a mão } \\
\text { utilizada para escrever antes do } \\
\text { derrame é a mais afetada, } \\
\text { pontue o item; se a mão que } \\
\text { não escrevia antes do derrame é } \\
\text { a mais afetada, pule o item e } \\
\text { assinale N/A) }\end{array}$ & $\begin{array}{l}\text { Se não, por quê? } \\
\text { Comentários: }\end{array}$ \\
\hline $\begin{array}{l}\text { 25) Carregar um objeto na mão } \\
\text { (dependurar um item sobre o } \\
\text { braço não é aceitável) }\end{array}$ & $\begin{array}{l}\text { Se não, por quê? } \\
\text { Comentários: }\end{array}$ \\
\hline $\begin{array}{l}\text { 26) Usar um garfo ou uma colher } \\
\text { para se alimentar (se refere à } \\
\text { ação de levar a comida até a } \\
\text { boca com o garfo ou colher) }\end{array}$ & $\begin{array}{l}\text { Se não, por quê? } \\
\text { Comentários: }\end{array}$ \\
\hline 27) Pentear o cabelo & $\begin{array}{l}\text { Se não, por quê? } \\
\text { Comentários: }\end{array}$ \\
\hline $\begin{array}{l}\text { 28) Levantar uma xícara pela } \\
\text { alça }\end{array}$ & $\begin{array}{l}\text { Se não, por quê? } \\
\text { Comentários: }\end{array}$ \\
\hline 29) Abotoar uma camisa & $\begin{array}{l}\text { Se não, por quê? } \\
\text { Comentários: }\end{array}$ \\
\hline $\begin{array}{l}\text { 30) Comer a metade de um } \\
\text { sanduíche, tira-gosto ou petiscos } \\
\text { (qualquer alimento que se come } \\
\text { com a mão) }\end{array}$ & $\begin{array}{l}\text { Se não, por quê? } \\
\text { Comentários: }\end{array}$ \\
\hline TOTAL: & \\
\hline
\end{tabular}

\begin{tabular}{|c|c|}
\hline ESCALA QUANTITATIVA & ESCALA QUALITATIVA \\
\hline 0 - Não usei o braço mais fraco (não usei). & $\begin{array}{l}0 \text { - O braço mais fraco não foi usado de forma } \\
\text { alguma para aquela atividade (nunca). }\end{array}$ \\
\hline $\begin{array}{l}.5 \\
1 \text { - Ocasionalmente usei o braço mais fraco, } \\
\text { apenas muito raramente (muito raramente). }\end{array}$ & $\begin{array}{l}.5 \\
1 \text { - O braço mais fraco se moveu durante } \\
\text { aquela atividade, mas não ajudou (muito } \\
\text { fraco). }\end{array}$ \\
\hline 1.5 & 1.5 \\
\hline $\begin{array}{l}2 \text { - Às vezes usei o braço mais fraco, mas fiz } \\
\text { a atividade a maior parte do tempo com meu } \\
\text { braço mais forte (raramente). }\end{array}$ & $\begin{array}{l}2 \text { - O braço mais fraco foi de alguma utilidade } \\
\text { durante esta atividade, porém, precisou de } \\
\text { ajuda do braço mais forte ou se moveu muito } \\
\text { lentamente ou com dificuldade (fraco). }\end{array}$ \\
\hline 2.5 & 2.5 \\
\hline $\begin{array}{l}\text { 3- Usei o braço mais fraco aproximadamente } \\
\text { metade das vezes que usava antes do } \\
\text { derrame (metade pré-derrame). }\end{array}$ & $\begin{array}{l}\text { 3- O braço mais fraco foi utilizado com o } \\
\text { propósito indicado, porém os movimentos } \\
\text { foram lentos ou foram efetuados apenas com } \\
\text { algum esforço (bom). }\end{array}$ \\
\hline 3.5 & 3.5 \\
\hline $\begin{array}{l}4 \text { - Usei o braço mais fraco quase o mesmo } \\
\text { tanto que antes do derrame (3/4 pré- } \\
\text { derrame). }\end{array}$ & $\begin{array}{l}4 \text { - Os movimentos feitos pelo braço mais } \\
\text { fraco foram quase normais, mas não } \\
\text { chegaram a ser tão rápidos ou precisos } \\
\text { quanto o normal (quase normal). }\end{array}$ \\
\hline 4.5 & 4.5 \\
\hline $\begin{array}{l}\text { 5- Usei o braço mais fraco com a mesma } \\
\text { frequência de antes do derrame (mesmo que } \\
\text { pré-derrame). }\end{array}$ & $\begin{array}{l}\text { 5- A habilidade de usar o braço mais fraco } \\
\text { para esta atividade foi tão bom quanto antes } \\
\text { do derrame (normal). }\end{array}$ \\
\hline
\end{tabular}


APÊNDICES 
APÊNDICE - Termo de Consentimento Livre e Esclarecido

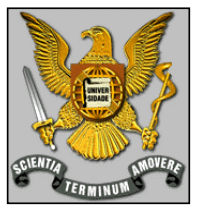

FACULDADE DE MEDICINA DE RIBEIRÃO PRETO UNIVERSIDADE DE SÃO PAULO

Programa de Pós-Graduação em Reabilitação e Desempenho Funcional Laboratório de Neuropsicobiologia e Comportamento Motor

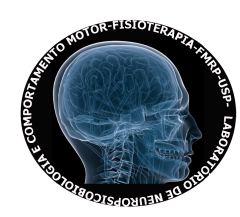

\section{TERMO DE CONSENTIMENTO LIVRE E ESCLARECIDO}

Prezado participante,

Gostaríamos de convidá-lo a participar do nosso estudo, que é direcionado a pessoas que sofreram um Acidente Vascular Cerebral (AVC), e tiveram como sequela a hemiparesia (não consegue utilizar adequadamente uma metade do corpo).

Esse estudo, intitulado: "Eficácia e aceitação de um protocolo de 12 horas diárias de constrição de movimento - Estudo prospectivo randomizado aberto com avaliação cega de desfechos (PROBE) do Protocolo Brasileiro de Terapia de Uso Forçado (BRTUF12)", tem como objetivo recuperar rapidamente o braço e o lado que foram afetados pelo AVC, para isso, estamos fazendo uma proposta de estimulação desse braço com exercícios e uma técnica que estamos estudando. Haverá dois grupos de participantes nesse estudo, que serão separados aleatoriamente, onde um grupo receberá como forma de tratamento essa técnica que estamos estudando e o tratamento por meio de cinesioterapia por FNP e o outro grupo receberá o apenas o tratamento com cinesioterapia por FNP.

Você receberá o tratamento através desta técnica, que consiste na constrição braço não afetado com uma malha tubular e realização de suas atividades cotidianas normalmente com o braço afetado, para que esse braço volte a funcionar e você possa utilizá-lo novamente.

Essa imobilização será realizada de segunda a sexta, por 12 horas, ou seja, a constrição será colocada pela manhã e retirada a noite, durante 4 semanas, e durante todos esses dias retiraremos a malha, limparemos o braço e colocaremos uma nova malha. Você receberá também um tratamento com 2 sessões semanais de cinesioterapia clássica, por um período de 4 semanas, com técnicas voltadas para a reabilitação da hemiparesia, que consiste na realização de qualquer exercício voltado para o movimento e no restabelecimento da dinâmica de movimento normal do corpo 
que não utilize equipamentos elétricos ou mecânicos no processo de reabilitação. Durante esse período, você terá que anotar todas as suas atividades cotidianas em um diário que será entregue no momento da primeira avaliação, bem como o tempo diário que permaneceu com a malha. Você deve estar ciente da veracidade das anotações realizadas no diário.

A aplicação da técnica será realizada no Centro Integrado de Reabilitação (CIR) anexo do Hospital Estadual de Ribeirão Preto (HERP). Durante esse período, você participará de 7 avaliações com técnicas específicas, entre elas: exame de eletromiografia de superfície e dinamometria de preensão palmar.

O exame de eletromiografia de superfície necessita do preparo da pele onde serão captados os sinais elétricos dos músculos, os possíveis pelos na área de colocação dos eletrodos serão retirados utilizando-se a raspagem de pelos, retirada de células mortas e limpeza com álcool 70\%. Os eletrodos superficiais autoadesivos e descartáveis serão colocados em alguns pontos motores do antebraço e será solicitado o movimento voluntário, ou seja, na posição sentada com o antebraço apoiado sobre uma mesa, realizar o movimento de extensão e flexão de punho contra uma resistência, onde terá que movimentar a mão para cima e para baixo contra uma resistência.

Já para a dinamometria, esse exame não requer nenhuma preparação, apenas que você permaneça sentado, com o antebraço apoiado sobre uma mesa e aperte com sua mão um aparelho, (o dinamômetro de preensão palmar), com o máximo de força que conseguir por 5 segundos.

É possível que aconteçam desconfortos durante o tratamento com a constrição do braço sadio, tais como as frustrações ou a ansiedade, pois a técnica exige um esforço considerável do lado afetado na realização das atividades do dia a dia. Se houver necessidade você poderá ser encaminhado para atendimento com terapeutas ocupacionais e psicólogos durante o período da aplicação da técnica. Outra coisa que pode acontecer é o aumento do risco de quedas, para que isso não aconteça é preciso que você esteja sempre alerta ao executar uma atividade. Se caso as quedas aumentarem durante a terapia, interromperemos o protocolo e trataremos as lesões ocasionadas pela queda. Já sabemos que essa forma de terapia, muito usada nos Estados Unidos e Alemanha, é eficiente e trará benefício a você, melhorando função do lado afetado, ou seja, facilitando o uso do braço com dificuldade. 
Durante todo o período da pesquisa você tem o direito de tirar qualquer dúvida ou pedir qualquer outro esclarecimento, bastando para isso entrar em contato, com o pesquisador ou com o Comitê de Ética em Pesquisa.

Os resultados obtidos por essa pesquisa serão confidencias, e divulgadas apenas em eventos e/ou publicações científicas. Deste modo não haverá identificação dos participantes, assegurando o sigilo sobre sua participação.

Você tem garantido o seu direito de não aceitar participar ou de sair do estudo, a qualquer momento, sem nenhum tipo de prejuízo pela sua decisão. Pedimos somente que nos informe.

Os gastos necessários para a realização das terapias serão assumidos pelos pesquisadores. O sujeito precisará de disponibilidade de transporte até o CIR. A assistente social do serviço tentará auxiliá-lo para facilitar sua vinda. Fica também garantida indenização em casos de danos comprovadamente decorrentes da participação na pesquisa, conforme as leis vigentes.

Você receberá uma via desse termo devidamente assinada por você e pelo pesquisador responsável.

Pesquisador: Tamyris Padovani dos Santos.

Assinatura do pesquisador:

Data: I__ I

Participante:

Assinatura do participante:

Data:

Para esclarecer quaisquer dúvidas, contate:

Comitê de Ética em Pesquisa do Hospital das Clínicas e da Faculdade de Medicina de Ribeirão Preto

Telefone: (16) 3602-2228

Tamyris Padovani dos Santos

Telefone: (16) 3315-0740 / e-mail: tamyrispadovani@.usp.br 